MARCEL CARLOS DA MATA MARTINS

\title{
UMA ESTRATÉGIA PARA AVALIAÇÃO DA RESILIÊNCIA NA MOBILIDADE URBANA
}

Dissertação apresentada ao Departamento de Engenharia de Transportes da Escola de Engenharia de São Carlos da Universidade de São Paulo para obtenção do título de Mestre em Ciências, Programa de Engenharia de Transportes

Área de Concentração: Planejamento e Operação de Sistemas de Transportes

Orientador: Prof. Dr. Antônio Nélson Rodrigues da Silva

São Carlos, SP 
AUTORIZO A REPRODUÇÃO TOTAL OU PARCIAL DESTE TRABALHO, POR QUALQUER MEIO CONVENCIONAL OU ELETRÔNICO, PARA FINS DE ESTUDO E PESQUISA, DESDE QUE CITADA A FONTE.

Ficha catalográfica elaborada pela Biblioteca Prof. Dr. Sérgio Rodrigues Fontes da EESC/USP com os dados inseridos pelo(a) autor(a)

M379u

Martins, Marcel Carlos da Mata

Uma estratégia para avaliação da resiliência na mobilidade urbana / Marcel Carlos da Mata Martins; orientador Antônio Nélson Rodrigues da Silva. São Carlos, 2018.

Dissertação (Mestrado) - Programa de Pós-Graduação em Engenharia de Transportes e Área de Concentração em Planejamento e Operação de Sistemas de Transporte -Escola de Engenharia de São Carlos da Universidade de São Paulo, 2018.

1. Resiliência, 2. Mobilidade urbana. 3. Modos ativos. 4. Modo a pé. 5. Modo bicicleta. 6. Veículos motorizados. I. Título.

Eduardo Graziosi Silva - CRB - 8/8907 


\section{FOLHA DE JULGAMENTO}

Candidato: Engenheiro MARCEL CARLOS DA MATA MARTINS.

Título da dissertação: "Uma estratégia para avaliação da resiliência na mobilidade urbana".

Data da defesa: 02/03/2018.

Comissão Julgadora:

Resultado:

Prof. Titular Antônio Nélson Rodrigues da Silva

(Orientador)

(Escola de Engenharia de São Carlos/EESC)

Prof. Dr. Nuno Eduardo Norte Pinto

APROVADO

(University of Manchester)

Prof. Dr. Alexandre Lima Marques da Silva

APROVADO

(Universidade Federal de Alagoas/UFAL)

Coordenadora do Programa de Pós-Graduação em Engenharia de Transportes:

Prof ${ }^{a}$. Associada Ana Paula Camargo Larocca

Presidente da Comissão de Pós-Graduação:

Prof. Associado Luis Fernando Costa Alberto 


\section{AGRADECIMENTOS}

Agradeço ao professor Antônio Nélson, tanto pelas aulas como pela orientação na pesquisa, mostrando-se sempre prestativo e paciente.

À minha família, meus pais e meu irmão, por me apoiarem e me aconselharem sempre, procurando de todas as formas o melhor para mim.

À minha namorada, Beatriz, por estar sempre ao meu lado, mesmo distante, nesses dois anos de mestrado.

À Secretaria de Transporte e Desenvolvimento de Alagoas (SETRAND-AL), representada na superintendente Roberta Rosas, que encontrou tempo para me receber e fornecer dados necessários para esta pesquisa.

Aos amigos e colegas do STT, pela amizade e por estarem sempre dispostos a ajudar.

Agradeço a todos, que de forma direta ou indireta, auxiliaram nesse trabalho. Muito obrigado. 


\section{RESUMO}

MARTINS, M. C. M. Uma estratégia para avaliação da resiliência na mobilidade urbana 2018. Dissertação (Mestrado) - Escola de Engenharia de São Carlos da Universidade de São Paulo, 2018.

O objetivo deste estudo foi elaborar uma estratégia para avaliação da resiliência na mobilidade urbana, focando-se na restrição ao transporte motorizado. Assim, assumiu-se hipoteticamente que as viagens poderiam ser feitas apenas a pé ou de bicicleta. As viagens foram classificadas como persistentes, adaptáveis e transformáveis. As viagens persistentes e adaptáveis foram consideradas resilientes, enquanto as viagens transformáveis foram consideradas vulneráveis. Uma nova segmentação precisou ser criada para este trabalho: a excepcionalidade, que engloba viagens por modo a pé ou bicicleta além dos limites das Distâncias Máximas Possíveis (DMP). Os estudos de caso foram feitos na cidade de São Carlos e em um conjunto de três municípios da Região Metropolitana de Maceió (RMM): Maceió, Rio Largo e Satuba. No estudo em São Carlos, o pior cenário teve 40,4\% de resiliência, e atingiu 100\% com $11 \mathrm{~km}$ de DMP de bicicleta. Na RMM, o cenário mais pessimista apresentou uma resiliência de 43,0\%, e atingiu o seu máximo aos $28 \mathrm{~km}$. Os resultados também revelaram diferentes padrões espaciais de viagens para cada condição da resiliência. Em São Carlos, viagens persistentes apresentaram um padrão pontual. Viagens adaptáveis mostraram um padrão radial. As viagens transformáveis exibiam um padrão mais diametral, de um extremo ao outro da cidade. A análise por zona mostrou que as viagens transformáveis têm maior frequência em zonas afastadas do centro da cidade. Em RMM, os padrões encontrados foram semelhantes. As viagens persistentes, por exemplo, também eram predominantemente intrazonais. Além disso, as viagens adaptáveis tornaram-se mais concentradas em partes específicas da área urbanizada (por exemplo, ao norte da região), a medida que os valores de DMP aumentaram. O trabalho mostra a necessidade da adoção de políticas de incentivo aos modos ativos de transporte, no intuito de diminuir a dependência da sociedade de veículos motorizados.

Palavras chave: Resiliência, Mobilidade urbana, Modos ativos, Modo a pé, Modo bicicleta, Veículos motorizados. 


\begin{abstract}
MARTINS, M. C. M. A strategy for the evaluation of urban mobility resilience. 2018. Dissertation (Master's) - São Carlos School of Engineering, University of São Paulo, 2018.

The objective of this study was the development of a strategy to evaluate how urban mobility resilience would be affected by constraints imposed to motorized transport modes. The analysis was based on the hypothetical assumption that only walking and cycling trips would be possible. The trips were initially classified as persistent, adaptable and transformable. Trips in the first two groups were considered resilient trips, whereas the trips in the third group were vulnerable trips. A fourth category was created to accommodate walking and cycling trips that went beyond the Maximum Distances (MD) per mode that were also defined as part of the method. Case studies were conducted in the city of São Carlos and in Maceió Metropolitan Region (MMR), which contains three municipalities: Maceió, Rio Largo and Satuba. In the case of São Carlos, we found a resilience value of $40.4 \%$ in the worst scenario. Resilience values would increase for larger MD values, reaching a maximum resilience of $100 \%$ for a MD of $11 \mathrm{~km}$. In MMR, the minimum resilience value found was $43.0 \%$, and the maximum resilience value corresponded to a $\mathrm{MD}$ of $28 \mathrm{~km}$. The results also indicated different spatial patterns for each group of trips. In São Carlos, persistent trips were mainly intrazonal trips, adaptable trips had a radial pattern, and transformable trips crossed the urban area. The analysis per zone have shown a concentration of transformable trips in zones far from the city center. In MMR, the patterns were similar. Persistent trips, for example, were also mostly intrazonal trips. In addition, adaptable trips became more concentrated in specific parts of the urbanized area (e.g. the northern part of the region) as MD values increased. This study indicate the need for policies that encourage the use of active modes of transportation, in order to decrease the dependence of society in motorized vehicles.
\end{abstract}

Keywords: Resilience, Urban Mobility, Active Modes, Walking Mode, Cycling Mode, Motorized Vehicles. 


\section{LISTA DE TABELAS}

Tabela 1. Distâncias recomendadas para o uso de modos ativos de transporte. 30

Tabela 2. Nível de resiliência na mobilidade urbana.

Tabela 3. Descrição das etapas da metodologia de avaliação da resiliência na mobilidade urbana e suas localizações nos capítulos de Metodologia e Resultados.

Tabela 4. Divisão dos modos de transporte motorizado por categoria na Região Metropolitana de Maceió.

Tabela 5. Maiores distâncias entre centroides das zonas de tráfego em São Carlos.

Tabela 6. Maiores distâncias entre centroides das zonas de tráfegos na RMM.

Tabela 7. Matriz de cenários de acordo com as Distâncias Máximas Possíveis (DMP) a pé e bicicleta dos casos de São Carlos e da Região Metropolitana de Maceió (RMM).

Tabela 8. Valor da resiliência por cenário na cidade São Carlos.

Tabela 9. Valor da resiliência por cenário na Região Metropolitana de Maceió.

Tabela 10. Parâmetros para a equação representativa da resiliência na mobilidade urbana, transformabilidade e adaptabilidade em São Carlos e na Região Metropolitana de Maceió. 60

Tabela 11. Parâmetros para a equação representativa da excepcionalidade e da persistência em São Carlos e na Região Metropolitana de Maceió.

Tabela 12. Matriz de cenários de acordo com as Distâncias Máximas Possíveis (DMP) do caso de São Carlos e da Região Metropolitana de Maceió (RMM).Os cenários marcados serão usados para ilustração do padrão de viagens excepcionais, persistentes, adaptáveis e transformáveis de ambos os estudos de caso. Os cenários marcados em amarelo representam o caso de São Carlos, enquanto os vermelhos representam os casos da RMM.

Tabela 13. Cenários intermediários usados para ilustração da proporção de viagens excepcionais, persistentes, adaptáveis e transformáveis por zona dos estudos de caso de São

Carlos e Região Metropolitana de Maceió.

Tabela 14. Cenários e zonas de Origem e Destino com as principais viagens persistentes em São Carlos. 70

Tabela 15. Cenários e zonas de Origem e Destino com as principais viagens persistentes na Região Metropolitana de Maceió 


\section{LISTA DE FIGURAS}

Figura 1. Distâncias $d_{i j}$ entre centroides das zonas de tráfego i e j (i,j= A, B, C, D) de uma cidade ou região hipotética.

Figura 2. Esquema visual da caracterização das viagens (excepcionais, persistentes, adaptáveis e transformáveis) de acordo com o modo de transporte utilizado dentro das Distâncias Máximas Possíveis para os modos a pé e bicicleta.

Figura 3. Conjunto de procedimentos e ferramentas que formam a metodologia, separados em etapas e associados aos subitems do capítulo de Resultados.

Figura 4. Zonas de tráfego da cidade de São Carlos sobre imagem de satélite obtida pelo Google Earth (2017).

Figura 5 . Zonas de tráfego da Região Metropolitana de Maceió utilizadas na pesquisa: Maceió (branco), Satuba (azul) e Rio Largo (vermelho) sobre imagem de satélite obtida pelo Google Earth (2015).

Figura 6. Distribuição de viagens produzidas por zona em São Carlos.

Figura 7. Distribuição de viagens produzidas por zona na Região Metropolitana de Maceió. 49

Figura 8. Frequência de distância entre centroides das zonas de tráfego da Região

Metropolitana de Maceió, em 2014, e de São Carlos, em 2007/08.

Figura 9. Número de viagens por distância entre os centroides das zonas de tráfego da Região Metropolitana de Maceió, em 2014, e em São Carlos, em 2007/08.

Figura 10. Variação da resiliência na mobilidade em São Carlos e na Região Metropolitana de Maceió para diferentes valores de Distância Máxima Possível de bicicleta. 58

Figura 11. Variação da transformabilidade da resiliência na mobilidade em São Carlos e na Região Metropolitana de Maceió para diferentes valores de Distância Máxima Possível de bicicleta.

Figura 12. Variação da adaptabilidade da resiliência na mobilidade em São Carlos e na Região Metropolitana de Maceió para diferentes valores de Distância Máxima Possível de bicicleta.

Figura 13. Modelo da função representativa da excepcionalidade no caso de São Carlos para

diferentes valores de Distância Máxima Possível a pé e de bicicleta.

Figura 14. Modelo da função representativa da persistência no caso de São Carlos para diferentes valores de Distância Máxima Possível a pé e de bicicleta.

Figura 15. Modelo da função representativa da excepcionalidade no caso da Região Metropolitana de Maceió para diferentes valores de Distância Máxima Possível a pé e de bicicleta. 
Figura 16. Modelo da função representativa da persistência no caso da Região Metropolitana de Maceió para diferentes valores de Distância Máxima Possível a pé e de bicicleta.

Figura 17. Variação da resiliência na mobilidade em São Carlos e na Região Metropolitana de Maceió para diferentes valores de Distância Máxima Possível de bicicleta. Os pontos marcados representam a posição no gráfico dos cenários utilizados para representar as viagens excepcionais, persistentes, adaptáveis e transformáveis dos estudos de caso. Ao lado do ponto marcado está o cenário que está representado.

Figura 18. Principais viagens excepcionais, adaptáveis, transformáveis no cenário 5, São Carlos e na Região Metropolitana de Maceió (RMM).

Figura 19. Principais viagens excepcionais nos cenários 12, 25, 38, 51, 64 e 76 em São Carlos.

Figura 20. Principais viagens adaptáveis nos cenários 12, 25, 38, 51, 64 e 76 em São Carlos.

Figura 21. Principais viagens transformáveis nos cenários 12, 25, 38, 51, 64 e 76 em São Carlos.

Figura 22. Principais viagens excepcionais nos cenários 37, 74, 111, 148, 185 e 222 na Região Metropolitana de Maceió.

Figura 23. Principais viagens adaptáveis nos cenários 37, 74, 111, 148, 185 e 222 na Região Metropolitana de Maceió.

Figura 24. Principais viagens transformáveis nos cenários 37, 74, 111, 148, 185 e 222 na Região Metropolitana de Maceió.

Figura 25. Proporção de viagens excepcionais, persistentes, adaptáveis e transformáveis por zona de tráfego no cenário 18 (DMP a pé $=3,5 \mathrm{~km}$ e DMP de bicicleta $=4 \mathrm{~km}$ ) na cidade de São Carlos. Nota: DMP significa Distância Máxima Possível.

Figura 26. Proporção de viagens excepcionais, persistentes, adaptáveis e transformáveis por zona de tráfego no cenário 36 (DMP a pé $=2,5 \mathrm{~km}$ e DMP de bicicleta $=6 \mathrm{~km}$ ) na cidade de São Carlos. Nota: DMP significa Distância Máxima Possível.

Figura 27. Proporção de viagens excepcionais, persistentes, adaptáveis e transformáveis por zona de tráfego no cenário 53 (DMP a pé $=3,5 \mathrm{~km}$ e DMP de bicicleta $=7,5 \mathrm{~km}$ ) na cidade de São Carlos. Nota: DMP significa Distância Máxima Possível. 79

Figura 28. Proporção de viagens excepcionais, persistentes, adaptáveis e transformáveis por zona de tráfego no cenário 71 (DMP a pé $=2,5 \mathrm{~km}$ e DMP de bicicleta $=9,5 \mathrm{~km}$ ) na cidade de São Carlos. Nota: DMP significa Distância Máxima Possível. 80

Figura 29. Proporção de viagens excepcionais, persistentes, adaptáveis e transformáveis por zona de tráfego no cenário 52 (DMP a pé $=3 \mathrm{~km}$ e DMP de bicicleta $=7,5 \mathrm{~km}$ ) na Região Metropolitana de Maceió. Nota: DMP significa Distância Máxima Possível. 
Figura 30. Proporção de viagens excepcionais, persistentes, adaptáveis e transformáveis por zona de tráfego no cenário 104 (DMP a pé $=4 \mathrm{~km}$ e DMP de bicicleta $=12,5 \mathrm{~km}$ ) na Região Metropolitana de Maceió. Nota: DMP significa Distância Máxima Possível.

Figura 31. Proporção de viagens excepcionais, persistentes, adaptáveis e transformáveis por zona de tráfego no cenário 155 (DMP a pé $=2 \mathrm{~km}$ e DMP de bicicleta $=18 \mathrm{~km}$ ) na Região Metropolitana de Maceió. Nota: DMP significa Distância Máxima Possível.

Figura 32. Proporção de viagens excepcionais, persistentes, adaptáveis e transformáveis por zona de tráfego no cenário 207 (DMP a pé $=3 \mathrm{~km}$ e DMP de bicicleta $=23 \mathrm{~km}$ ) na Região Metropolitana de Maceió. Nota: DMP significa Distância Máxima Possível. 


\section{LISTA DE SIGLAS E ABREVIATURAS E SIGLAS}

AMA Active Mode Accessibility

ARSAL

Agência Reguladora de Serviços Públicos de Alagoas

CBTU

Companhia Brasileira de Trens Urbanos

DMP

Distância Máxima Possível

RMM

Região Metropolitana de Maceió

RTS

Rapid Transit System

SETRAND-AL Secretaria de Transporte de Desenvolvimento de Alagoas

SIG

Sistema de Informação Geográfica

UFAL

Universidade Federal de Alagoas

UGB

Urban Growth Boundaries

VLT

Veículo Leve sobre Trilhos 


\section{SUMÁRIO}

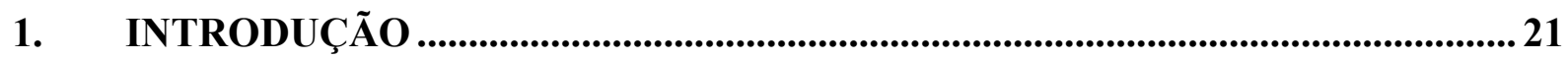

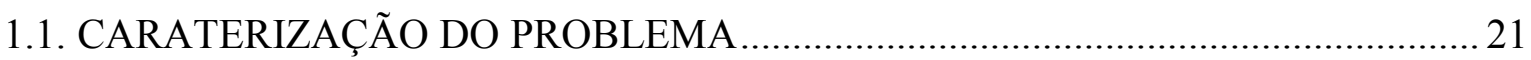

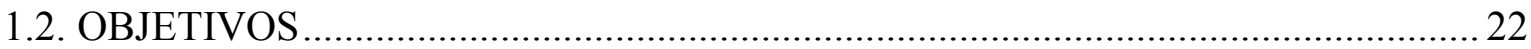

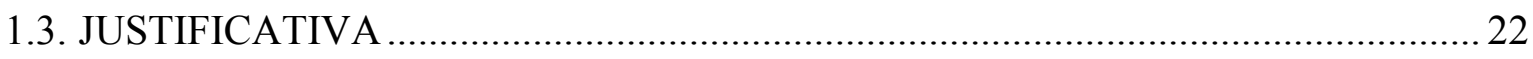

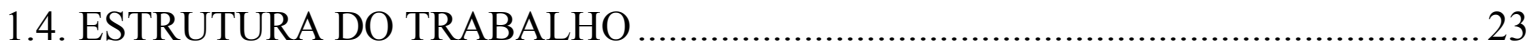

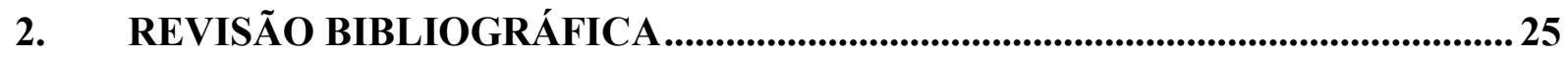

2.1. ESPRAIAMENTO URBANO E A DEPENDÊNCIA AOS MODOS

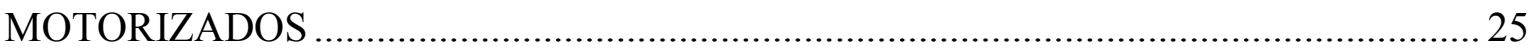

2.2. MODOS ATIVOS EM VIAGENS URBANAS DIÁRIAS …………………….......... 29

2.3. COMBUSTÍVEIS FÓSSEIS E O PICO DO PETRÓLEO …………………………....... 31

2.4. A RESILIÊNCIA NA MOBILIDADE URBANA.......................................................... 33

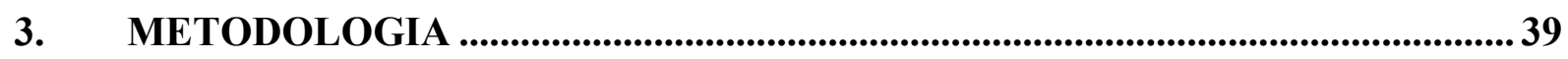

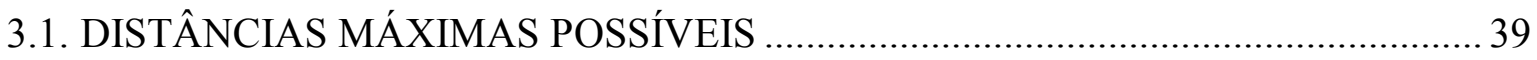

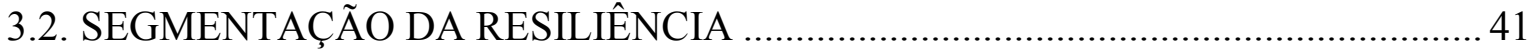

3.3. VARIAÇÃO DA RESILIÊNCIA E PADRÃO DE VIAGENS ……………………...... 42

4. RESULTADOS......................................................................................................... 45

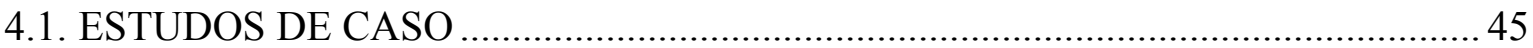

4.2. DISTÂNCIA ENTRE CENTROIDES E DISTRIBUIÇÃO DE VIAGENS ..................47

4.3. ELABORAÇÃO DOS CENÁRIOS DE ACORDO COM AS DISTÂNCIAS

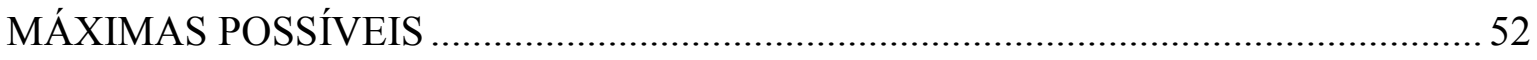

4.4. SEGMENTAÇÃO DAS VIAGENS E NÍVEL DE RESILIÊNCIA ................................56

4.5. PADRÃO DE VIAGENS E DISTRIBUIÇÃO POR ZONA ........................................... 64

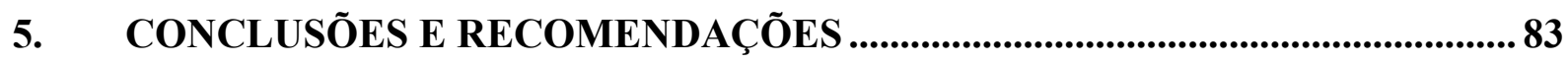

5.1. A ESTRATÉGIA PARA AVALIAÇÃO DA RESILIÊNCIA NA MOBILIDADE URBANA 83

5.2. PADRÕES DE RESILIÊNCIA OBSERVADOS NOS ESTUDOS DE CASO ...........84

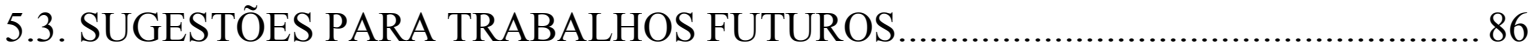

REFERÊNCIAS BIBLIOGRÁFICAS ............................................................................... 89

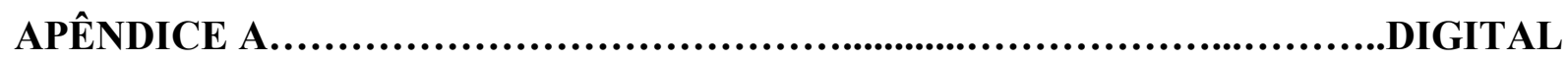

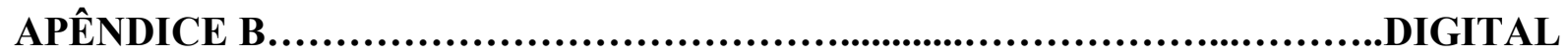




\section{INTRODUÇÃO}

Neste capítulo é realizada uma breve caracterização do problema abordado, envolvendo o ciclo entre espraiamento urbano e a dependência dos veículos motorizados, assim como a diminuição do uso de modos ativos de transportes. Também são apresentados os objetivos deste trabalho, a justificativa para o seu desenvolvimento, e por fim, a estrutura do documento.

\subsection{CARATERIZAÇÃO DO PROBLEMA}

O uso de combustíveis fósseis como fonte energética para veículos motorizados possibilitou o desenvolvimento das regiões urbanas, permitindo a realização de viagens mais longas. Isso criou condições para que os perímetros urbanos se expandissem para regiões mais afastadas de seus centros. Todavia, a expansão urbana sem planejamento causa o chamado espraiamento urbano, que tem como consequência baixas densidades e o distanciamento de atividades. Esta dispersão cria a necessidade de deslocamentos mais longos para que estas atividades possam ser realizadas, causando ainda mais dependência de veículos motorizados e maior consumo de combustíveis fósseis.

Entende-se então que o espraiamento urbano e a dependência ao uso dos modos motorizados são causa e consequência um do outro. Este ciclo gera dois desdobramentos: a diminuição no uso de modos ativos de transporte, até mesmo em curtas distâncias; e o aumento na demanda por combustíveis fósseis como fonte de energia no setor de transportes.

Alguns estudos mostram as curtas distâncias percorridas por pessoas através de modos a pé e bicicleta (HYDÉN et al., 1999; BOUSSAUW \& WITLOX, 2009; LARSEN et al., 2010; YANG e DIEZ-ROUX, 2012; OLIVEIRA et al., 2016), porém, acredita-se ser possível que estes modos possam ser usados em viagens mais longas, levando-se em consideração uma série de outros fatores, tais como saúde e idade do indivíduo, relevo e o clima da região, infraestrutura cicloviária, etc.

Os combustíveis fósseis são fontes predominantes de energia no setor de transportes, especialmente em países em desenvolvimento, que vêm aumentando o uso de modos motorizados. Isso causa preocupação devido ao denominado pico do petróleo, em que a produção atinge o seu máximo e então, decai. Tendo em vista as poucas opções de 
substituição aos combustíveis fósseis como fontes de energia para modos motorizados, vê-se o setor em risco diante de uma possível escassez do petróleo ou disparidade considerável entre oferta e demanda.

Com base nessas condições de provável escassez/diminuição de oferta de combustíveis e dependência do transporte motorizado, é inserido o conceito de resiliência. Aqui, ela é entendida como a capacidade de resistir e se adaptar diante de um evento que põe em risco um sistema. No caso deste estudo, o evento seria a restrição aos usos de veículos motorizados, e o que estaria em risco seria o sistema de transporte urbano. Assim, este trabalho tenta responder três perguntas principais:

1. Que distâncias poderiam ser percorridas por modos ativos, caso não houvesse veículos motorizados disponíveis?

2. Quais viagens seriam afetadas? Quais permaneceriam? É possível classificar estas viagens com base nas condições de resiliência?

3. Como se comportam cada um destes grupos de viagens?

\subsection{OBJETIVOS}

Esta pesquisa tem como objetivo principal elaborar uma estratégia para avaliação da resiliência na mobilidade urbana e testá-la em casos reais. Foca-se na restrição ao transporte motorizado. Assim, assume-se hipoteticamente que as viagens poderiam ser feitas apenas a pé ou de bicicleta.

Os objetivos parciais são os seguintes:

- Criar diversos cenários, otimistas e pessimistas, no intuito de analisar a variação da resiliência na mobilidade urbana;

- Avaliar o comportamento das viagens consideradas resilientes e vulneráveis.

\subsection{JUSTIFICATIVA}

Durante a pesquisa por trabalhos envolvendo o tema da resiliência no transporte urbano diante do pico do petróleo ou da escassez de combustíveis fósseis, constatou-se uma razoável carência de material bibliográfico e certa superficialidade no pouco que foi localizado. Notou- 
se também que os estudos estão predominantemente focados em regiões de países desenvolvidos, onde a expansão urbana ocorreu de forma distinta de países em desenvolvimento, como por exemplo, o Brasil. Além disso, vê-se neste trabalho a oportunidade de contribuir com a discussão acerca da políticas de transporte e planejamento urbano (como já feito por Akimura, 2015 e Guerreiro, 2017) .

\subsection{ESTRUTURA DO TRABALHO}

Este trabalho está constituído em 6 capítulos, sendo o primeiro esta introdução. O capítulo 2 aborda temas relevantes ao assunto, como o espraiamento urbano, o uso de modos ativos nos transportes e o pico do petróleo. Também são apresentados trabalhos relacionados à resiliência, com ênfase no transporte urbano. $\mathrm{O}$ capítulo 3 descreve a metodologia proposta para medir o nível de resiliência e as análises a serem realizadas após a medição. O quarto capítulo apresenta a aplicação da metodologia em estudos de caso e os resultados gerados. $\mathrm{O}$ capítulo 5 lista as principais conclusões obtidas com a pesquisa e recomendações para trabalhos futuros. O sexto e último capítulo segue com a listagem das referências citadas. 


\section{REVISÃO BIBLIOGRÁFICA}

Este capítulo aborda 4 aspectos. O primeiro trata do fenômeno do espraiamento e sua relação com a dependência por veículos motorizados. O segundo aspecto é a substituição, em viagens de curta distância, de caminhadas e das bicicletas pelo transporte motorizado, assim como alguns fatores de influência para a escolha do modo. O terceiro é a dependência por combustíveis fósseis do setor de transportes frente a um possível pico do petróleo. Por fim, o quarto aspecto apresenta o conceito de resiliência na literatura e enquadra o termo de resiliência na mobilidade de Fernandes et al. $(2015 ; 2017)$ para definir a análise feita neste trabalho.

\subsection{ESPRAIAMENTO URBANO E A DEPENDÊNCIA AOS MODOS MOTORIZADOS}

O uso do automóvel e outros veículos motorizados tornou-se fundamental para o crescimento e o desenvolvimento dos centros urbanos ao redor do mundo. O conforto e a comodidade, somados à capacidade de percorrer grandes distâncias em um relativo curto período de tempo ajudou na expansão em massa do uso de veículos motorizados ainda na segunda metade do século XX. Newman \& Kenworthy (2011) apontam, no entanto, para o fenômeno do "pico do uso do automóvel", afirmando que diversas cidades em países desenvolvidos (americanas, australianas e europeias) apresentam uma redução no uso do carro. Todavia, regiões ao sul do globo, em países em desenvolvimento, mostram que a dependência do transporte motorizado apenas cresce, sem expectativa de queda (MAJUMDAR \& MITRA, 2016; SCHWANEN, 2016; FRAME et al., 2016 e ARUP/SIEMENS, 2015).

A "motorização" do ambiente urbano, porém, vem com um custo envolvido. Como afirmam Rodrigues da Silva et al. (2007), existe uma forte relação entre o uso de modos motorizados e a dispersão de atividades em áreas urbanas, o que vem a causar o chamado espraiamento urbano.

O conceito deste fenômeno é apresentado diversas vezes e por vários autores. Brunner (2013), por exemplo, trata-o como uma expansão além dos limites urbanos, em direção a zonas rurais, que pode causar altos níveis de segregação e dependência do automóvel. Zhang \& Kockelman (2014) o veem como um crescimento urbano descoordenado e excessivo, de 
baixa densidade e com descentralização da população, comércio, indústrias e infraestrutura em direção aos limites das cidades.

Para Gervasoni et al. (2017) o espraiamento é formado por três dimensões fundamentais: dispersão, acessibilidade e uso misto do solo. A dispersão estaria relacionada à densidade urbana e seu oposto seria a compacidade. Regiões muito dispersas teriam grande relação com o aumento no custo de infraestrutura, serviços públicos, bem como perda de zonas agrícolas e ineficiência ou não-existência de transporte público. A acessibilidade teria ligação com a conectividade entre atividades (compras, saúde, lazer, etc.) e a origem da viagem (normalmente residência). Baixa acessibilidade causaria dependência de automóvel, congestionamentos e maior consumo de combustíveis, assim como obesidade e sedentarismo. Já o uso misto do solo seria a harmonização entre atividades comerciais e residenciais em uma mesma região. Os impactos negativos causados por baixo uso misto do solo seriam os mesmos da baixa acessibilidade.

O desequilíbrio no uso do solo também é apontado por Andrade et al. (2016), em seu estudo na cidade de Fortaleza, como causa para o espraiamento urbano. Este desequilíbrio acaba por criar processos de segregação imposta e autossegregação. A segregação imposta acontece quando famílias de baixa renda se mudam (ou são movidas) de áreas centrais para áreas mais periféricas da cidade, devido à gentrificação. Já a autossegregação é causada pelas classes com rendas mais altas, ocupando conjuntos residenciais fechados e de alto custo, de forma a fugir das regiões agitadas e inseguras mais próximas dos centros urbanos.

Brueckner (2000) aponta para três grandes forças causadoras da expansão urbana: o aumento populacional, o aumento da renda e a redução nos custos do transporte. Porém, para o fenômeno do espraiamento, três falhas de mercado são apresentadas: a falha ao estipular o valor social do espaço aberto, a falha ao estipular os custos sociais dos congestionamentos e a falha ao estipular os custos de infraestrutura para uma nova região.

Independentemente de sua estrutura teórica, ou das ações que envolvem este processo, todos os trabalhos citados apresentam um resultado em comum: afastando cada vez mais os centros atratores dos produtores de viagens, tem-se um aumento na necessidade de veículos motorizados para vencer tais distâncias. Esse aumento da demanda por automóveis gera uma demanda cada vez maior de combustíveis. Inúmeros trabalhos mostram esta relação. Em seu estudo nas regiões de Yorkshire and the Humber, Lovelave \& Philips (2013) apontaram para o fato de que $1 / 3$ das viagens realizadas diariamente ultrapassavam os $10 \mathrm{~km}$, enquanto 
consumiam 3/4 do total energético da região. Marino et al. (2017) calcularam o consumo de energia no transporte na região metropolitana de Melbourne, Austrália. Seus resultados mostraram, que, além da renda, a densidade populacional e as distâncias aos centros comerciais são os maiores causadores de impacto no consumo energético. Ao comparar o consumo de gasolina em cidades americanas e ao redor do mundo, Newman \& Kenworthy (1989) mostram a forte correlação entre densidade urbana e uso do solo, e o consumo de combustível. Eles chegam a sugerir que uma grande economia de combustíveis pode ser feita caso as cidades mudem sua densidade de 4 a 6 pessoas por acre (10 a 15 por hectare), para 12 a 14 (30 a 35 por hectare).

Shim et al. (2006), por sua vez, analisando 61 cidades de pequeno e médio porte na Coréia do Sul mostraram que não somente a densidade urbana é um fator que melhor explica o consumo de energia no transporte, mas também que cidades mononucleares, que possuem apenas um núcleo de concentração de atividades, tendem a ter uma menor eficiência energética do que aquelas multinuclearizadas, que possuem dois ou mais núcleos com concentração de atividades. Ou seja, para reduzir o consumo de gasolina por automóvel e melhorar seu consumo energético, a densidade urbana deve ser alta, porém, a cidade ser descentralizada.

Outros autores, como Boussauw \& Witlox (2009), na região de Flanders, na Bélgica; Rodrigues da Silva et al. (2007), nas 27 capitais brasileiras e em outras regiões do estado de São Paulo; e Modarres (2013), nos condados de Los Angeles e Orange, nos Estados Unidos, apontam para as mesmas conclusões. A densidade populacional e/ou as distâncias urbanas, fatores relacionados ao espraiamento urbano, têm grande impacto na dependência do automóvel e no consumo energético e logo, no consumo de combustíveis fósseis.

Há, no entanto, trabalhos que descartam a ideia de cidades mais compactas como forma de reduzir o consumo energético, os congestionamentos e o uso de áreas rurais (GORDON \& RICHARDSON, 1997; NEUMAN, 2005). Estes mesmos trabalhos, contudo, são refutados por outros autores, uma vez que o custo do mais alto solo em regiões mais densas e próximas do centro acaba por ser compensado com a economia feita no custo e manutenção do transporte (EWING, 1997, e HAMIDI \& EWING, 2015).

Entende-se, então, o espraiamento urbano e a dependência dos veículos motorizados como causa e consequência um do outro. Regiões mais afastadas começam a ser habitadas em baixa densidade, com isso, necessitando de infraestrutura viária para que estas áreas sejam 
conectadas com as outras. Dessa forma, um maior incentivo é dado ao uso de veículos motorizados, dando então liberdade para que estas populações se distanciem ainda mais, fechando um ciclo. Com isso, as medidas de mitigação ou prevenção do espraiamento urbano e as voltadas para a redução do consumo de combustíveis fósseis e de energia no transporte urbano podem ser consideradas como tendo o mesmo objetivo.

Políticas que visem taxar zonas rurais quando convertidas em urbanas, ou estruturas que visem atender apenas novos moradores, são estratégias recomendadas por Brueckner (2000) para reduzir os efeitos do espraiamento. Enquanto Newman \& Kenworthy (1989) sugerem projetos de reurbanização e reorientação das prioridades de transportes a fim de reduzir o uso de automóveis, as estratégias de UGB (Urban Growth Boudaries), que limitam a expansão urbana até certo ponto, são recomendadas por Zhang \& Kockelman (2014). Estes autores também afirmam que a melhor forma de otimizar o uso do solo é adotando políticas de descentralização e ao mesmo tempo de densificação, como também foi sugerido por Shim et al. (2006). Bertolini et al. (2005) estabelecem um raio de 30 minutos de viagem para acessar de forma sustentável as atividades necessárias, nas regiões de Roterdã e Haia, na Holanda. Através de ferramenta SIG, Saunders \& Rodrigues da Silva (2009) e Saunders (2010) apontam uma redução do consumo energético em um fator de 8 , em uma região da cidade de São Carlos, caso um ambiente amigável para a bicicleta fosse instalado. Já Brunner (2013) vê impactos positivos de um projeto de Smart Growth na região de Atlanta, Estados Unidos, reduzindo o uso de automóveis e diminuindo a emissão de $\mathrm{CO}_{2}$.

Pelos trabalhos analisados neste tópico, é possível perceber um foco em estratégias de compactação das cidades, visando a substituição dos modos motorizados por modos ativos de transporte. Se por um lado a baixa densidade urbana torna o uso de modos não-motorizados virtualmente impossível, em cidades mais compactas as oportunidades de caminhada e uso da bicicleta podem ser encorajadas, através de vias exclusivas para bicicletas e a "pedestrialização" dos centros urbanos (NEWMAN \& KENWORTHY, 1989). Entretanto, décadas de incentivo aos modos motorizados acabaram por desestimular o uso de modos ativos para transporte até mesmo para distâncias mais curtas, onde os trajetos podem facilmente ser realizados a pé ou por bicicleta. Ao mesmo tempo, outros fatores, que não a distância, também podem ser fundamentais para a escolha do modo de transporte, como será visto no tópico seguinte. 


\subsection{MODOS ATIVOS EM VIAGENS URBANAS DIÁRIAS}

Inversamente proporcional ao aumento no transporte motorizado é a diminuição de modos ativos, especialmente em viagens de curta distância. Como foi mostrado por Hydén et al. (1999), a média de viagens realizadas a pé na Europa não ultrapassa 1 viagem/pessoa/dia, com distância máxima de $1 \mathrm{~km}$. As viagens de bicicleta, por sua vez, têm em média 2,5 viagem/pessoa/dia, limitadas a $5 \mathrm{~km}$. Em um estudo para criar um indicador de adequação ao modo de transporte na cidade de São Carlos, Oliveira et al. (2016) apontam para uma média de $2 \mathrm{~km}$ no uso de modos ativos. Larsen et al. (2010) mostraram que em Montreal, Canadá, a média das viagens a pé foi de 650 metros, aumentando para 800 metros naquelas com destino ao trabalho. As viagens de bicicleta tiveram uma média de $2,2 \mathrm{~km}$, aumentando para $3 \mathrm{~km}$ quando o destino era trabalho. Nos Estados Unidos, Yang \& Diez-Roux (2012), usando como base o National Household Travel Survey de 2009, descobriram que, embora $65 \%$ das viagens a pé tivessem mais de 400 metros, apenas 18\% ultrapassavam 1 milha $(1,6 \mathrm{~km})$. Na região de Flanders, Bélgica, a média das viagens por bicicleta com destino ao trabalho foi de $4,07 \mathrm{~km}$, enquanto a pé foi de 2,15 km (BOUSSAUW \& WITLOX, 2009).

Como é possível constatar, as distâncias percorridas por modos ativos podem variar muito, a depender da região analisada. Porém, muitos destes valores ainda estão longe dos estabelecidos por alguns autores como apropriados para serem percorridas a pé ou de bicicleta, seja por distância, seja por tempo (Tabela 1). Diversas razões para isso são apresentadas na literatura. Em regiões mais urbanizadas, moradores tendem a superestimar as distâncias de viagem (HORNING et al., 2007), o mesmo ocorrendo com viagens cujos destinos estão mais próximos de casa (MCCORMACK et al., 2008). Esse efeito de superestimação causa no indivíduo a sensação de que ele percorreu uma distância maior do que a real. Outro fator psicológico para a escolha do modo de transporte é apresentado por Moudon et al. (2006). Ao analisarem as características que tornariam uma vizinhança mais “caminhável", mostraram que a variável mais significativa era a "Percepção do ambiente social da vizinhança", onde o conhecimento dos vizinhos e a presença de pessoas que caminham e andam de bicicleta no bairro influencia o indivíduo a usar ou não modos ativos de transporte. 
Tabela 1. Distâncias recomendadas para o uso de modos ativos de transporte.
Autores
Distâncias aconselháveis (km e/ou min.)

Hydén et al.

(1999)

Afirmam que distâncias de 3 a $5 \mathrm{~km}$ podem ser percorridas por bicicleta

Newman \&

Kenworthy

(1989)

Philips (2014)

Dantas et al. (2010)

Sugihara et al. (2017)

Bertolini et al. (2005)
Ao assumirem que as pessoas caminham de 5 a $8 \mathrm{~km} / \mathrm{h}$, e com um limite de 1 hora de viagem, estabelecem que o limite no uso de modos ativos em uma cidade deve ser de 5 a $8 \mathrm{~km}$. Ao mesmo tempo, esta seria a extensão máxima para a chamada Cidade Caminhável.

Baseado no "Livro Branco" dos Transportes do Reino Unido, ele limita as viagens de bicicleta em $8 \mathrm{~km}$ e as caminhadas em $5 \mathrm{~km}$.

Para a região de estudo, eles limitam as viagens de bicicleta em $15 \mathrm{~km}$, e as viagens a pé, em $2 \mathrm{~km}$.

Utilizam-se da estratégia da "Vizinhança de 20 minutos", onde os serviços essenciais devem estar a uma distância de 20 minutos de caminhada.

Estabelecem um raio de 30 minutos da residência a todos os serviços necessários, através de modos sustentáveis.

Logicamente, o aumento da idade tende a diminuir a velocidade e o tempo de caminhada do indivíduo, o que também tem um grande peso na escolha do modo de transporte (BOHANNON, 1997; ODANI \& TERAYAMA, 2017 E LARSEN et al., 2010).

Uma série de outros fatores, dos mais diversos tipos, são apontados na literatura como influenciadores na escolha do modo de transporte. O risco de acidentes, a largura e a visibilidade das vias foram, por exemplo, os principais fatores na escolha ou não da bicicleta em Kharagpur, na Índia (MAJUMDAR \& MITRA, 2016). Com foco também no modo bicicleta, Philips (2014) relaciona os seguintes fatores:

- Tempo disponível: tempo disponível para a realização do percurso de viagem. Depende das limitações físicas e sociais do indivíduo;

- Energia para pedalar: relacionado à velocidade de pedalada, que irá variar conforme a idade e outras características físicas do indivíduo;

- Características da bicicleta: peso, resistência ao vento e outros fatores que determinam a sua velocidade; 
- Disponibilidade de bicicleta: a posse de uma bicicleta irá depender da renda do indivíduo;

- Topografia: rotas com muitas subidas e descidas têm um gasto de energia, bem como uma velocidade média, diferente de regiões mais planas;

- Clima: chuvas fortes e temperaturas extremas afetam a escolha e a capacidade do uso da bicicleta. Ventos fortes também comprometem a velocidade de viagem.

Hydén et al. (1999), por outro lado, desconsideram fatores relacionados ao veículo (bicicleta) e entendem que, no uso de modos ativos (a pé e bicicleta), estão envolvidos 6 problemas fundamentais. O valor social relaciona o baixo status social das caminhadas e uso da bicicleta comparado ao uso do automóvel. O problema da saúde mostra que um nível mínimo de condição física e saúde devem ser esperados para se pedalar e até caminhar certas distâncias. A estética questiona se o ambiente de percurso é convidativo visualmente. Um caminho sem bancos, lixeiras, abrigos para intempéries e banheiros apresenta um problema de conforto. O problema da mobilidade está relacionado à falta de conectividade das vias exclusivas para ciclistas. Por fim, o problema da segurança, onde ciclistas devem estar separados dos automóveis, e os pedestres, separados dos ciclistas e dos automóveis.

Apesar dos inúmeros fatores apresentados na literatura, as recomendações para um uso maior dos modos ativos nas cidades seguem muito similares. Melhores estruturas e ambientes mais seguros para os ciclistas (MARQUÉS et al., 2015; MAJUMDAR \& MITRA, 2016; FRAME et al., 2016 e RODRIGUES DA SILVA et al., 2007), maior densificação urbana e uso misto do solo (LIU \& TITHERIDGE, 2016; HORNING et al., 2007; LARSEN et al., 2010 e BUEHLER et al., 2010)

\subsection{COMBUSTÍVEIS FÓSSEIS E O PICO DO PETRÓLEO}

Sendo o petróleo responsável por $57 \%$ da energia consumida, e o gás natural, 3\% (FERNANDES et al., 2015), os combustíveis fósseis têm papel primordial no setor de transportes mundial. E como foi visto nos tópicos anteriores, com o espraiamento urbano, a dependência por modos motorizados em países em desenvolvimento e o pouco incentivo a modos ativos de transporte, a demanda por combustíveis fósseis continua a crescer. Todavia, o petróleo, como uma fonte natural finita, está sujeito a esgotamento. Aproximadamente 1,1 trilhão de barris de petróleo já foram consumidos desde o começo da sua extração. Acredita- 
se que as reservas mundiais guardem ainda 1 trilhão de barris, enquanto mais outro trilhão ainda esteja para ser descoberto (AFTABUZZAMAN \& MAZLOUMI, 2011). Apesar dos altos números ainda existentes, o consumo também é igualmente elevado. Somente no ano de 2003, 80 milhões de barris de petróleo foram consumidos por dia. A expectativa é que a demanda aumente em 50\% até o ano de 2025 (HIRSCH et al., 2005).

Hubbert (1949) já alertava para o alto consumo de combustíveis fósseis como forma de produção energética e o declínio certo de sua produção em algum momento no futuro. Esse processo ficou conhecido como o pico do petróleo, no qual a produção de petróleo atinge o seu máximo e então decai, sem possibilidade de recuperação (DANTAS et al., 2010); AFTABUZZAMAN \& MAZLOUMI, 2011 e PHILIPS, 2014).

Ninguém sabe ao certo quando a produção de petróleo atingirá o seu máximo, porém, geólogos não têm dúvidas de que isso irá acontecer (HIRSCH et al., 2005). Alguns estimam que esse pico já foi atingido, no ano de 2014 (AFTABUZZAMAN \& MAZLOUMI, 2011).

Experiências globais relativamente recentes já provaram o impacto negativo que uma diminuição na oferta de combustíveis fósseis pode causar na sociedade. O pico da produção mundial de petróleo, no atual nível de consumo energético e econômico, pode vir a criar uma crise ainda maior do que a experimentada durante o embargo do petróleo de 1973, o corte de petróleo iraniano de 1979, ou os picos do preço do petróleo de 2007-2008. Para o setor de transportes, que depende fortemente do petróleo, o aumento do preço dos combustíveis deve causar redução na mobilidade dos indivíduos e interrupção do transporte de carga e atividade comercial (AFTABUZZAMAN \& MAZLOUMI, 2011).

Para se ter ideia das proporções de um choque provocado pelo pico do petróleo, durante o embargo de 1973-74, o preço dos combustíveis, em dólar, aumentou por um fator de 3, e em 1979-82, por um fator de 2. Além disso, países em desenvolvimento tendem a sofrer mais com esse tipo de crise do que países desenvolvidos (HIRSCH et al., 2005). Essa soma de efeitos negativos resultantes dos preços elevados do petróleo, ou até mesmo pela sua escassez, é chamado por Lovelace \& Philips (2014) de vulnerabilidade do petróleo.

A mudança para modos alternativos de transporte, o transporte integrado, o planejamento no uso do solo e o desenvolvimento e implantação de combustíveis alternativos são apresentadas como estratégias de mitigação e prevenção para um possível choque. Muitos países tomaram medidas para introduzir ou melhorar o uso de combustíveis alternativos, 
como o gás natural, etanol e metanol. Energia elétrica, solar e de hidrogênio também podem alimentar os veículos, mas o seu custo, devido à tecnologia necessária, ainda não é economicamente vantajoso para o consumidor (AFTABUZZAMAN \& MAZLOUMI, 2011). A substituição no uso de veículos movidos por combustíveis fósseis para veículos elétricos como substituição em um futuro próximo também é improvável. Não exatamente pelo seu preço, pois o próprio preço do petróleo pode vir a aumentar a ponto de ser possível uma competição no mercado, mas pela imprevisibilidade do público geral quanto à mudança de tecnologia e o ritmo lento em que se dá a sua substituição. (HIRSCH et al., 2005; PALOHEIMO et al., 2016; PELTAN et al., 2017).

Assim, as melhores alternativas de combate a uma possível crise causada pelo pico do petróleo ainda são o planejamento e uso misto do solo, de forma a encorajar o uso de bicicletas e da caminhada em regiões urbanas como formas principais de transporte. É nesse contexto de maior necessidade de independência de veículos motorizados, que o conceito de resiliência é inserido. Mais especificamente, a resiliência dos transportes ou da mobilidade.

\subsection{A RESILIÊNCIA NA MOBILIDADE URBANA}

O termo Resiliência emergiu no campo da ecologia, nos anos de 1970, com o objetivo de descrever a capacidade de um sistema resistir ou se recuperar diante de alguma perturbação (BHOITE et al., 2015). Chan \& Schofer (2016) a definem como a habilidade de um sistema de transportes vivenciar um evento danoso e retornar ao seu estado operacional em um período de tempo razoável. Para Walker \& Cooper (2011), a resiliência é uma estratégia operacional para a gestão de risco, recente nos campos financeiro, urbano e ambiental. Já Leu et al. (2010) a consideram como a habilidade de um sistema para atingir certos objetivoschaves, quando confrontado com ambientes desafiadores.

Diversos autores procuraram estabelecer propriedades que pudessem melhor descrever a resiliência. Apesar de algumas variações, as propriedades destacadas a seguir foram as mencionadas na literatura pesquisada:

- Robustez ou Endurecimento: trata da habilidade dos elementos (geralmente estruturas físicas) de um sistema de resistir e absorver os fortes impactos causados por eventos de risco, sem sofrer danos significativos (BRUNEAU et al., 2003; BHOITE et al., 2015; ARUP/SIEMENS, 2015; e CHAN \& SCHOFER, 2016); 
- Redundância: refere-se à capacidade de repor, propositalmente, algum componente do sistema. A redundância permite que este sistema não seja afetado com a interrupção de algum elemento ou caminho prejudicado (BRUNEAU et al., 2003; BHOITE et al., 2015; ARUP/SIEMENS, 2015; e CHAN \& SCHOFER, 2016);

- Flexibilidade: trata da habilidade dos sistemas de mudarem, evoluírem e se adaptarem diante das circunstâncias, através da distribuição descentralizada de recursos e do uso de novas práticas e tecnologias (BHOITE et al., 2015; e ARUP/SIEMENS, 2015).

Outras propriedades, mais particulares de cada autor, também são apontadas. Bruneau et al. (2003) citam a Rapidez, como a capacidade de, em um período de tempo apropriado, conter os danos e evitar crises futuras. Chan \& Schofer (2016) reconhecem a Elasticidade como a absorção temporária dos impactos, com sua continuidade normal ao final deste tempo. A Reflexividade, a Desenvoltura, a Inclusividade, e a Integralidade (BHOITE et al., 2015), bem como a Capacidade de Resposta e a Coordenação (ARUP/SIEMENS, 2015), também são propriedades e qualidades citadas na literatura.

Por ser um conceito relativamente abrangente, a resiliência pode estar relacionada a diversos campos científicos, abordada de diferentes formas. Galderisi (2014) procurou dividir a resiliência em 4 grupos com características comuns entre si. No primeiro grupo estariam os campos relacionados à ecologia e à sustentabilidade, focado em ecossistemas e sistemas sócio-ecológicos. O segundo grupo teria seu foco nos eventos de risco ocorridos em comunidades. O terceiro grupo está dirigido para a resiliência de sistemas econômicos, de uma escala urbana a regional. $\mathrm{O}$ quarto e último grupo estaria relacionado às alterações climáticas e seus riscos para as comunidades.

É possível perceber, com isso, que uma análise da resiliência em regiões urbanas é completamente aplicável, pois as cidades são sistemas complexos em constante mudança e adaptação, cada vez mais vulneráveis a colapsos vindos de eventos físicos ou sociais (BHOITE et al., 2015).

Aproveitando a citação à vulnerabilidade, é importante fazer menção a ela, uma vez que é o oposto de um estado resiliente, caracterizado pela redução na qualidade dos sistemas em consequência das ações ocorridas pelos eventos de risco (REGGIANI et al., 2015).

Quando aplicada em problemas relacionados a aspectos particulares de um sistema, causados por eventos também particulares, a resiliência é considerada específica. Em casos 
onde a preocupação é voltada para todas as crises, incluindo os tipos mais recentes, a resiliência é considerada geral (FOLKE et al., 2010). Um exemplo de resiliência mais abrangente é a de Bhoite et al. (2015), que definem a resiliência das cidades como a capacidade de funcionamento, de forma que pessoas que vivem e/ou trabalhem nelas, possam sobreviver e prosperar diante de algum evento de risco. Seu trabalho foi criar um índice de avaliação da resiliência (geral) de uma cidade, formado por 4 dimensões (saúde e bem-estar, economia e sociedade, infraestrutura e meio ambiente, liderança e estratégia), 12 objetivos e 52 indicadores. Um índice também é usado por Imrana \& Cheynea (2016) para medir a resiliência na região de Manawatu-Whanganui, na Nova Zelândia. Similar a Bhoite et al. (2015), eles dimensionaram a resiliência como econômica, social, ambiental, de serviços, de engenharia e institucional. Seu indicador foi baseado em dados qualitativos e entrevistas com especialistas.

Uma resiliência com um foco mais específico foi abordada por Bruneau et al. (2003). Ao criarem um sistema para quantificar a resiliência sísmica em comunidades, os autores trabalharam com uma resiliência contextualizada em 4 dimensões: técnica, organizacional, social e econômica (TOSE). A dimensão técnica refere-se à performance dos elementos físicos de um sistema em um abalo sísmico. A dimensão organizacional trata da capacidade das organizações responsáveis em lidar com as instalações em situação crítica, bem como a tomada de decisões relacionadas ao desastre, de forma a atingir um alto nível de resiliência. A dimensão social consiste em medidas para diminuir os danos nas comunidades atingidas pelos abalos, causando perda ou diminuição de serviços essenciais. Por fim, a dimensão econômica trata da capacidade de reduzir perdas econômicas, diretas e indiretas, resultantes dos terremotos.

Desastres naturais em regiões urbanas também foram o foco do trabalho de Aydin et al. (2017), que investigaram as consequências do terremoto Gorkha e seus abalos sísmicos secundários em abril e maio de 2015, em Kathmandu, no Nepal. Seus resultados mostraram uma baixa resiliência tratando-se da acessibilidade a hospitais e muitos pontos vulneráveis devido à ausência de serviços próximos. Arup/Siemens (2015) apresenta um relatório onde se avaliam as melhores estratégias tecnológicas para criar uma "mobilidade urbana resiliente" na cidade de Ho Chin Minh, no Vietnã, diante de algum choque climático. Donovan \& Work (2017), por sua vez, se utilizaram de aparelhos GPS nos táxis de Nova York para avaliar a resiliência na infraestrutura de transporte em uma escala de cidade. Seus resultados de 4 anos de acúmulo de dados mostraram que, no evento do Furacão Sandy, o atraso nas viagens foi de 
até 2 minutos por milha. Chan \& Schofer (2016) avaliaram a resiliência dos serviços de transporte na cidade de Nova Iorque, antes, durante e depois dos furacões Irene e Sandy.

Para além dos desastres naturais, outros estudos também tiveram foco nos sistemas de transporte urbano. Leu et al. (2010) trabalharam com sistema GPS na região metropolitana de Melbourne para medir a resiliência nos transportes, indicando a falta de redundância e a baixa quantidade de rotas alternativas na rede. Nelson et al. (2015) avaliaram o impacto no sistema de transportes após os choques econômicos de 2000 e 2008. Serulle et al. (2011) tentam medir a resiliência no transporte de Santo Domingo, na República Dominicana, como forma de direcionar investimentos em áreas pouco resilientes na rede de transporte. Wen et al. (2018), abordando a resiliência de forma mais holística, criam um índice para medi-la em Rapid Transit Systems (RTS) em Cingapura. King \& Shalaby (2016), em Toronto, e Fotouhi et al. (2017), em Minneapolis, também tiveram seus estudos focados na avaliação da resiliência na rede de transportes locais.

Entretanto, nenhum destes estudos teve como foco uma adequação ao modo de transporte utilizado nas viagens urbanas, priorizando modos ativos, tampouco na dependência aos modos motorizados que causam o alto consumo de combustíveis fósseis. Constatou-se, na revisão de literatura para este trabalho, que os primeiros autores a relacionarem todos estes temas foram Dantas et al. (2010). O estudo, apesar de não se utilizar diretamente do termo "resiliência", avaliou o risco ao transporte e no planejamento urbano para o caso de uma diminuição na oferta de combustível. Em seu trabalho, eles dividem as viagens em três níveis, a depender da sua essencialidade:

- Opcionais: viagens que podem ser eliminadas sem prejuízo ao bem-estar;

- Necessárias: viagens que eliminadas, causam prejuízo social e econômico;

- Essenciais: viagens que pessoas teriam dificuldade em eliminar, uma vez que isto causaria danos à saúde, à economia, e limitação ao acesso a necessidades básicas.

O mesmo é feito com o nível de impacto:

- Baixo Impacto: a disparidade entre oferta e demanda é mínima e não restringe viagens;

- Médio Impacto: viagens opcionais são eliminadas; 
- Alto Impacto: viagens necessárias são eliminadas;

- Impacto Muito Alto: viagens essenciais são eliminadas.

Seus resultados mostraram que a região de Christchurch, Nova Zelândia, no ano de 2041 poderá ter maior possibilidade de mudança do modo motorizado para os modos a pé e bicicleta, caso adote uma estrutura urbana mais concentrada. Rendall et al. (2011) também usaram essa mesma região para introduzir o conceito de Active Mode Accessibility (AMA), ou seja, a proporção de atividades que podem ser feitas através de modos ativos. Os autores mostraram que todas as atividades da região poderiam ser realizadas por modo a pé, bicicleta ou por transporte público no ano de 2041.

Philips (2014) utilizou o termo "resiliência evolucionária" para representar sua avaliação do potencial de caminhada e uso de bicicleta para viagens diárias, diante de uma crise de combustíveis na Inglaterra. Ele indica que somente $44 \%$ das viagens da amostra poderiam ser efetuadas nessa situação. Já Exner et al. (2016) avaliaram a "resiliência comunitária" pós-pico do petróleo de municípios da Áustria como moderada, onde regiões de maior atividade rural são mais resilientes, pois conseguem manter a distribuição de alimentos para a comunidade.

No Brasil, mesmo sem abordar a questão dos combustíveis fósseis, Oliveira et al. (2016) propuseram um indicador relacionado à adequação da escolha do modo de transporte, baseado na variável distância, no contexto de um campus universitário. A partir de uma amostra de entrevistados, e por meio de um SIG (Sistema de Informação Geográfica), obtiveram as distâncias percorridas diariamente pelos indivíduos, bem como seus modos de transporte. $\mathrm{O}$ indicador de 0,847 (variando de 0 a 1), mostrou que a maioria dos entrevistados utilizava o modo adequado em seus deslocamentos no caso estudado.

Mattioli et al. (2017), por sua vez, desenvolveram um método de medição de "vulnerabilidade" diante do aumento do preço dos combustíveis, na Inglaterra, através de um indicador com 3 dimensões: Exposição (custo do combustível), Sensibilidade (renda) e Capacidade Alternativa (acessibilidade a outros serviços através de modos que não o carro).

Como pôde-se notar, poucos foram os trabalhos sobre resiliência encontrados, cujo foco foram os modos ativos de transportes. Além disso, em sua grande maioria foram estudos de caso em regiões ao norte do globo, em países desenvolvidos. Dessa forma, espera-se abordar neste trabalho a dependência aos veículos motorizados e o espraiamento urbano em um 
cenário onde há escassez de combustíveis fósseis, com estudos de caso em regiões em desenvolvimento. A base teórica do trabalho advém de Fernandes et al. (2015; 2017), que adotam o termo "resiliência na mobilidade urbana", entendido como o potencial de persistir e se adaptar diante de um risco à mobilidade urbana. Eles se utilizam primordialmente dos conceitos de Folke et al. (2010), que tratam a resiliência como um sistema ecológico-social, e a segmentam em persistência, adaptabilidade e transformabilidade. A persistência está relacionada com a continuidade do modo usado, sem comprometer a qualidade de vida. A adaptabilidade equivale à mudança de modo sem o comprometimento do bem-estar do indivíduo ou grupo. Por fim, a transformabilidade se insere onde nenhum dos outros segmentos são possíveis, ou seja, existe considerável impacto social e econômico nesse segmento. 


\section{METODOLOGIA}

Neste capítulo, é proposta uma estratégia metodológica para se avaliar o nível da resiliência na mobilidade nas cidades analisadas baseada em 3 perguntas fundamentais:

1. Que distâncias poderiam ser percorridas por modos ativos, caso não houvesse veículos motorizados disponíveis?

2. Quais viagens seriam afetadas? Quais permaneceriam? É possível classificar estas viagens com base nas condições de resiliência?

3. Como se comportam cada um destes grupos de viagens?

O primeiro subitem aborda as Distâncias Máximas Possíveis (DMP) e os métodos usados para a medição das distâncias entre as zonas de tráfego. O segundo subitem trata da segmentação da resiliência utilizada nas viagens, aqui feita com base em Folke et al. (2010). Estas viagens são rotuladas de acordo com Dantas et al. (2010). Apenas as viagens consideradas necessárias ou essenciais foram utilizadas nesta pesquisa, consequentemente, com níveis de impacto alto e muito alto, respectivamente.

\subsection{DISTÂNCIAS MÁXIMAS POSSÍVEIS}

Esta metodologia parte do pressuposto de que um indivíduo pode caminhar ou pedalar até certas distâncias. As Distâncias Máximas Possíveis (DMP) referem-se ao limite teórico que uma pessoa é capaz de percorrer a pé ou de bicicleta. Para os fins deste estudo, quando as DMP para os modos ativos são estabelecidas, significa que distâncias maiores seriam percorridas apenas por veículos motorizados. Assume-se ainda que as DMP para o modo a pé sejam sempre menores ou iguais as DMP para o modo bicicleta, nunca maiores. Quanto menores os valores das DMP, mais pessimista é considerado o cenário, enquanto que DMP mais altas representam cenários cada vez mais otimistas.

Em seguida, é necessário medir a distância das viagens em si. Estas viagens podem ser obtidas através da pesquisa de Origem e Destino da cidade ou região trabalhada, e suas distâncias medidas com auxílio de uma Sistema de Informação Geográfica (SIG). Os centroides das zonas de tráfego servem como pontos comuns de origem ou destino das viagens nas respectivas zonas. Isso quer dizer que todas as viagens originadas de uma certa zona têm como mesmo ponto de origem o centroide desta zona. $\mathrm{O}$ mesmo acontece com as 
zonas de destino (Figura 1). Para facilitar o entendimento, o termo "trajeto" será designado para todas as possíveis viagens realizadas entre as zonas de tráfego (ex.: AC, DB, CA, etc.), ou seja, de acordo com a pesquisa de Origem e Destino, uma certa quantidade de viagens é realizada em cada trajeto possível na cidade. É importante salientar que, apesar desta abordagem de centroides, as viagens intrazonais não são necessariamente descartadas, mas apenas resumidas ao centroide, com uma distância teórica de $0 \mathrm{~km}$.

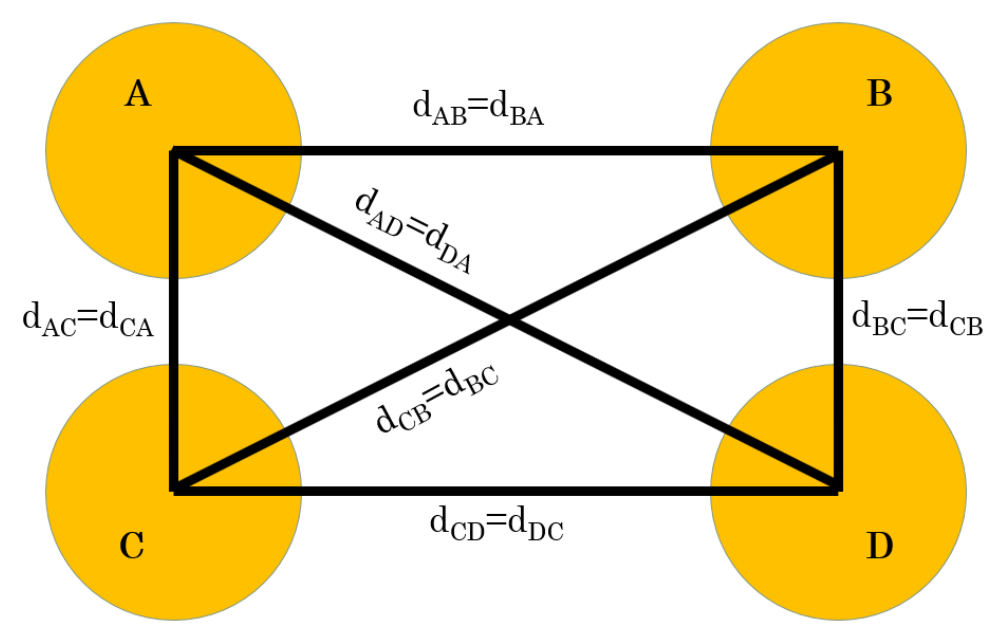

Figura 1. Distâncias $d_{i j}$ entre centroides das zonas de tráfego i e j (i,j $\left.=\mathbf{A}, \mathbf{B}, \mathrm{C}, \mathrm{D}\right)$ de uma cidade ou região hipotética.

As distâncias "d" entre os centroides são, então, comparadas com as DMP estabelecidas para cada cenário. Adotando um valor X para a DMP a pé e Y para bicicleta, as condições de viagem são as seguintes:

- $\quad$ Se $\mathrm{d} \leq \mathrm{X}$, o trajeto entre as zonas pode ser feito andando ou de bicicleta;

- Se $\mathrm{X}<\mathrm{d} \leq \mathrm{Y}$, a distância é demasiada longa para o modo a pé, porém pode ser feita de bicicleta;

- Se d > Y, as zonas são muito distantes para serem percorridas diariamente sem o uso de transporte motorizado. Em caso de restrição aos modos motorizados, o indivíduo será necessariamente afetado.

Sendo as viagens intrazonais de curta distância, elas são representadas pontualmente pelos centroides da zona, com distância de viagem igual a zero $\left(\mathrm{d}_{\mathrm{AA}}=\mathrm{d}_{\mathrm{BB}}=\mathrm{d}_{\mathrm{CC}}=\mathrm{d}_{\mathrm{DD}}=0\right)$. Logo, podem ser realizadas a pé ou de bicicleta. Além disso, as viagens entre zonas diferentes 
terão a mesma distância, independente de qual for a origem e qual for o destino. Por exemplo, viagens originadas de A para B terão a mesma distância que aquelas originadas de B para A $\left(\mathrm{d}_{\mathrm{AB}}=\mathrm{d}_{\mathrm{BA}}\right)$.

\subsection{SEGMENTAÇÃO DA RESILIÊNCIA}

Nesta etapa, cada viagem é classificada de acordo com Folke et al. (2010), como segue: persistente, adaptável ou transformável. As viagens persistentes são aquelas realizadas por modos ativos dentro dos limites das suas DMP, ou seja, viagens a pé até a DMP a pé, e viagens de bicicleta até a DMP de bicicleta. As viagens adaptáveis são feitas por modos motorizados, porém, dentro dos limites das DMP, podendo migrar de modo de transporte caso haja restrição. As viagens transformáveis são aquelas feitas por modos motorizados acima das DMP. Logo, não podem, teoricamente, ser realizadas por modos ativos.

É importante lembrar que as DMP estão sendo aqui adotadas sem levar em consideração a idade dos indivíduos ou o relevo do terreno, por exemplo. São, porém, valores que procuram englobar, dentro de seus limites, o maior número de pessoas. Logo, é possível que pessoas percorram, por modos ativos, distâncias acima das estabelecidas como DMP para os modos a pé e bicicleta. Para esse tipo de viagem, foi criada uma nova segmentação: a excepcionalidade. As viagens excepcionais, juntamente com as persistentes e as adaptáveis, são consideradas resilientes. Um esquema explicativo de cada condição é apresentado na Figura 2. O nível de resiliência será dado pelo número de viagens persistentes, adaptáveis e excepcionais, e de acordo com a Tabela 2. As viagens transformáveis representarão o nível de vulnerabilidade do sistema, o qual terá uma escala inversamente proporcional à da resiliência. 


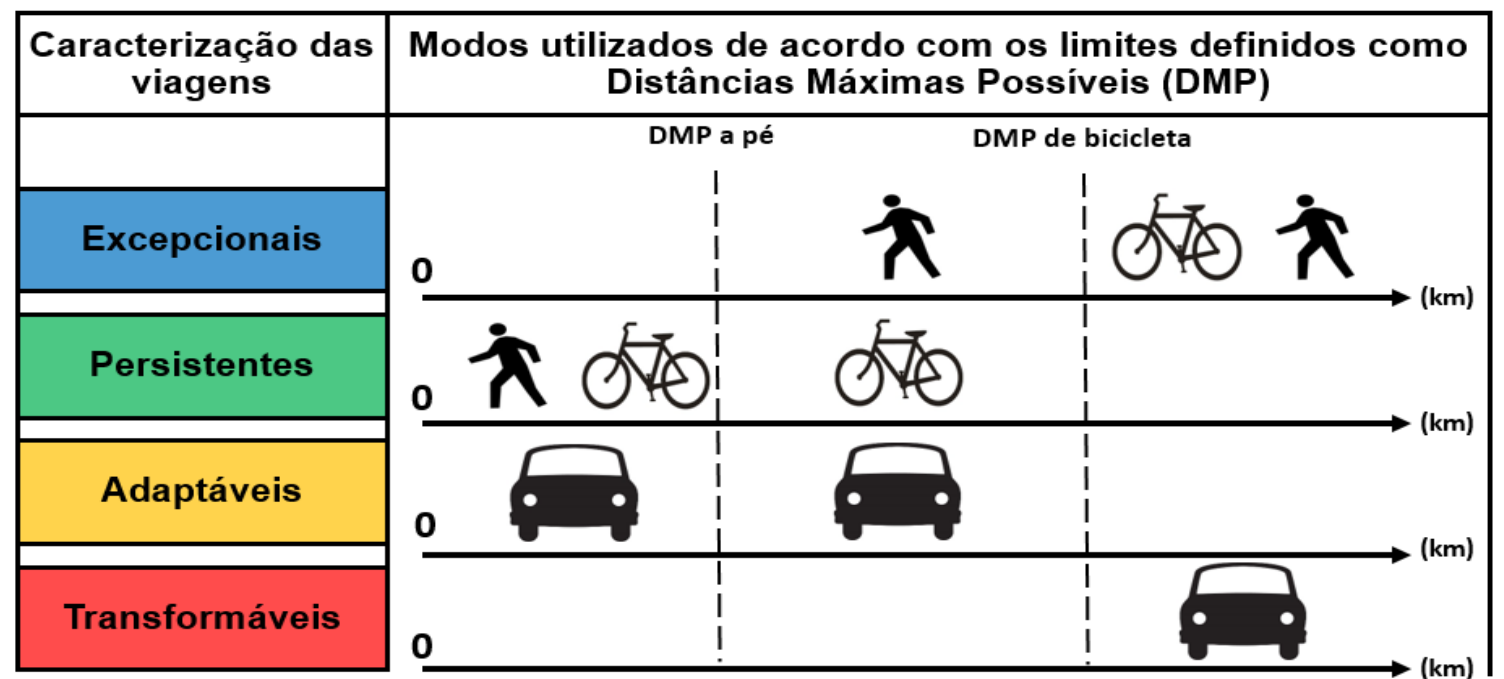

Figura 2. Esquema visual da caracterização das viagens (excepcionais, persistentes, adaptáveis e transformáveis) de acordo com o modo de transporte utilizado dentro das Distâncias Máximas Possíveis para os modos a pé e bicicleta.

Tabela 2. Nível de resiliência na mobilidade urbana.

\begin{tabular}{cccccc}
\hline Nível de Resiliência & Muito Baixa & Baixa & Média & Alta & Muito Alta \\
\hline Viagens resilientes (\%) & $0-20,0$ & $20,1-40,0$ & $40,1-60,0$ & $60,1-80,0$ & $80,1-100$ \\
\hline
\end{tabular}

\subsection{VARIAÇÃO DA RESILIÊNCIA E PADRÃO DE VIAGENS}

O nível de resiliência na mobilidade irá variar de acordo com o cenário trabalhado. Com isso, será possível analisar a variação da resiliência de acordo com a variação das DMP. Espera-se encontrar algum tipo de padrão nesta variação, de forma que possa ser representado graficamente para melhor visualização, tanto para a resiliência em si, como para seus respectivos segmentos.

Outra análise possível de ser realizada é a dos padrões de viagem. Uma vez com os cenários estabelecidos e as variações da resiliência e seus segmentos disponíveis, pode-se isolar as viagens de cada um destes segmentos e avaliar como elas estão distribuídas pela cidade ou região. De onde partem e para onde vão as viagens adaptáveis, por exemplo, e como elas se comportam conforme os cenários vão mudando. A análise das viagens por zonas de tráfego também pode auxiliar na identificação de áreas com maior concentração de viagens persistentes, adaptáveis, transformáveis ou excepcionais. 
A Tabela 3 e o diagrama da Figura 3 contém as etapas e subetapas da metodologia. As 3 etapas apresentadas correspondem aos 3 subitems deste capítulo.

Tabela 3. Descrição das etapas da metodologia de avaliação da resiliência na mobilidade urbana e suas localizações nos capítulos de Metodologia e Resultados.

\begin{tabular}{|c|c|c|c|}
\hline Etapa & $\begin{array}{c}\text { Subitem relacionado } \\
\text { em Metodologia }\end{array}$ & $\begin{array}{l}\text { Subitem relacionado } \\
\text { em Resultados }\end{array}$ & Descrição da etapa \\
\hline \multirow{3}{*}{1} & \multirow{3}{*}{3.1} & 4.2 & $\begin{array}{l}\text { Medição da distância entre os pontos de } \\
\text { origem e destino das viagens entre zonas. }\end{array}$ \\
\hline & & \multirow{2}{*}{4.3} & $\begin{array}{l}\text { Definição dos valores para as Distâncias } \\
\text { Máximas Possíveis (DMP) para o modo a pé } \\
\text { e para o modo bicicleta. }\end{array}$ \\
\hline & & & $\begin{array}{c}\text { Comparação das distâncias das viagens com } \\
\text { valores das DMP. }\end{array}$ \\
\hline \multirow[b]{2}{*}{2} & \multirow[b]{2}{*}{3.2} & \multirow[b]{2}{*}{4.4} & $\begin{array}{c}\text { Classificação de viagens a pé e bicicleta em } \\
\text { Excepcionais e Persistentes, e viagens por } \\
\text { modo motorizado em Adaptáveis e } \\
\text { Transformáveis. }\end{array}$ \\
\hline & & & $\begin{array}{l}\text { Determinação do nível de resiliência pela } \\
\text { proporção de viagens Excepcionais, } \\
\text { Persistentes e Adaptáveis. } \\
\text { Determinação do nível de vulnerabilidade } \\
\text { pela proporção de viagens Transformáveis. }\end{array}$ \\
\hline \multirow[t]{2}{*}{3} & \multirow{2}{*}{3.3} & \multirow{2}{*}{4.5} & $\begin{array}{c}\text { Análise dos padrões das viagens } \\
\text { excepcionais, persistentes, adaptáveis e } \\
\text { transformáveis (origem-destino) na região } \\
\text { estudada. }\end{array}$ \\
\hline & & & $\begin{array}{l}\text { Análise das proporções de viagens } \\
\text { excepcionais, persistentes, adaptáveis e } \\
\text { transformáveis por zona de tráfego. }\end{array}$ \\
\hline
\end{tabular}




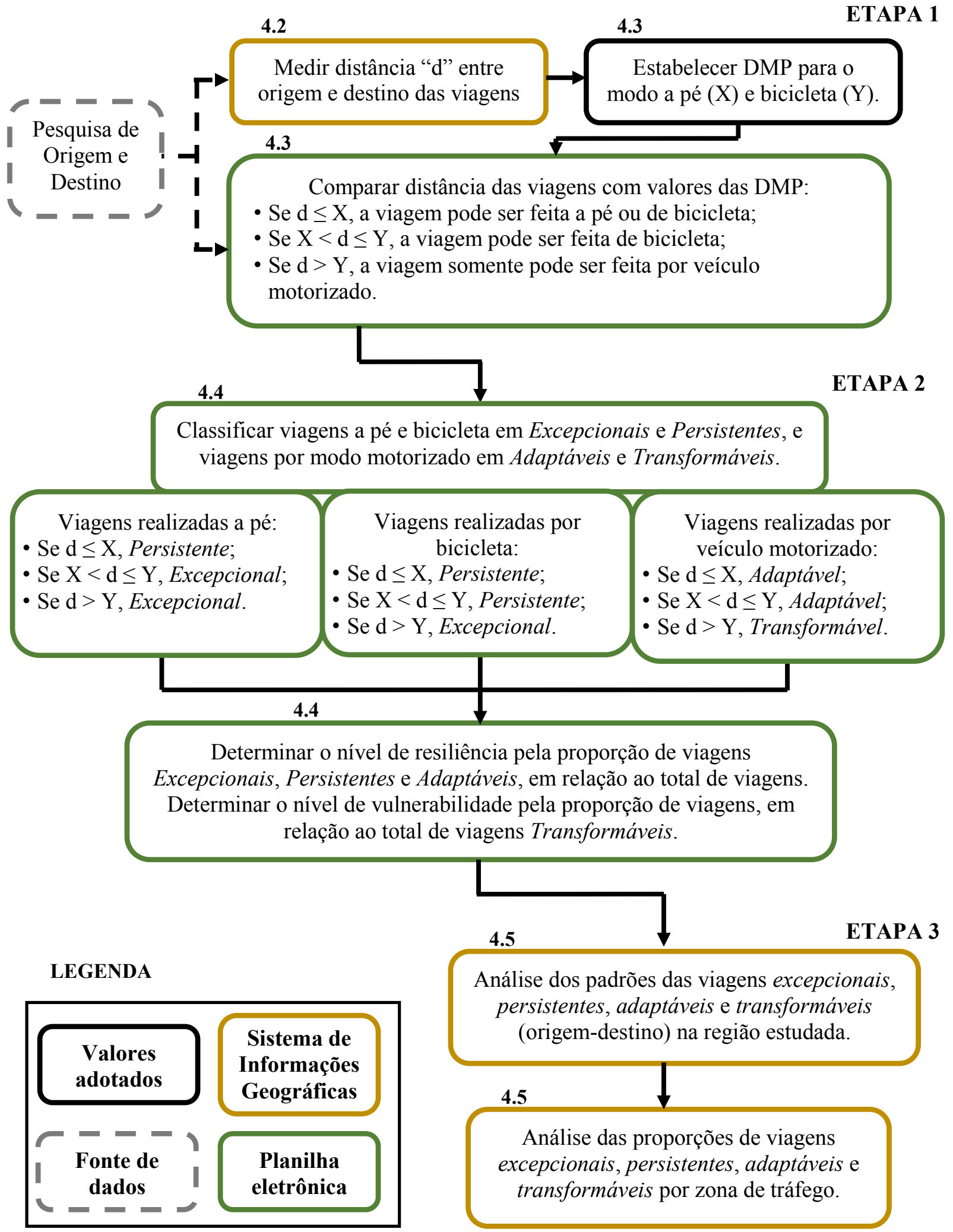

Figura 3. Conjunto de procedimentos e ferramentas que formam a metodologia, separados em etapas e associados aos subitems do capítulo de Resultados. 


\section{RESULTADOS}

Neste capítulo é apresentada a implantação da metodologia de avaliação da resiliência em dois estudos de caso, que são introduzidos no primeiro subitem. O segundo subitem aborda a aplicação da metodologia e discute alguns resultados relacionados à distância entre os centroides das zonas de tráfego e da distribuição de viagens. O terceiro tópico apresenta a elaboração dos cenários de acordo com as DMP. Em seguida, os resultados da variação da resiliência por cenário são apresentados. O quinto e último subitem mostra o comportamento de cada condição da resiliência por estudo de caso e por zona de tráfego.

\subsection{ESTUDOS DE CASO}

Os estudos de caso deste trabalho foram na cidade de São Carlos - SP (Figura 4) e na Região Metropolitana de Maceió - AL (RMM), que abrange Maceió e outros dois municípios: Rio Largo e Satuba (Figura 5). Os dados de São Carlos foram obtidos da pesquisa de Origem e Destino realizada em 2007/08. Neste trabalho, foram usadas as 41 zonas de tráfego da cidade, excluindo-se, devido à distância, os distritos de Santa Eudóxia e Água Vermelha. Quanto a RMM, utilizou-se da pesquisa de Origem e Destino do ano de 2014, encomendada pelo governo do estado de Alagoas, e adquiridos através da Secretaria de Transporte e Desenvolvimento (SETRAND-AL). Das 90 zonas de tráfego englobando os 3 municípios, 7 delas precisaram ser excluídas, pois 6 representavam zonas rurais ou agrícolas, e 1 se referia à lagoa Mundaú. Em outras 5 zonas de tráfego não foram realizadas entrevistas em domicílios. Dessa forma, nenhuma delas possui viagens geradas. Todavia, pelo fato de representarem zonas de destino, optou-se por mantê-las no trabalho. Por fim, um total de 83 zonas de tráfego foram usadas no estudo de caso da RMM. 


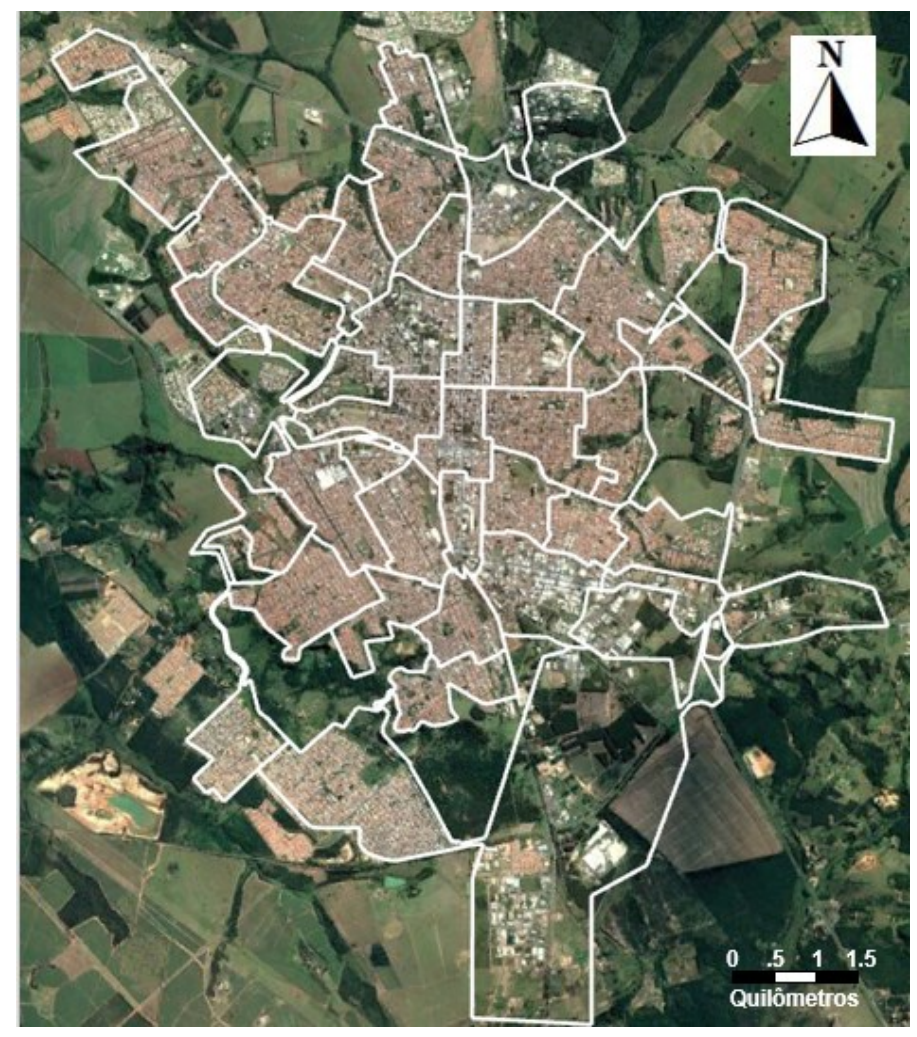

Figura 4. Zonas de tráfego da cidade de São Carlos sobre imagem de satélite obtida pelo Google Earth (2017).

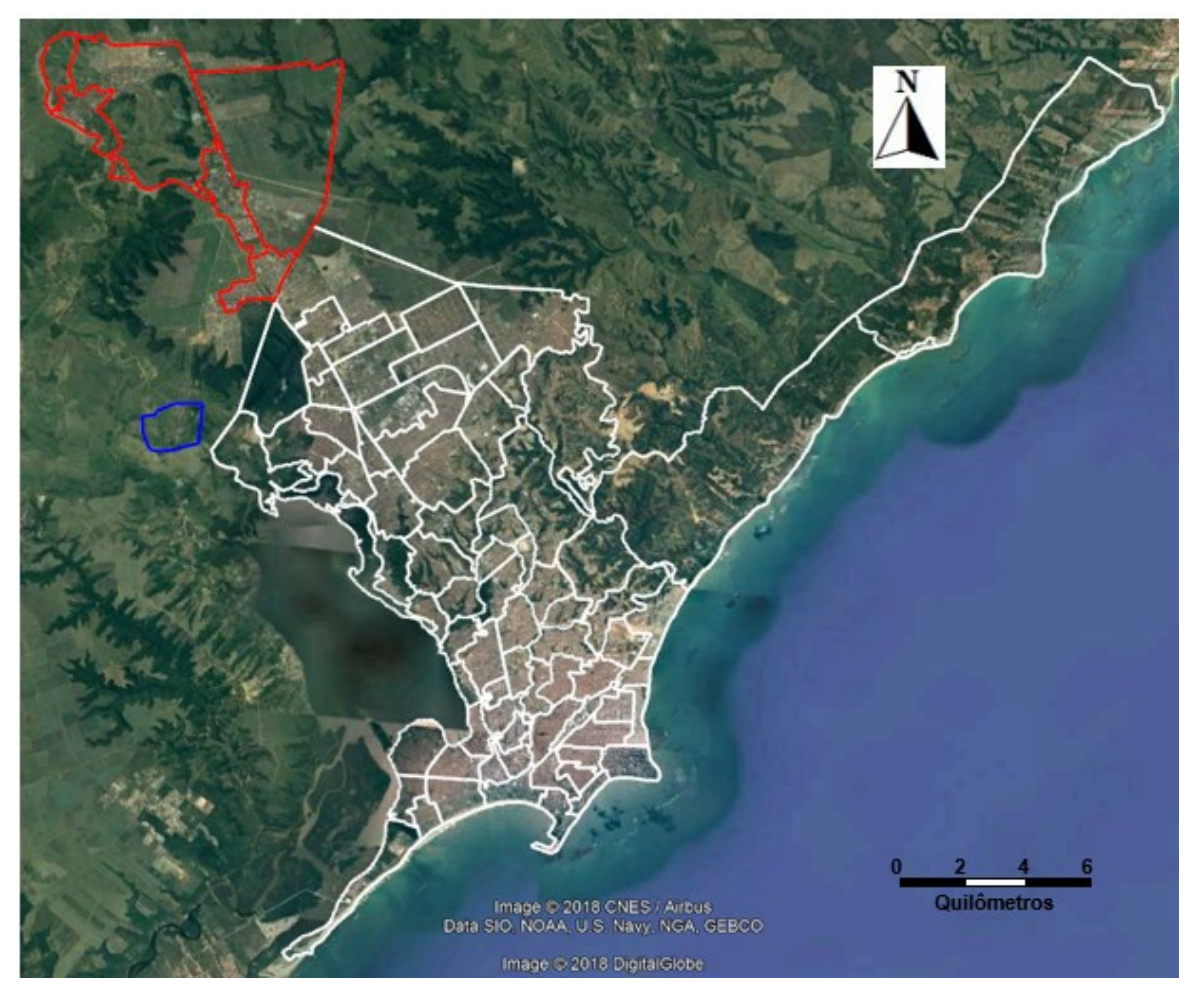

Figura 5. Zonas de tráfego da Região Metropolitana de Maceió utilizadas na pesquisa: Maceió (branco), Satuba (azul) e Rio Largo (vermelho) sobre imagem de satélite obtida pelo Google Earth (2015). 


\subsection{DISTÂNCIA ENTRE CENTROIDES E DISTRIBUIÇÃO DE VIAGENS}

No caso de São Carlos, foram consideradas as viagens realizadas em todos os horários do dia, com os seguintes motivos: trabalho, estudo, negócios, assuntos pessoais e saúde. Excluiu-se aquelas com motivo de lazer, pois este não foi considerado um tipo de viagem necessária ou essencial, e aquelas com motivo residência, no intuito de evitar viagens repetidas. No total, 6821 viagens foram consideradas (Apêndice A - Tabela A.1). Viagens por veículo motorizado foram divididas em duas subcategorias: ônibus e automóvel, com 1445 e 2871, respectivamente. O modo a pé teve 2883 viagens, e o modo bicicleta, 222.

No caso da RMM, as viagens utilizadas foram aquelas com origem residencial, em todos os horários do dia, e cujos destinos eram trabalho, estudo, compras, saúde, assuntos pessoais ou procura de emprego, visto que estes se encaixam nos tipos de viagens consideradas essenciais ou necessárias. As viagens não consideradas na pesquisa foram aquelas com objetivo de lazer ou integração e/ou transferência para outro modo de transporte. Também foram segregadas pelo modo de viagem: transporte individual (1917), transporte coletivo (1764), bicicleta (277) e a pé (2080). No total, 6038 viagens foram utilizadas (Apêndice B - Tabelas B.1). A Tabela 4 apresenta os modos englobados em cada categoria, para o caso dos modos motorizados.

As Figuras 6 e 7 mostram a distribuição geográfica das viagens de origem por zona de tráfego na cidade de São Carlos e na RMM, respectivamente. Apesar de, em ambos os casos, as principais zonas estarem dispersas pela região, é importante salientar que estas também apresentam um padrão residencial, o que explica a quantidade de viagens geradas. 
Tabela 4. Divisão dos modos de transporte motorizado por categoria na Região Metropolitana de Maceió.

\begin{tabular}{|c|c|}
\hline Modo & Categoria \\
\hline \multicolumn{2}{|l|}{ Dirigindo Auto } \\
\hline \multicolumn{2}{|l|}{ Passageiro Auto } \\
\hline Táxi & \multirow{4}{*}{$\begin{array}{c}\text { Transporte } \\
\text { Individual (TI) }\end{array}$} \\
\hline Moto & \\
\hline Mototáxi & \\
\hline Passageiro Moto & \\
\hline \multicolumn{2}{|l|}{ Transporte Escolar } \\
\hline \multicolumn{2}{|l|}{ Lotação/Van/Perua } \\
\hline \multicolumn{2}{|l|}{ Ônibus Fretado } \\
\hline \multicolumn{2}{|l|}{ Ônibus Intermunicipal (Rodoviário) } \\
\hline Ônibus Municipal - Outros & $\begin{array}{c}\text { Transporte } \\
\text { Coletivo (TC) }\end{array}$ \\
\hline \multicolumn{2}{|l|}{ Ônibus Municipal - Maceió } \\
\hline \multicolumn{2}{|l|}{ Ônibus Intermunicipal (ARSAL) } \\
\hline Complementar Intermunicipal (ARSAL) & \\
\hline Trem - VLT (CBTU) & \\
\hline
\end{tabular}




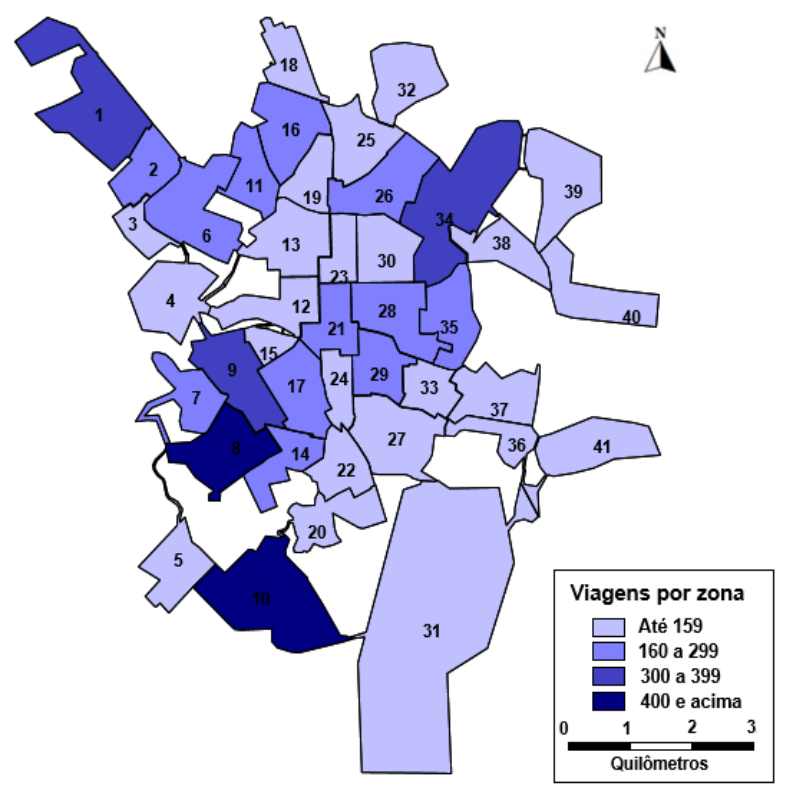

Figura 6. Distribuição de viagens produzidas por zona em São Carlos.

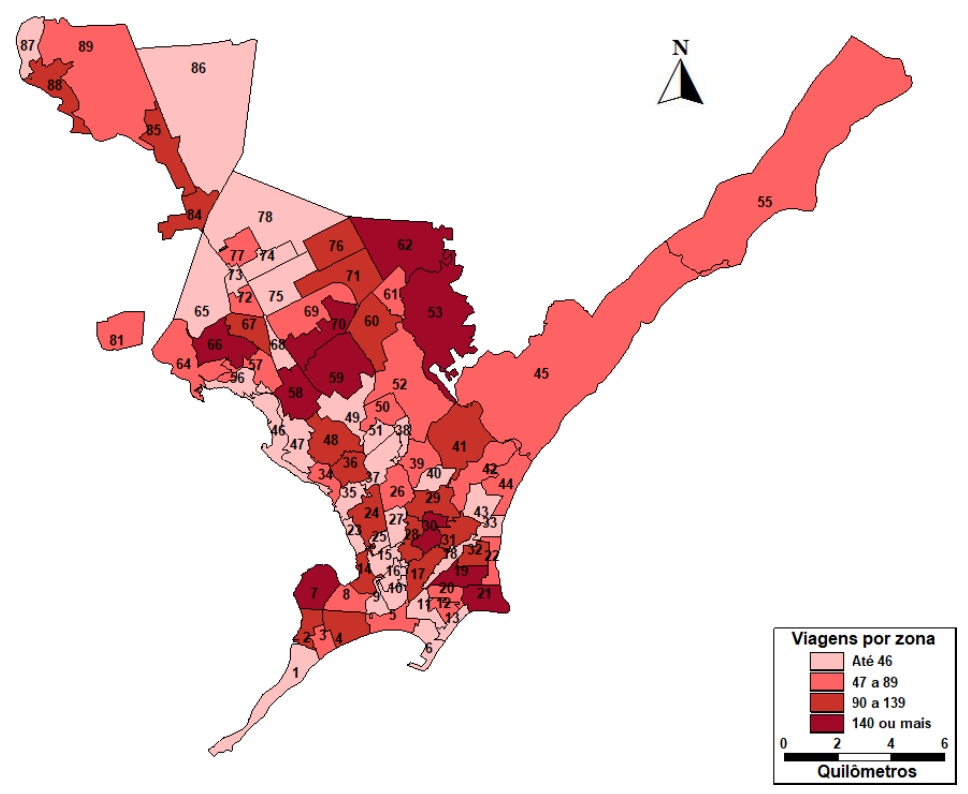

Figura 7. Distribuição de viagens produzidas por zona na Região Metropolitana de Maceió.

Com as viagens categorizadas, o passo seguinte foi medir as distâncias entre os centroides das zonas de tráfego. No caso de São Carlos, as distâncias entre os 41 centroides das zonas de tráfego foram medidas em linha reta (distância euclidiana). Estas distâncias precisaram então ser multiplicadas por um "fator de rota" ou "fator de circuito", para se aproximarem da distância real entre os centroides numa malha viária predominantemente 
ortogonal. A partir de trabalhos analisados (Dill, 2004; Ballou et al., 2002 e Gonçalves et al., 2014) decidiu-se utilizar um fator de aumento de 30\%, como recomendado por Novaes (1989) para regiões urbanas (Apêndice A - Tabelas A.2). As maiores distâncias, euclidianas e majoradas, podem ser vistas na Tabela 5 .

No caso da RMM, as distâncias entre os centroides foram medidas através da malha viária (Apêndice B - Tabelas B.2). As maiores distâncias foram medidas entre as zonas urbanas dos municípios de Rio Largo e Satuba, e as zonas 55, no litoral norte, (bairro de Ipioca), e 1, no litoral sul (bairro do Pontal da Barra), como pode ser visto na Tabela 6.

Tabela 5. Maiores distâncias entre centroides das zonas de tráfego em São Carlos.

\begin{tabular}{cccc}
\hline $\begin{array}{c}\text { Distâncias em } \\
\text { linha reta }(\mathrm{km})\end{array}$ & $\begin{array}{c}\text { Distâncias em linha reta } \\
\text { majoradas em } 30 \%(\mathrm{~km})\end{array}$ & $\begin{array}{c}\text { Zonas } \\
\text { de O } \backslash \mathrm{D}\end{array}$ \\
\hline 9,29 & 12,07 & 1 & 31 \\
9,20 & 11,95 & 1 & 41 \\
9,06 & 11,78 & 18 & 31 \\
8,68 & 11,28 & 5 & 39 \\
8,51 & 11,06 & 31 & 32 \\
8,47 & 11,01 & 5 & 32 \\
8,43 & 10,95 & 2 & 31 \\
8,42 & 10,95 & 2 & 41 \\
8,32 & 10,82 & 10 & 32 \\
8,31 & 10,80 & 10 & 18 \\
\hline
\end{tabular}


Tabela 6. Maiores distâncias entre centroides das zonas de tráfegos na RMM.

\begin{tabular}{ccc}
\hline Maiores distâncias entre centroides $(\mathrm{km})$ & \multicolumn{2}{l}{ Zonas de $\mathrm{O} \backslash \mathrm{D}$} \\
\hline 42,98 & 55 & 87 \\
41,69 & 55 & 88 \\
40,71 & 55 & 86 \\
37,81 & 55 & 85 \\
35,46 & 55 & 81 \\
34,51 & 55 & 84 \\
33,41 & 55 & 64 \\
33,09 & 1 & 87 \\
32,97 & 1 & 89 \\
31,70 & 59 & \\
\hline
\end{tabular}

Também foi possível analisar a frequência das distâncias entre os centroides das zonas de tráfego, bem como o número de viagens por distância nos dois estudos de caso, que são apresentados, respectivamente, nas Figuras 8 e 9. Em São Carlos, 89,2\% das distâncias entre centroides eram igual ou menor que $8 \mathrm{~km}$, ao mesmo tempo que $97,6 \%$ das viagens realizadas enquadram-se nesse limite. $\mathrm{Na} \mathrm{RMM}, 40,6 \%$ dos trajetos possíveis tinham limite de $8 \mathrm{~km}$, enquanto apenas 9,6\% estavam acima dos $20 \mathrm{~km}$. Em relação as viagens, $81,3 \%$ são realizadas em até $8 \mathrm{~km}$ de distância entre centroides, e apenas 1,2\% são realizadas acima dos $20 \mathrm{~km}$. Estas análises iniciais mostram o potencial no uso de modos ativos (a pé e bicicleta) para percursos diários, em ambos os casos. 


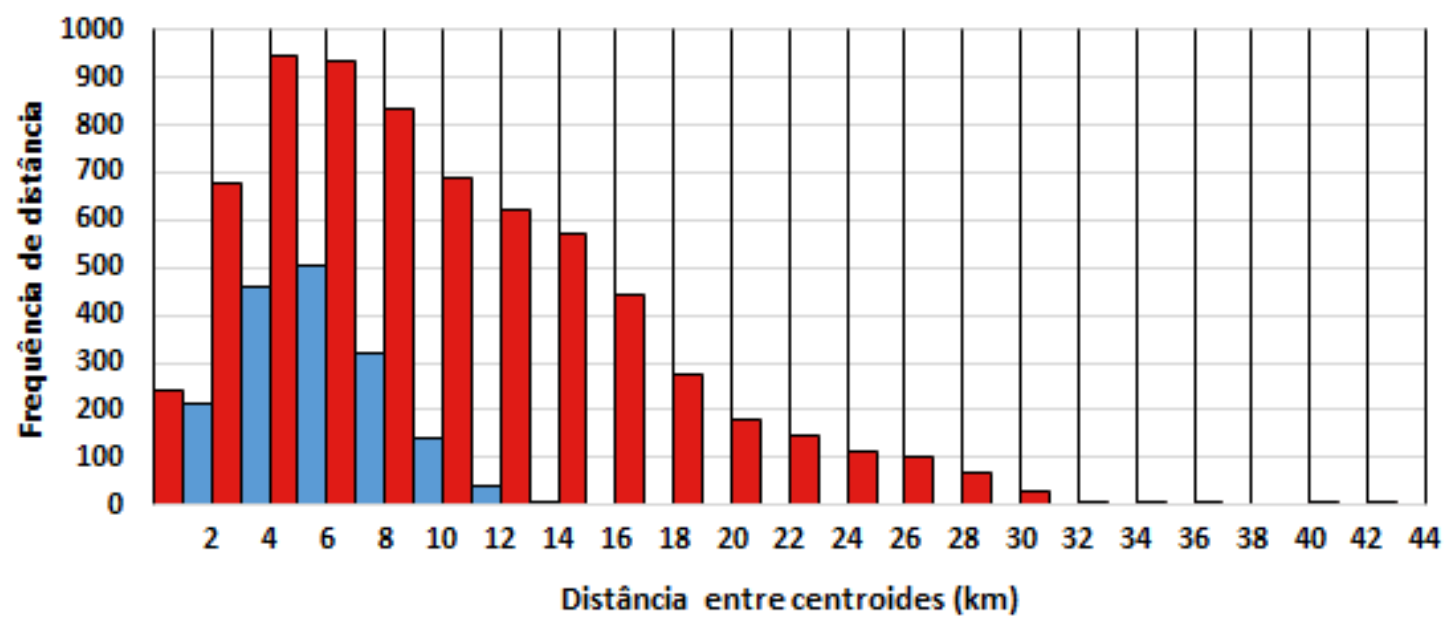

口Região Metropolitana de Maceió aSão Carlos

Figura 8. Frequência de distância entre centroides das zonas de tráfego da Região Metropolitana de Maceió, em 2014, e de São Carlos, em 2007/08.

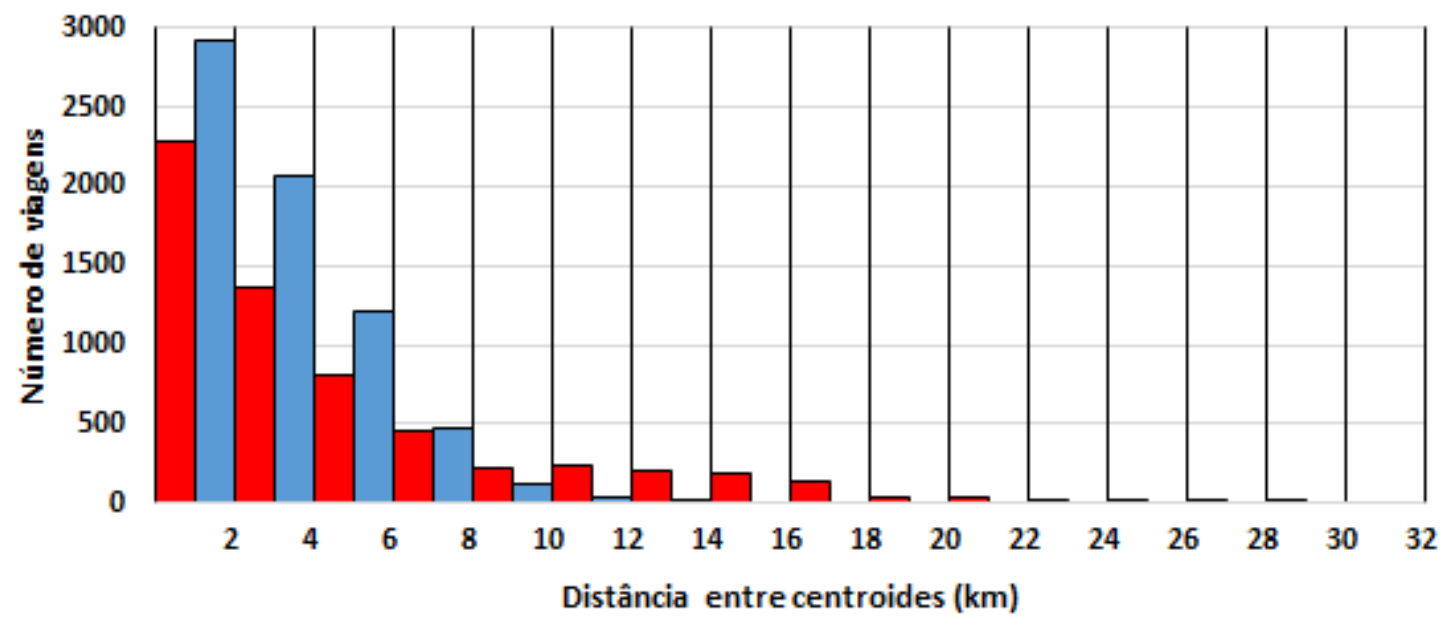

$\square$ Região Metropolitana de Maceió aSão Carlos

Figura 9. Número de viagens por distância entre os centroides das zonas de tráfego da Região Metropolitana de Maceió, em 2014, e em São Carlos, em 2007/08.

\subsection{ELABORAÇ̃̃O DOS CENÁRIOS DE ACORDO COM AS DISTÂNCIAS MÁXIMAS POSSÍVEIS}

Para adotar os valores das DMP, deve-se levar em consideração que o limite de cada indivíduo irá variar de acordo com a sua idade, condição física e de saúde, além de fatores específicos da cidade, como relevo, por exemplo. Dessa forma, para melhor averiguar a 
variação da resiliência na mobilidade urbana nos estudos de caso, optou-se por variar as DMP a partir da sua distância mínima $(0 \mathrm{~km})$, até o valor em que ela atingisse o seu máximo, ou seja, $100 \%$ de viagens resilientes. Para isso, foram criados diversos cenários, com diferentes valores de DMP a pé e para bicicleta. Partindo da regra que a DMP a pé deve ser sempre menor ou igual a DMP de bicicleta, foi necessário estabelecer uma quantidade de DMP a pé para cada DMP de bicicleta. Com exceção dos primeiros 14 cenários, que serão explicados mais adiante, para cada DMP de bicicleta foram usados 5 DMP a pé, variando de 2 a $4 \mathrm{~km}$, a cada 500 metros. Ou seja, para cada DMP de bicicleta foram criados 5 cenários, com 5 DMP a pé diferentes. As DMP de bicicleta também variam a cada 500 metros.

Nos 14 primeiros cenários, existem menos valores de DMP a pé para cada DMP de bicicleta, uma vez que estas distâncias diminuem gradativamente até 0 . A Tabela 7 apresenta uma matriz com a distribuição dos cenários de acordo com as DMP a pé e bicicleta, enquanto as Tabelas 8 e 9 apresentam os cenários iniciais e finais do caso de São Carlos e da RMM, respectivamente. Também estão ilustrados os valores da resiliência e de cada tipo de viagem, que serão discutidos no subitem a seguir e podem ser vistos na Tabela 7. O caso de São Carlos apresentou uma variação de 89 cenários, da DMP mínima de zero quilômetros, até a resiliência máxima em $11 \mathrm{~km}$ de DMP de bicicleta (Apêndice A - Tabela A.3). O caso da RMM apresentou um total de 259 cenários, e atingiu a resiliência máxima quando a DMP considerada para a bicicleta era igual a 28 km (Apêndice B - Tabela B.3).

Tabela 7. Matriz de cenários de acordo com as Distâncias Máximas Possíveis (DMP) a pé e bicicleta dos casos de São Carlos e da Região Metropolitana de Maceió (RMM).

\begin{tabular}{|c|c|c|c|c|c|c|c|c|c|c|}
\hline \multicolumn{11}{|c|}{ Matriz de cenários pelas DMP a pé e bicicleta } \\
\hline & & \multicolumn{9}{|c|}{ DMP a pé } \\
\hline \multirow{14}{*}{ 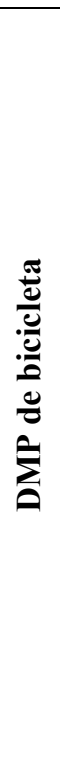 } & & 0 & 0,5 & 1,0 & 1,5 & 2,0 & 2,5 & 3,0 & 3,5 & 4,0 \\
\hline & 0 & 1 & - & - & - & - & - & - & - & - \\
\hline & 0,5 & - & 2 & - & - & - & - & - & - & - \\
\hline & 1,0 & - & - & 3 & - & - & - & - & - & - \\
\hline & 1,5 & - & - & - & 4 & - & - & - & - & - \\
\hline & 2,0 & - & - & - & - & 5 & - & - & - & - \\
\hline & 2,5 & - & - & - & - & 6 & 7 & - & - & - \\
\hline & 3,0 & - & - & - & - & 8 & 9 & 10 & - & - \\
\hline & 3,5 & - & - & - & - & 11 & 12 & 13 & 14 & - \\
\hline & 4,0 & - & - & - & - & 15 & 16 & 17 & 18 & 19 \\
\hline & 4,5 & - & - & - & - & 20 & 21 & 22 & 23 & 24 \\
\hline & 5,0 & - & - & - & - & 25 & 26 & 27 & 28 & 29 \\
\hline & 5,5 & - & - & - & - & 30 & 31 & 32 & 33 & 34 \\
\hline & 6,0 & - & - & - & - & 35 & 36 & 37 & 38 & 39 \\
\hline
\end{tabular}




\begin{tabular}{|c|c|c|c|c|c|c|c|c|c|}
\hline 6,5 & - & - & - & - & 40 & 41 & 42 & 43 & 44 \\
\hline 7,0 & - & - & - & - & 45 & 46 & 47 & 48 & 49 \\
\hline 7,5 & - & - & - & - & 50 & 51 & 52 & 53 & 54 \\
\hline 8,0 & - & - & - & - & 55 & 56 & 57 & 58 & 59 \\
\hline 8,5 & - & - & - & - & 60 & 61 & 62 & 63 & 64 \\
\hline 9,0 & - & - & - & - & 65 & 66 & 67 & 68 & 69 \\
\hline 9,5 & - & - & - & - & 70 & 71 & 72 & 73 & 74 \\
\hline 10,0 & - & - & - & - & 75 & 76 & 77 & 78 & 79 \\
\hline 10,5 & - & - & - & - & 80 & 81 & 82 & 83 & 84 \\
\hline 11,0 & - & - & - & - & 85 & 86 & 87 & 88 & $89^{*}$ \\
\hline 11,5 & - & - & - & - & 90 & 91 & 92 & 93 & 94 \\
\hline 12,0 & - & - & - & - & 95 & 96 & 97 & 98 & 99 \\
\hline 12,5 & - & - & - & - & 100 & 101 & 102 & 103 & 104 \\
\hline 13,0 & - & - & - & - & 105 & 106 & 107 & 108 & 109 \\
\hline 13,5 & - & - & - & - & 110 & 111 & 112 & 113 & 114 \\
\hline 14,0 & - & - & - & - & 115 & 116 & 117 & 118 & 119 \\
\hline 14,5 & - & - & - & - & 120 & 121 & 122 & 123 & 124 \\
\hline 15,0 & - & - & - & - & 125 & 126 & 127 & 128 & 129 \\
\hline 15,5 & - & - & - & - & 130 & 131 & 132 & 133 & 134 \\
\hline 16,0 & - & - & - & - & 135 & 136 & 137 & 138 & 139 \\
\hline 16,5 & - & - & - & - & 140 & 141 & 142 & 143 & 144 \\
\hline 17,0 & - & - & - & - & 145 & 146 & 147 & 148 & 149 \\
\hline 17,5 & - & - & - & - & 150 & 151 & 152 & 153 & 154 \\
\hline 18,0 & - & - & - & - & 155 & 156 & 157 & 158 & 159 \\
\hline 18,5 & - & - & - & - & 160 & 161 & 162 & 163 & 164 \\
\hline 19,0 & - & - & - & - & 165 & 166 & 167 & 168 & 169 \\
\hline 19,5 & - & - & - & - & 170 & 171 & 172 & 173 & 174 \\
\hline 20,0 & - & - & - & - & 175 & 176 & 177 & 178 & 179 \\
\hline 20,5 & - & - & - & - & 180 & 181 & 182 & 183 & 184 \\
\hline 21,0 & - & - & - & - & 185 & 186 & 187 & 188 & 189 \\
\hline 21,5 & - & - & - & - & 190 & 191 & 192 & 193 & 194 \\
\hline 22,0 & - & - & - & - & 195 & 196 & 197 & 198 & 199 \\
\hline 22,5 & - & - & - & - & 200 & 201 & 202 & 203 & 204 \\
\hline 23,0 & - & - & - & - & 205 & 206 & 207 & 208 & 209 \\
\hline 23,5 & - & - & - & - & 210 & 211 & 212 & 213 & 214 \\
\hline 24,0 & - & - & - & - & 215 & 216 & 217 & 218 & 219 \\
\hline 24,5 & - & - & - & - & 220 & 221 & 222 & 223 & 224 \\
\hline 25,0 & - & - & - & - & 225 & 226 & 227 & 228 & 229 \\
\hline 25,5 & - & - & - & - & 230 & 231 & 232 & 233 & 234 \\
\hline 26,0 & - & - & - & - & 235 & 236 & 237 & 238 & 239 \\
\hline 26,5 & - & - & - & - & 240 & 241 & 242 & 243 & 244 \\
\hline 27,0 & - & - & - & - & 245 & 246 & 247 & 248 & 249 \\
\hline 27,5 & - & - & - & - & 250 & 251 & 252 & 253 & 254 \\
\hline 28,0 & - & - & - & - & 255 & 256 & 257 & 258 & 259 \\
\hline
\end{tabular}

* Último cenário do caso de São Carlos 
Tabela 8. Valor da resiliência por cenário na cidade São Carlos.

São Carlos

\begin{tabular}{cccccccc}
\hline & \multicolumn{5}{c}{ DMP $(\mathrm{km})$} & \multicolumn{5}{c}{ Viagens $(\%)$} & \\
\cline { 2 - 6 } Cenário & $\begin{array}{c}\text { A } \\
\text { pé }\end{array}$ & Bicicleta & $\begin{array}{c}\text { Excepcionais } \\
(\mathrm{E})\end{array}$ & $\begin{array}{c}\text { Persistentes } \\
(\mathrm{P})\end{array}$ & $\begin{array}{c}\text { Adaptáveis } \\
(\mathrm{A})\end{array}$ & $\begin{array}{c}\text { Transformáveis } \\
(\mathrm{T})\end{array}$ & $\begin{array}{c}\text { Resiliência } \\
(\mathrm{E}+\mathrm{P}+\mathrm{A})\end{array}$ \\
\hline 1 & 0 & 0 & 22,2 & 14,5 & 3,7 & 59,6 & 40,4 \\
2 & 0,5 & 0,5 & 22,2 & 14,5 & 3,7 & 59,6 & 40,4 \\
3 & 1 & 1 & 20,4 & 16,3 & 4,8 & 58,4 & 41,5 \\
4 & 1,5 & 1,5 & 13,6 & 23,2 & 10,2 & 53,1 & 47,0 \\
$\ldots$ & $\ldots$ & $\ldots$ & $\ldots$ & $\ldots$ & $\ldots$ & $\ldots$ & 100 \\
85 & 2 & 11 & 6,9 & 29,8 & 63,3 & 0,0 & 100 \\
86 & 2,5 & 11 & 4,6 & 32,1 & 63,3 & 0,0 & 100 \\
87 & 3 & 11 & 3,2 & 33,5 & 63,3 & 0,0 & 100 \\
88 & 3,5 & 11 & 2,4 & 34,3 & 63,3 & 0,0 & \\
\hline 8 & 4 & 11 & 1,8 & 34,9 & 63,3 & 0,0 & \\
\hline
\end{tabular}


Tabela 9. Valor da resiliência por cenário na Região Metropolitana de Maceió.

\begin{tabular}{|c|c|c|c|c|c|c|c|}
\hline \multicolumn{8}{|c|}{ Região Metropolitana de Maceió } \\
\hline \multirow[b]{2}{*}{ Cenário } & \multicolumn{2}{|c|}{ DMP (km) } & \multicolumn{4}{|c|}{ Viagens $(\%)$} & \multirow[b]{2}{*}{$\begin{array}{l}\text { Resiliência } \\
(\mathrm{E}+\mathrm{P}+\mathrm{A})\end{array}$} \\
\hline & $\begin{array}{l}\text { A } \\
\text { pé }\end{array}$ & Bicicleta & $\begin{array}{l}\text { Excepcionais } \\
\text { (E) }\end{array}$ & $\begin{array}{l}\text { Persistentes } \\
\text { (P) }\end{array}$ & $\begin{array}{l}\text { Adaptáveis } \\
\text { (A) }\end{array}$ & $\begin{array}{l}\text { Transformáveis } \\
\text { (T) }\end{array}$ & \\
\hline 1 & 0 & 0 & 15,6 & 23,5 & 4,0 & 57,0 & 43,0 \\
\hline 2 & 0,5 & 0,5 & 15,6 & 23,5 & 4,0 & 57,0 & 43,0 \\
\hline 3 & 1 & 1 & 15,0 & 24,1 & 4,1 & 56,8 & 43,2 \\
\hline 4 & 1,5 & 1,5 & 12,9 & 26,1 & 5,6 & 55,4 & 44,6 \\
\hline$\cdots$ & $\cdots$ & $\cdots$ & $\cdots$ & $\cdots$ & $\cdots$ & $\cdots$ & $\cdots$ \\
\hline 255 & 2 & 28,0 & 7,0 & 32,0 & 70,0 & 0,0 & 100 \\
\hline 256 & 2,5 & 28,0 & 3,8 & 35,2 & 70,0 & 0,0 & 100 \\
\hline 257 & 3 & 28,0 & 2,5 & 36,6 & 70,0 & 0,0 & 100 \\
\hline 258 & 3,5 & 28,0 & 1,8 & 37,2 & 70,0 & 0,0 & 100 \\
\hline 259 & 4 & 28,0 & 1,0 & 38,0 & 70,0 & 0,0 & 100 \\
\hline
\end{tabular}

\subsection{SEGMENTAÇÃO DAS VIAGENS E NÍVEL DE RESILIÊNCIA}

Foram consideradas persistentes as viagens realizadas a pé ou de bicicleta dentro das DMP estabelecidas. Ocorrendo restrição a veículos motorizados, estas viagens não seriam afetadas. Quanto as viagens adaptáveis, seriam aquelas feitas por veículo motorizado nos limites das DMP, ou seja, com possibilidade de mudança para um modo ativo quando houvesse restrição. As viagens transformáveis se utilizam de modos motorizados, percorrendo distâncias acima das DMP. Dessa forma, com uma restrição, estas viagens seriam afetadas. Viagens excepcionais, por fim, são aquelas realizadas por modos ativos (a pé ou bicicleta) também acima das DMP estabelecidas. Dessa forma, não seriam afetadas no caso de restrição.

Como apresentado na Tabela 8 , em São Carlos, o cenário mais pessimista $(0 \mathrm{~km})$ mostrou uma resiliência de 40,4\%, considerado um nível de resiliência médio. Esse valor representa a soma das viagens intrazonais $(18,2 \%)$ e excepcionais $(22,2 \%)$. Na RMM, o pior 
cenário apresentou uma resiliência de 43,0\%, também considerada de nível médio. Deste total, $27,4 \%$ das viagens são intrazonais, enquanto as outras $15,6 \%$ são excepcionais, como foi visto na Tabela 9.

No caso da RMM, considerou-se inicialmente que o baixo resultado da resiliência e a grande distância necessária para se alcançar a resiliência máxima fossem causados pelas viagens oriundas dos municípios de Rio Largo e Satuba, com destino a cidade de Maceió, uma vez que as distâncias entre as zonas destes municípios para o centro da cidade de Maceió são consideráveis. Assim, as viagens originadas nestes dois municípios foram isoladas e seus destinos analisados. A suposição mostrou-se infundada, pois o total de viagens destes dois municípios somava apenas 7,8\% das 6038 no estudo, 414 de Rio Largo e 59 de Satuba. Além disso, $303(73,2 \%)$ viagens que partiam de Rio Largo tinham como destino o próprio município. Em Satuba, esse valor era de 45 (76,3\%). No total, apenas 26,2\% das viagens de Rio Largo e Satuba saíam dos próprios municípios.

O que se notou com a variação dos cenários foi que o valores da resiliência, assim como seus segmentos de transformabilidade e de adaptabilidade, são somente modificados quando a DMP para o modo bicicleta muda. A DMP para o modo a pé varia apenas os valores excepcionais e persistentes entre si. Como ambos os segmentos estão contidos no total da resiliência, a migração das viagens de um segmento ao outro não altera o valor final desta. Quanto à DMP para o modo bicicleta, esta modifica todos os segmentos, e com isso, altera o valor da resiliência. Com estas informações, foi possível plotar um gráfico em duas dimensões da variação da resiliência em função da DMP de bicicleta (Figura 10). O mesmo foi feito para os segmentos de transformabilidade e adaptabilidade, respectivamente, Figuras 11 e 12. 


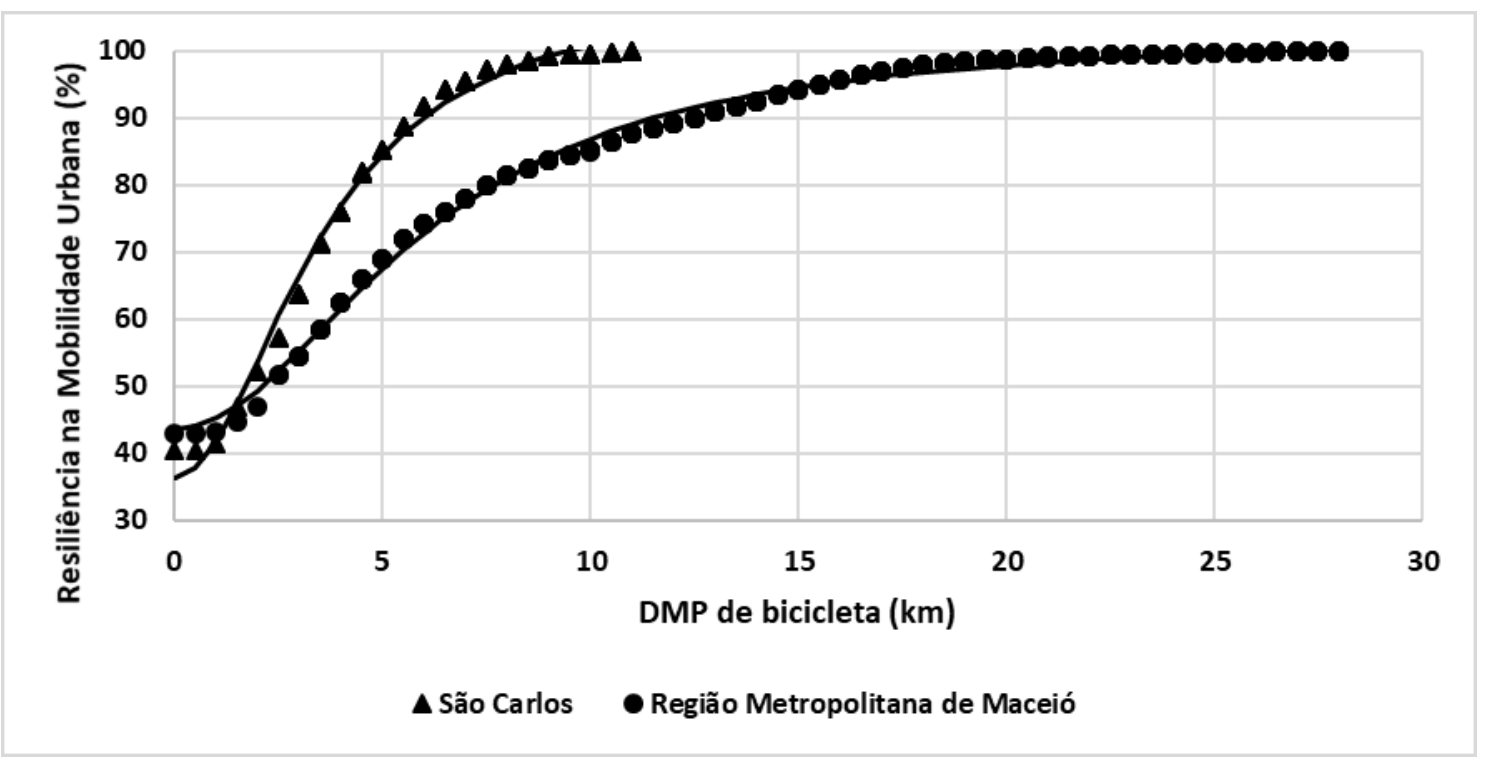

Figura 10. Variação da resiliência na mobilidade em São Carlos e na Região Metropolitana de Maceió para diferentes valores de Distância Máxima Possível de bicicleta.

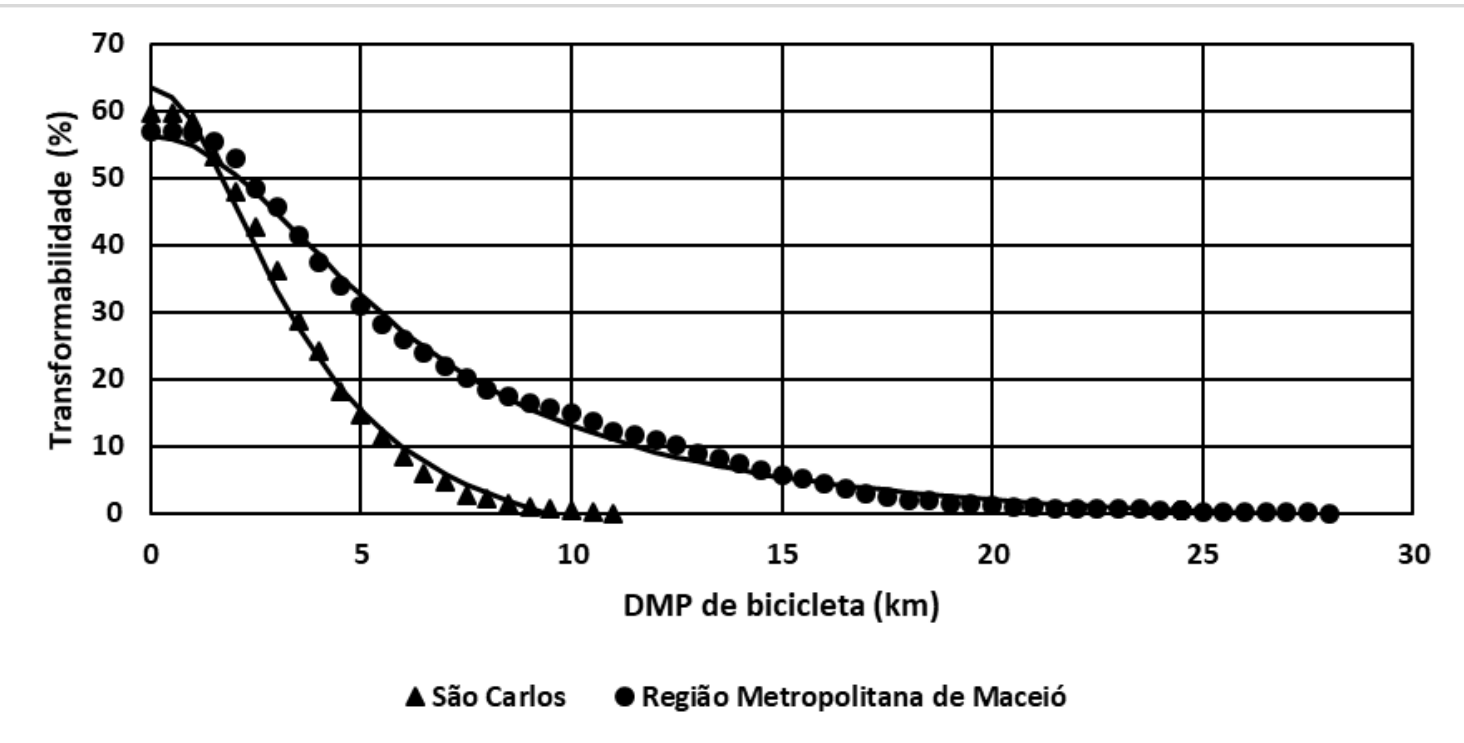

Figura 11. Variação da transformabilidade da resiliência na mobilidade em São Carlos e na Região Metropolitana de Maceió para diferentes valores de Distância Máxima Possível de bicicleta. 


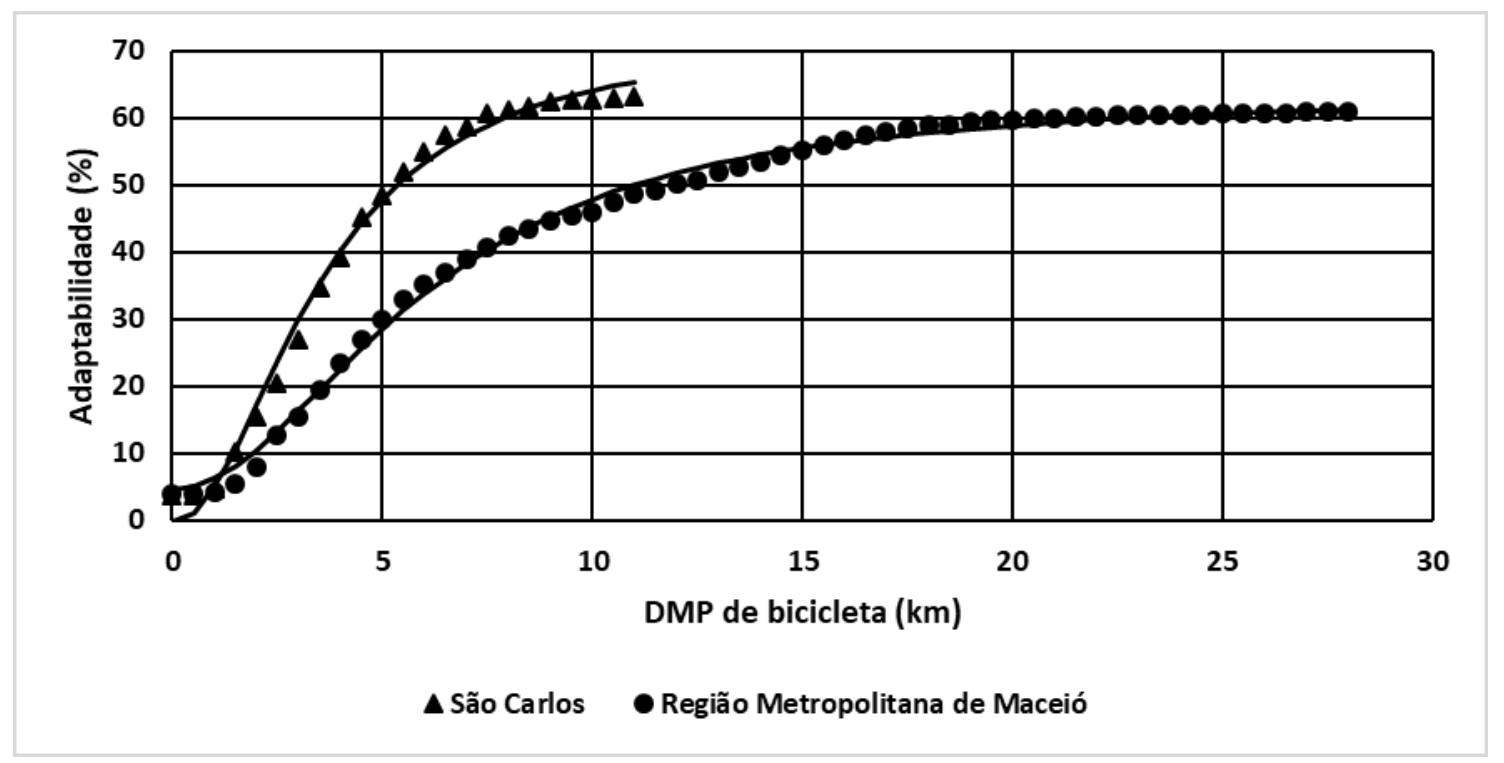

Figura 12. Variação da adaptabilidade da resiliência na mobilidade em São Carlos e na Região Metropolitana de Maceió para diferentes valores de Distância Máxima Possível de bicicleta.

Com os pontos calculados, foi possível ajustar os dados a uma curva teórica (obviamente de difícil interpretação como um fenômeno físico) para representar a variação da resiliência na mobilidade urbana nas regiões de estudo. A análise dos valores pontuais, no entanto, já é suficiente para o que se pretende nesta pesquisa.

Em uma primeira análise, foi necessário levar em consideração a variação da vulnerabilidade, representada pelas viagens transformáveis. Sabendo que a resiliência e a vulnerabilidade se completam e são inversamente proporcionais, decidiu-se por escolher um tipo de função que melhor se adequasse a ambas as variações. Isto significa que, se uma certa função se ajustasse bem para a resiliência, mas não representasse bem a vulnerabilidade, esta então seria descartada. A função que melhor se adequou para representar a resiliência em São Carlos e na RMM foi a Equação 1, que está plotada nas Figuras 10 e 11. Os valores dos parâmetros para cada segmento e estudo de caso são apresentados na Tabela 10.

Em um segundo momento, percebeu-se que, assim como a resiliência e a transformabilidade, a variação da adaptabilidade também apresentava padrão similar. As viagens transformáveis tornam-se adaptáveis conforme a DMP de bicicleta aumenta. Dessa forma, entendeu-se que as 3 variações devem ser representadas pelo mesmo tipo de função. Após uma segunda análise nas funções que melhor se encaixavam, chegou-se ao mesmo resultado da primeira análise (Equação 1). Os parâmetros para a adaptabilidade também são mostrados na Tabela 10 e a função está plotada na Figura 12. Nota-se que, tanto nos casos da 
resiliência (Res) e da transformabilidade (Tr), como no da adaptabilidade (Ad), um mesmo tipo de função se adequou aos dois estudos de casos.

$$
\operatorname{Res} / \operatorname{Tr} / \operatorname{Ad}=\frac{(A+D M P b i c)}{\left(B+C^{*} D M P b i c^{2}\right)}+D
$$

Tabela 10. Parâmetros para a equação representativa da resiliência na mobilidade urbana, transformabilidade e adaptabilidade em São Carlos e na Região Metropolitana de Maceió.

\begin{tabular}{ccccccc}
\hline & \multicolumn{2}{c}{ Resiliência (Res) } & \multicolumn{2}{c}{ Transformabilidade (Tr) } & \multicolumn{2}{c}{ Adaptabilidade (Ad) } \\
& São Carlos & RMM & São Carlos & RMM & São Carlos & RMM \\
\hline Parâmetros $\backslash \mathrm{R}^{2}$ & 0,9907 & 0,9950 & 0,9907 & 0,9950 & 0,9908 & 0,9950 \\
A & $-17830,00$ & $-15410,00$ & $-17870,00$ & $-15570,00$ & $-18060,00$ & $-15520,00$ \\
B & 245,70 & 259,80 & 246,20 & $-262,60$ & 248,80 & 261,80 \\
C & 19,48 & 6,97 & $-19,48$ & $-7,05$ & 19,69 & 7,02 \\
D & 109,00 & 103,00 & $-8,98$ & $-2,98$ & 72,28 & 63,97 \\
\hline
\end{tabular}

Onde:

$\cdot$ Res $=$ Valor da resiliência na mobilidade urbana (\%)

$\cdot \operatorname{Tr}=$ Valor da transformabilidade $(\%)$

$\cdot \mathrm{Ad}=$ Valor da adaptabilidade (\%)

- DMPbic $=$ Valor da DMP para o modo bicicleta $(\mathrm{km})$

A excepcionalidade (Exc) e a persistência (Pers) são alteradas com a variação de ambas as DMP (a pé e bicicleta). Assim, para melhor visualização, optou-se por uma plotagem tridimensional. Todavia, tomou-se o mesmo cuidado de encontrar uma função que se adaptasse bem a ambas as condições, visto que os dois seguem o mesmo padrão de variação, assim como a resiliência, a transformabilidade e a adaptabilidade. Da mesma forma que nos gráficos em duas dimensões, o mesmo tipo de função se adequou tanto para o caso de São Carlos como para o caso da RMM. As Figuras 13 e 14 mostram, respectivamente, os modelos representativos da variação da excepcionalidade e da persistência, no caso de São Carlos. As 
Figuras 15 e 16 apresentam o mesmo, porém para o caso da RMM. A função representativa da excepcionalidade e da persistência é mostrada na Equação 2, enquanto os parâmetros para cada um destes segmentos e para cada estudo de caso encontram-se na Tabela 11.

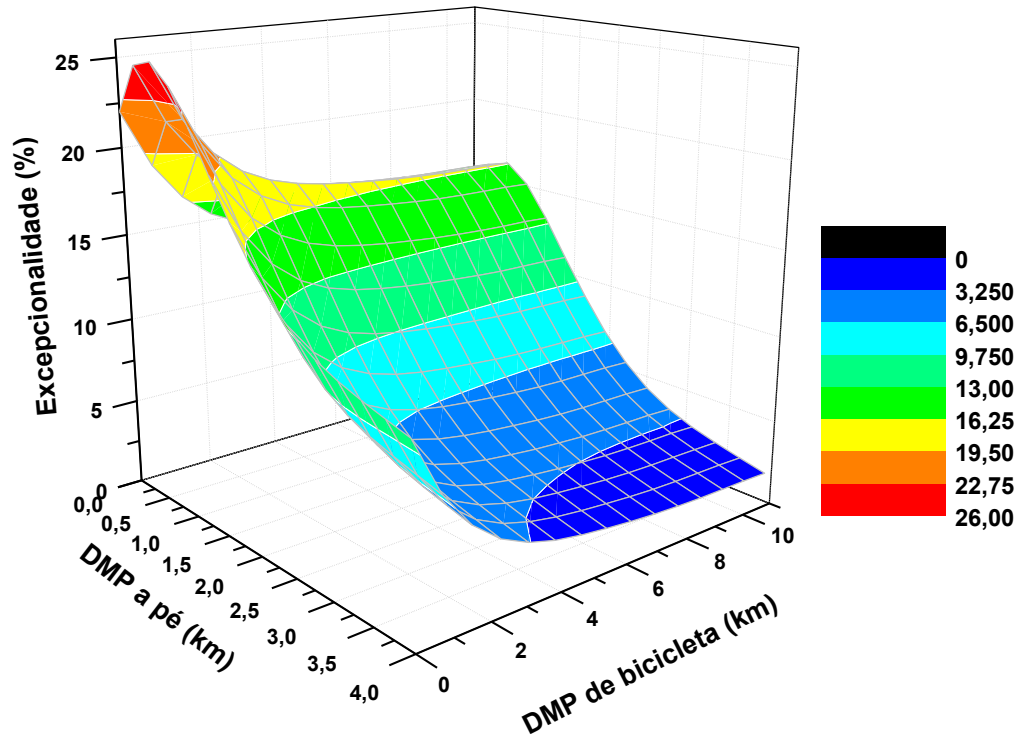

Figura 13. Modelo da função representativa da excepcionalidade no caso de São Carlos para diferentes valores de Distância Máxima Possível a pé e de bicicleta.

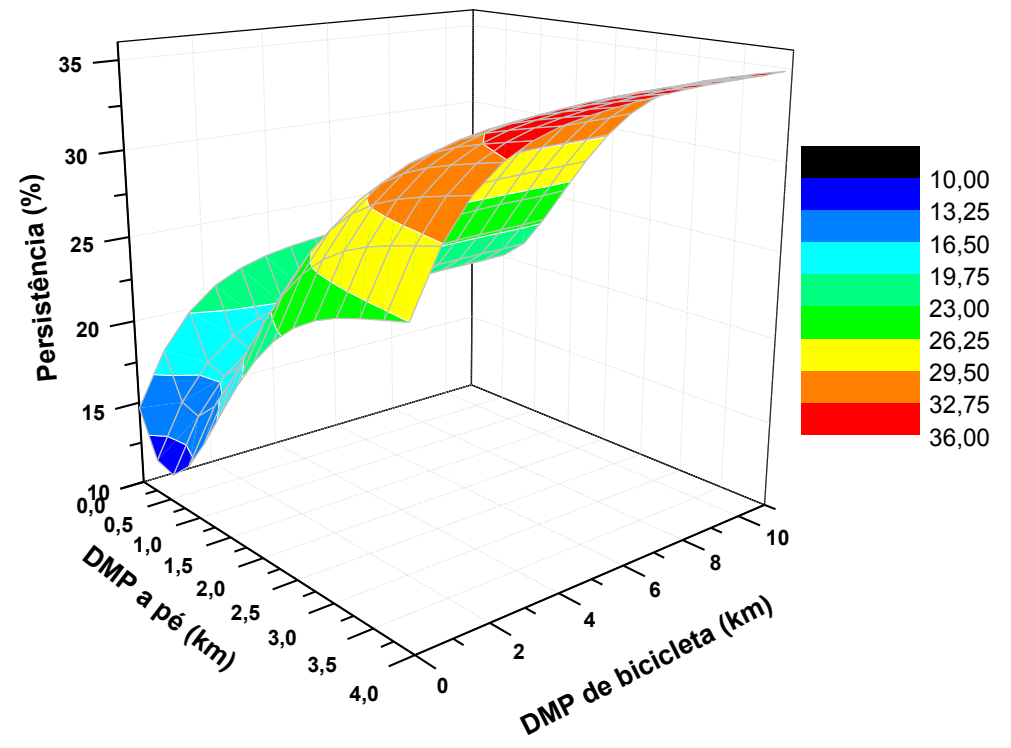

Figura 14. Modelo da função representativa da persistência no caso de São Carlos para diferentes valores de Distância Máxima Possível a pé e de bicicleta. 


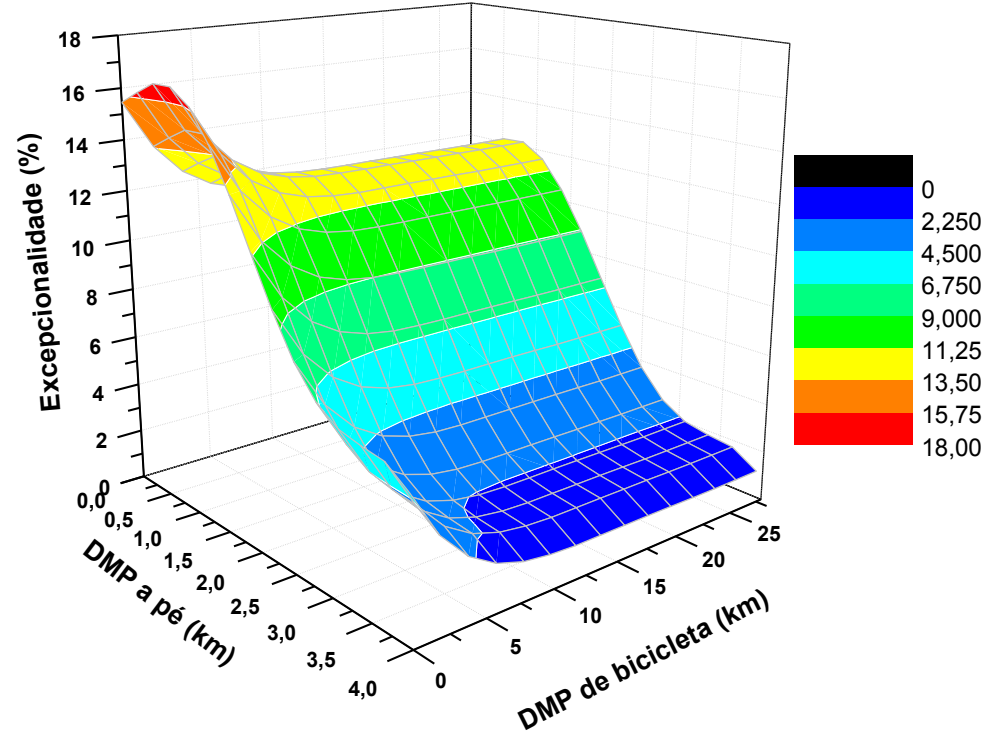

Figura 15. Modelo da função representativa da excepcionalidade no caso da Região Metropolitana de Maceió para diferentes valores de Distância Máxima Possível a pé e de bicicleta.

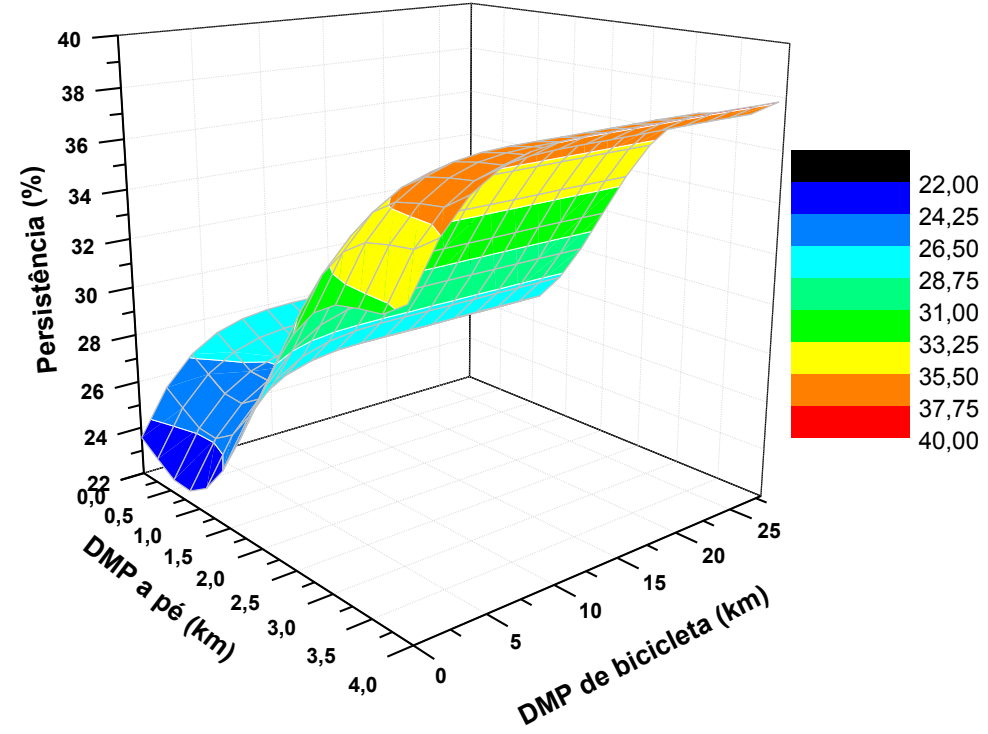

Figura 16. Modelo da função representativa da persistência no caso da Região Metropolitana de Maceió para diferentes valores de Distância Máxima Possível a pé e de bicicleta. 


$$
\begin{gathered}
\text { Exc/Pers }=z 0+A 1 * D M P p e+A 2 * D M P p e^{2}+A 3 * D M P p e^{3} \\
+A 4 * D M P p e^{4}+A 5 * D M P p e^{5}+B 1 * D M P b i c+B 2 * D M P b i c^{2} \\
+B 3 * D M P b i c^{3}+B 4 * D M P b i c^{4}+B 5 * D M P b i c^{5}
\end{gathered}
$$

\begin{tabular}{|c|c|c|c|c|}
\hline & \multicolumn{2}{|c|}{ Excepcionalidade (Exc) } & \multicolumn{2}{|c|}{ Persistência (Pers) } \\
\hline & São Carlos & RMM & São Carlos & RMM \\
\hline Parâmetros $\backslash \mathrm{R}^{2}$ & 0,9976 & 0,99751 & 0,9975 & 0,9976 \\
\hline z0 & 22,03319 & 15,45698 & 14,66485 & 23,57019 \\
\hline A1 & 15,19055 & 1,29061 & $-15,00813$ & $-1,228$ \\
\hline $\mathrm{A} 2$ & $-21,68486$ & 3,67393 & 21,76355 & $-3,79026$ \\
\hline A3 & 9,12928 & $-6,00881$ & $-9,23079$ & 6,08719 \\
\hline A4 & $-1,65094$ & 2,11095 & 1,68098 & $-2,13296$ \\
\hline A5 & 0,11055 & $-0,22456$ & $-0,1134$ & 0,22674 \\
\hline B1 & $-5,17786$ & $-1,17437$ & 4,94581 & 1,17771 \\
\hline $\mathrm{B} 2$ & 1,3764 & 0,12618 & $-1,29211$ & $-0,12682$ \\
\hline B3 & $-0,19251$ & $-0,00661$ & 0,17851 & 0,00666 \\
\hline B4 & 0,01353 & $1,68413 \mathrm{E}-4$ & $-0,01245$ & $-1,70268 \mathrm{E}-4$ \\
\hline B5 & $-3,75027 \mathrm{E}-4$ & $-1,6748 \mathrm{E}-6$ & $3,4318 \mathrm{E}-4$ & $1,69885 \mathrm{E}-6$ \\
\hline
\end{tabular}

Tabela 11. Parâmetros para a equação representativa da excepcionalidade e da persistência em São Carlos e na Região Metropolitana de Maceió.

Onde:

$\cdot$ Exc $=$ Valor da excepcionalidade $(\%)$

$\cdot$ Pers $=$ Valor da persistência $(\%)$

- DMPpe = Valor da DMP para o modo a pé $(\mathrm{km})$

- DMPbic $=$ Valor da DMP para o modo bicicleta $(\mathrm{km})$ 


\subsection{PADRÃO DE VIAGENS E DISTRIBUIÇÃO POR ZONA}

Nesta etapa da pesquisa, devido ao grande número de cenários utilizados, tornou-se necessário a escolha de apenas alguns deles para ilustrar os padrões de viagens e a distribuição por zona. $\mathrm{Na}$ análise do padrão de viagens por segmento, 8 cenários igualmente espaçados foram escolhidos. Excluiu-se o primeiro e o último cenário, restando apenas os 6 intermediários para serem ilustrados. No caso de São Carlos, foram os cenários 12, 25, 38, 51, 64 e 76. Na RMM, foram os cenários 37, 74, 111, 148, 185 e 222. As DMP de cada um destes cenários pode ser vista na Tabela 12. Para melhor visualização, a Figura 17 expõe a variação da resiliência nos dois estudos de caso, com as posições dos cenários utilizados para ilustração marcadas em amarelo para a cidade de São Carlos e em vermelho para a RMM. Na análise por zona, 6 cenários foram igualmente espaçados, excluiu-se o primeiro e o último, e os 4 cenários intermediários foram escolhidos para serem ilustrados. Em São Carlos, estes cenários foram o 18, 36, 53 e 71. Na RMM, os cenários foram o 52, 104, 155 e 207. Estes cenários estão descritos na Tabela 13. 
Tabela 12. Matriz de cenários de acordo com as Distâncias Máximas Possíveis (DMP) do caso de São Carlos e da Região Metropolitana de Maceió (RMM). Os cenários marcados em cores serão usados para ilustração dos padrões de viagens excepcionais, persistentes, adaptáveis e transformáveis de ambos os estudos: em amarelo para o caso de São Carlos e em vermelho para o caso da RMM.

\begin{tabular}{|c|c|c|c|c|c|c|c|c|c|c|}
\hline & \multicolumn{10}{|c|}{ Matriz de cenários pelas DMP a pé e bicicleta } \\
\hline & & \multicolumn{9}{|c|}{ DMP a pé } \\
\hline \multirow{36}{*}{ 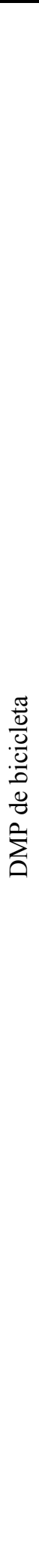 } & & 0 & 0,5 & 1,0 & 1,5 & 2,0 & 2,5 & 3,0 & 3,5 & 4,0 \\
\hline & 0 & 1 & - & - & - & - & - & - & - & - \\
\hline & 0,5 & - & 2 & - & - & - & - & - & - & - \\
\hline & 1,0 & - & - & 3 & - & - & - & - & - & - \\
\hline & 1,5 & - & - & - & 4 & - & - & - & - & - \\
\hline & 2,0 & - & - & - & - & 5 & - & - & - & - \\
\hline & 2,5 & - & - & - & - & 6 & 7 & - & - & - \\
\hline & 3,0 & - & - & - & - & 8 & 9 & 10 & - & - \\
\hline & 3,5 & - & - & - & - & 11 & 12 & 13 & 14 & - \\
\hline & 4,0 & - & - & - & - & 15 & 16 & 17 & 18 & 19 \\
\hline & 4,5 & - & - & - & - & 20 & 21 & 22 & 23 & 24 \\
\hline & 5,0 & - & - & - & - & 25 & 26 & 27 & 28 & 29 \\
\hline & 5,5 & - & - & - & - & 30 & 31 & 32 & 33 & 34 \\
\hline & 6,0 & - & - & - & - & 35 & 36 & 37 & 38 & 39 \\
\hline & 6,5 & - & - & - & - & 40 & 41 & 42 & 43 & 44 \\
\hline & 7,0 & - & - & - & - & 45 & 46 & 47 & 48 & 49 \\
\hline & 7,5 & - & - & - & - & 50 & 51 & 52 & 53 & 54 \\
\hline & 8,0 & - & - & - & - & 55 & 56 & 57 & 58 & 59 \\
\hline & 8,5 & - & - & - & - & 60 & 61 & 62 & 63 & 64 \\
\hline & 9,0 & - & - & - & - & 65 & 66 & 67 & 68 & 69 \\
\hline & 9,5 & - & - & - & - & 70 & 71 & 72 & 73 & 74 \\
\hline & 10,0 & - & - & - & - & 75 & 76 & 77 & 78 & 79 \\
\hline & 10,5 & - & - & - & - & 80 & 81 & 82 & 83 & 84 \\
\hline & 11,0 & - & - & - & - & 85 & 86 & 87 & 88 & $89 *$ \\
\hline & 11,5 & - & - & - & - & 90 & 91 & 92 & 93 & 94 \\
\hline & 12,0 & - & - & - & - & 95 & 96 & 97 & 98 & 99 \\
\hline & 12,5 & - & - & - & - & 100 & 101 & 102 & 103 & 104 \\
\hline & 13,0 & - & - & - & - & 105 & 106 & 107 & 108 & 109 \\
\hline & 13,5 & - & - & - & - & 110 & 111 & 112 & 113 & 114 \\
\hline & 14,0 & - & - & - & - & 115 & 116 & 117 & 118 & 119 \\
\hline & 14,5 & - & - & - & - & 120 & 121 & 122 & 123 & 124 \\
\hline & 15,0 & - & - & - & - & 125 & 126 & 127 & 128 & 129 \\
\hline & 15,5 & - & - & - & - & 130 & 131 & 132 & 133 & 134 \\
\hline & 16,0 & - & - & - & - & 135 & 136 & 137 & 138 & 139 \\
\hline & 16,5 & - & - & - & - & 140 & 141 & 142 & 143 & 144 \\
\hline & 17,0 & - & - & - & - & 145 & 146 & 147 & 148 & 149 \\
\hline
\end{tabular}




\begin{tabular}{|l|l|l|l|l|l|l|l|l|l|}
\hline 17,5 & - & - & - & - & 150 & 151 & 152 & 153 & 154 \\
\hline 18,0 & - & - & - & - & 155 & 156 & 157 & 158 & 159 \\
\hline 18,5 & - & - & - & - & 160 & 161 & 162 & 163 & 164 \\
\hline 19,0 & - & - & - & - & 165 & 166 & 167 & 168 & 169 \\
\hline 19,5 & - & - & - & - & 170 & 171 & 172 & 173 & 174 \\
\hline 20,0 & - & - & - & - & 175 & 176 & 177 & 178 & 179 \\
\hline 20,5 & - & - & - & - & 180 & 181 & 182 & 183 & 184 \\
\hline 21,0 & - & - & - & - & 185 & 186 & 187 & 188 & 189 \\
\hline 21,5 & - & - & - & - & 190 & 191 & 192 & 193 & 194 \\
\hline 22,0 & - & - & - & - & 195 & 196 & 197 & 198 & 199 \\
\hline 22,5 & - & - & - & - & 200 & 201 & 202 & 203 & 204 \\
\hline 23,0 & - & - & - & - & 205 & 206 & 207 & 208 & 209 \\
\hline 23,5 & - & - & - & - & 210 & 211 & 212 & 213 & 214 \\
\hline 24,0 & - & - & - & - & 215 & 216 & 217 & 218 & 219 \\
\hline 24,5 & - & - & - & - & 220 & 221 & 222 & 223 & 224 \\
\hline 25,0 & - & - & - & - & 225 & 226 & 227 & 228 & 229 \\
\hline 25,5 & - & - & - & - & 230 & 231 & 232 & 233 & 234 \\
\hline 26,0 & - & - & - & - & 235 & 236 & 237 & 238 & 239 \\
\hline 26,5 & - & - & - & - & 240 & 241 & 242 & 243 & 244 \\
\hline 27,0 & - & - & - & - & 245 & 246 & 247 & 248 & 249 \\
\hline 27,5 & - & - & - & - & 250 & 251 & 252 & 253 & 254 \\
\hline 28,0 & - & - & - & - & 255 & 256 & 257 & 258 & 259 \\
\hline
\end{tabular}

* Último cenário do caso de São Carlos 


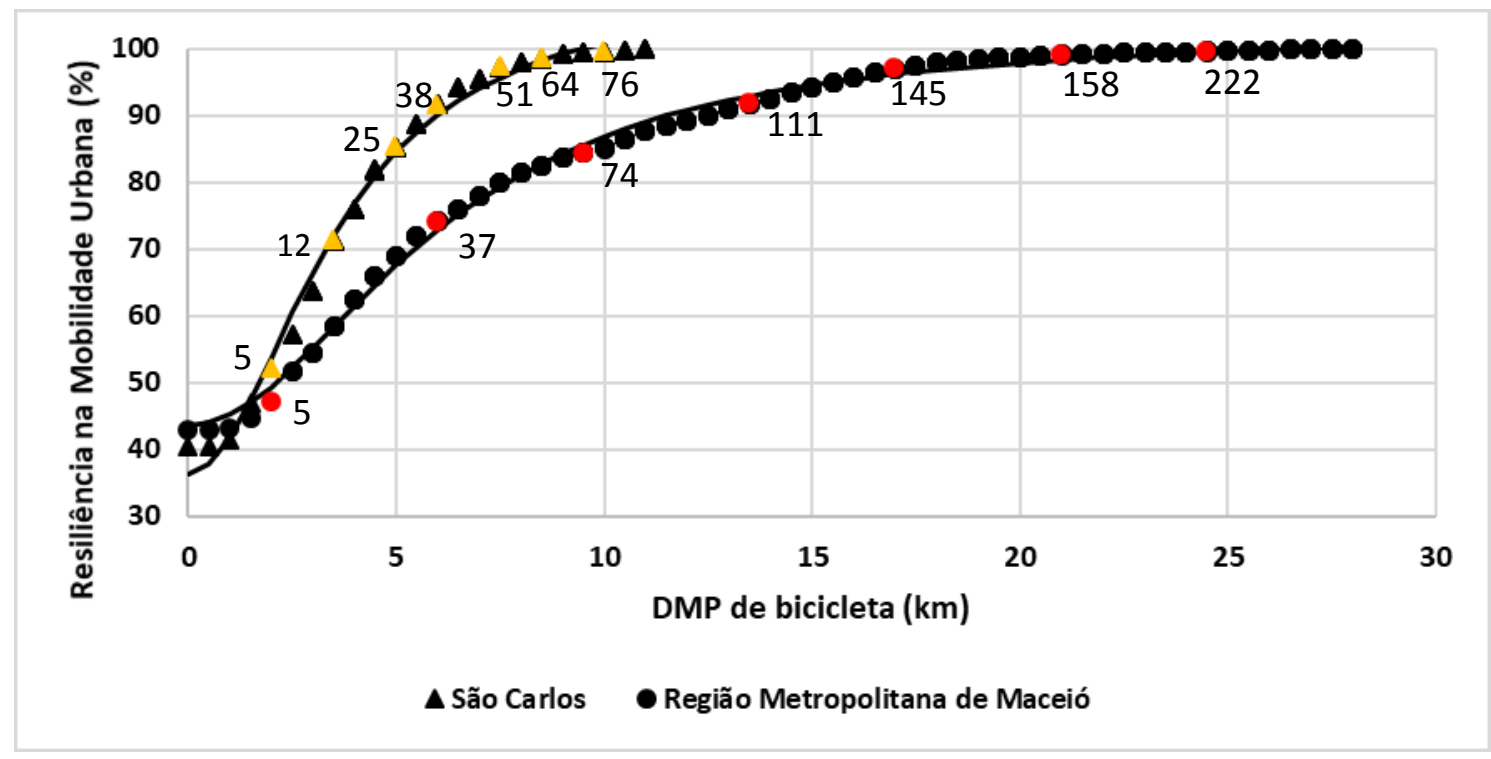

Figura 17. Variação da resiliência na mobilidade em São Carlos e na Região Metropolitana de Maceió para diferentes valores de Distância Máxima Possível de bicicleta. Os pontos marcados representam a posição no gráfico dos cenários utilizados para representar as viagens excepcionais, persistentes, adaptáveis e transformáveis dos estudos de caso. Ao lado do ponto marcado está o cenário que está representado.

Tabela 13. Cenários intermediários usados para ilustração da proporção de viagens excepcionais, persistentes, adaptáveis e transformáveis por zona dos estudos de caso de São Carlos e Região Metropolitana de Maceió.

\begin{tabular}{|c|c|c|c|c|c|}
\hline \multicolumn{3}{|c|}{ São Carlos } & \multicolumn{3}{|c|}{ RMM } \\
\hline \multirow{3}{*}{ Cenário } & \multicolumn{2}{|c|}{ DMP (km) } & \multirow{3}{*}{ Cenário } & \multicolumn{2}{|c|}{ DMP (km) } \\
\hline & & & & & \\
\hline & A pé & Bicicleta & & A pé & Bicicleta \\
\hline 18 & 3,5 & 4 & 52 & 3 & 7,5 \\
\hline 36 & 2,5 & 6 & 104 & 4 & 12,5 \\
\hline 53 & 3,5 & 7,5 & 155 & 2 & 18 \\
\hline 71 & 2,5 & 9,5 & 207 & 3 & 23 \\
\hline
\end{tabular}

Primeiramente, ilustrou-se os padrões de viagem no cenário 5 para cada uma das condições da resiliência (Figura 18). Os cenários seguintes foram usados para avaliar se os 
padrões iniciais permaneciam, se intensificavam, ou se mudavam completamente.

Quando os demais cenários foram analisados individualmente, notou-se um certo padrão nas viagens em cada estudo de caso. Em São Carlos, as viagens persistentes variaram de $14,5 \%$, no pior cenário, até $34,9 \%$ no melhor cenário. Como esperado, a maioria das viagens foi intrazonal, com algumas poucas sendo realizadas entre zonas vizinhas, ou seja, em distâncias curtas (Tabela 14). As viagens excepcionais não apresentaram um padrão espacial reconhecível (Figura 19). As viagens adaptáveis variaram de 3,7\% para 63,3\% e apresentaram um padrão radial, onde as viagens se originam, em grande parte, de zonas remotas com destino ao centro da cidade, especialmente a zona 21, a zona central (Figura 20). As viagens transformáveis foram de $59,6 \%$ do cenário mais pessimista para $0 \%$ no mais otimista. Conforme as DMP aumentavam, estas viagens começaram a assumir um padrão mais diametral, originando-se de um extremo da cidade, e com destino no extremo oposto (Figura 21). 

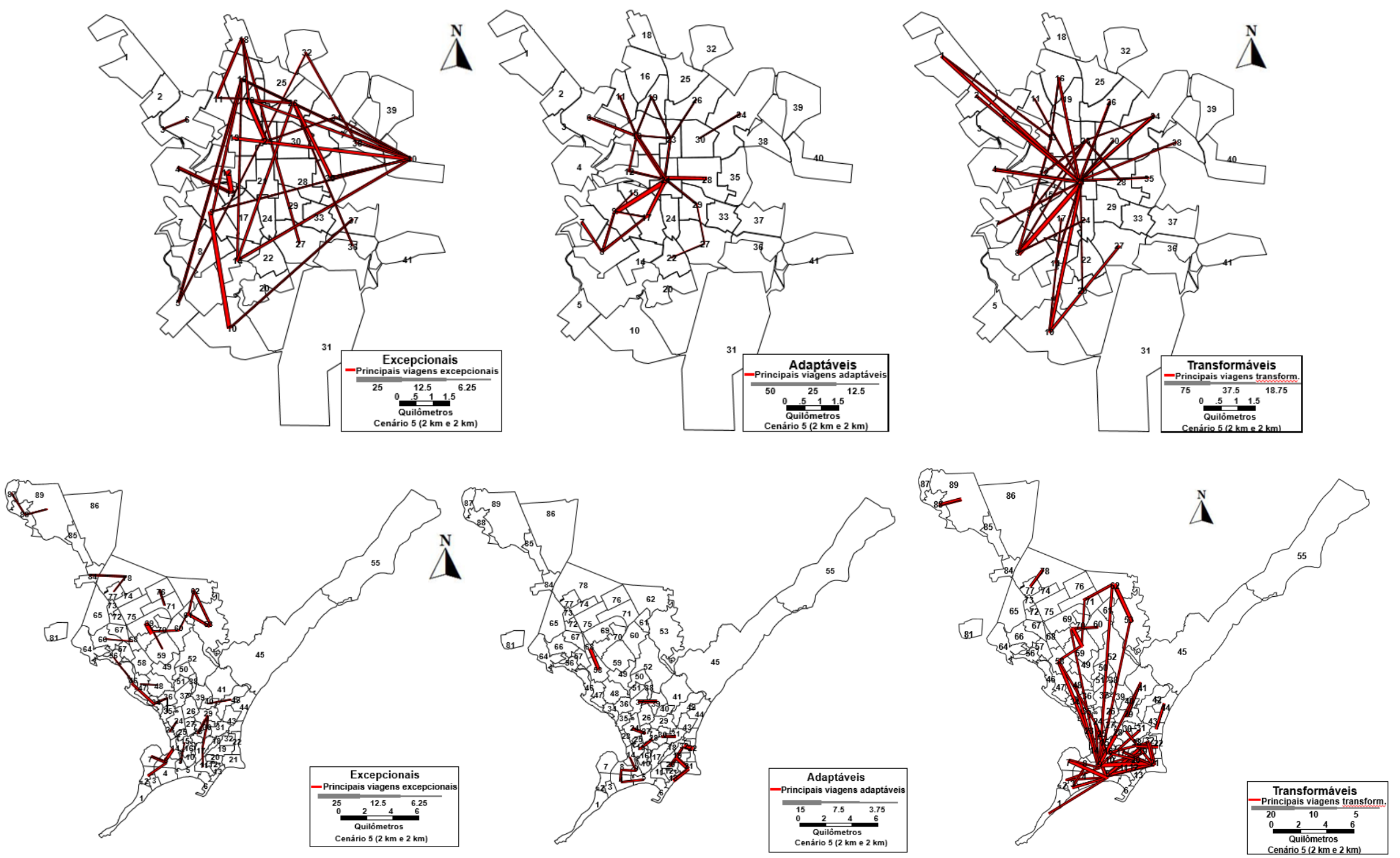

Figura 18. Principais viagens excepcionais, adaptáveis e transformáveis no cenário 5, em São Carlos e na Região Metropolitana de Maceió (RMM). 
Tabela 14. Cenários e zonas de Origem e Destino com as principais viagens persistentes em São Carlos.

\begin{tabular}{|c|c|c|c|c|c|c|c|c|c|c|c|c|c|c|}
\hline \multirow{3}{*}{$\begin{array}{c}\text { Cenário } \\
\begin{array}{c}N^{0} \text { de } \\
\text { viagens }\end{array}\end{array}$} & \multicolumn{2}{|c|}{5} & \multicolumn{2}{|c|}{12} & \multicolumn{2}{|c|}{25} & \multicolumn{2}{|c|}{38} & \multicolumn{2}{|c|}{51} & \multicolumn{2}{|c|}{64} & \multicolumn{2}{|c|}{76} \\
\hline & \multicolumn{2}{|c|}{ Zonas } & \multicolumn{2}{|c|}{ Zonas } & \multicolumn{2}{|c|}{ Zonas } & \multicolumn{2}{|c|}{ Zonas } & \multicolumn{2}{|c|}{ Zonas } & \multicolumn{2}{|c|}{ Zonas } & \multicolumn{2}{|c|}{ Zonas } \\
\hline & $\mathbf{O}$ & D & $\mathbf{O}$ & D & $\mathbf{O}$ & D & $\mathbf{O}$ & D & $\mathbf{O}$ & D & $\mathbf{O}$ & D & $\mathbf{O}$ & D \\
\hline 314 & 10 & 10 & 10 & 10 & 10 & 10 & 10 & 10 & 10 & 10 & 10 & 10 & 10 & 10 \\
\hline 114 & 8 & 8 & 8 & 8 & 8 & 8 & 8 & 8 & 8 & 8 & 8 & 8 & 8 & 8 \\
\hline 60 & 9 & 9 & 9 & 9 & 9 & 9 & 9 & 9 & 9 & 9 & 9 & 9 & 9 & 9 \\
\hline 52 & 1 & 1 & 1 & 1 & 1 & 1 & 1 & 1 & 1 & 1 & 1 & 1 & 1 & 1 \\
\hline 45 & 18 & 18 & 18 & 18 & 18 & 18 & 18 & 18 & 18 & 18 & 18 & 18 & 18 & 18 \\
\hline 43 & 34 & 26 & 34 & 26 & 26 & 34 & 26 & 34 & 26 & 34 & 26 & 34 & 26 & 34 \\
\hline 40 & 26 & 26 & 26 & 26 & 26 & 26 & 26 & 26 & 26 & 26 & 26 & 26 & 26 & 26 \\
\hline 35 & 20 & 22 & 20 & 22 & 22 & 20 & 22 & 20 & 22 & 20 & 22 & 20 & 22 & 20 \\
\hline 29 & 2 & 2 & 2 & 2 & 2 & 2 & 2 & 2 & 2 & 2 & 2 & 2 & 2 & 2 \\
\hline 28 & 29 & 29 & 29 & 29 & 29 & 29 & 29 & 29 & 29 & 29 & 29 & 29 & 29 & 29 \\
\hline
\end{tabular}




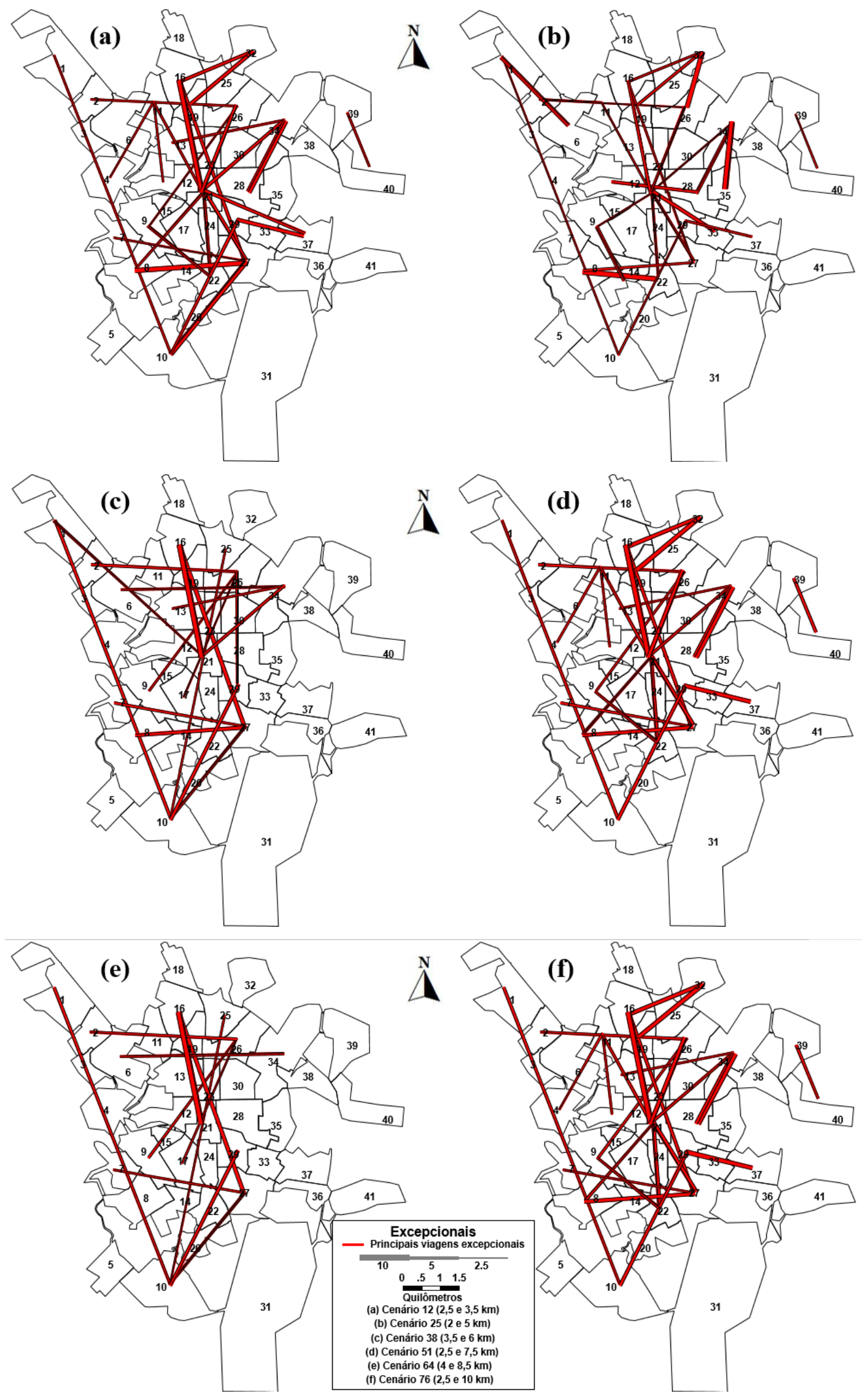

Figura 19. Principais viagens excepcionais nos cenários 12, 25, 38, 51, 64 e 76 em São Carlos. 

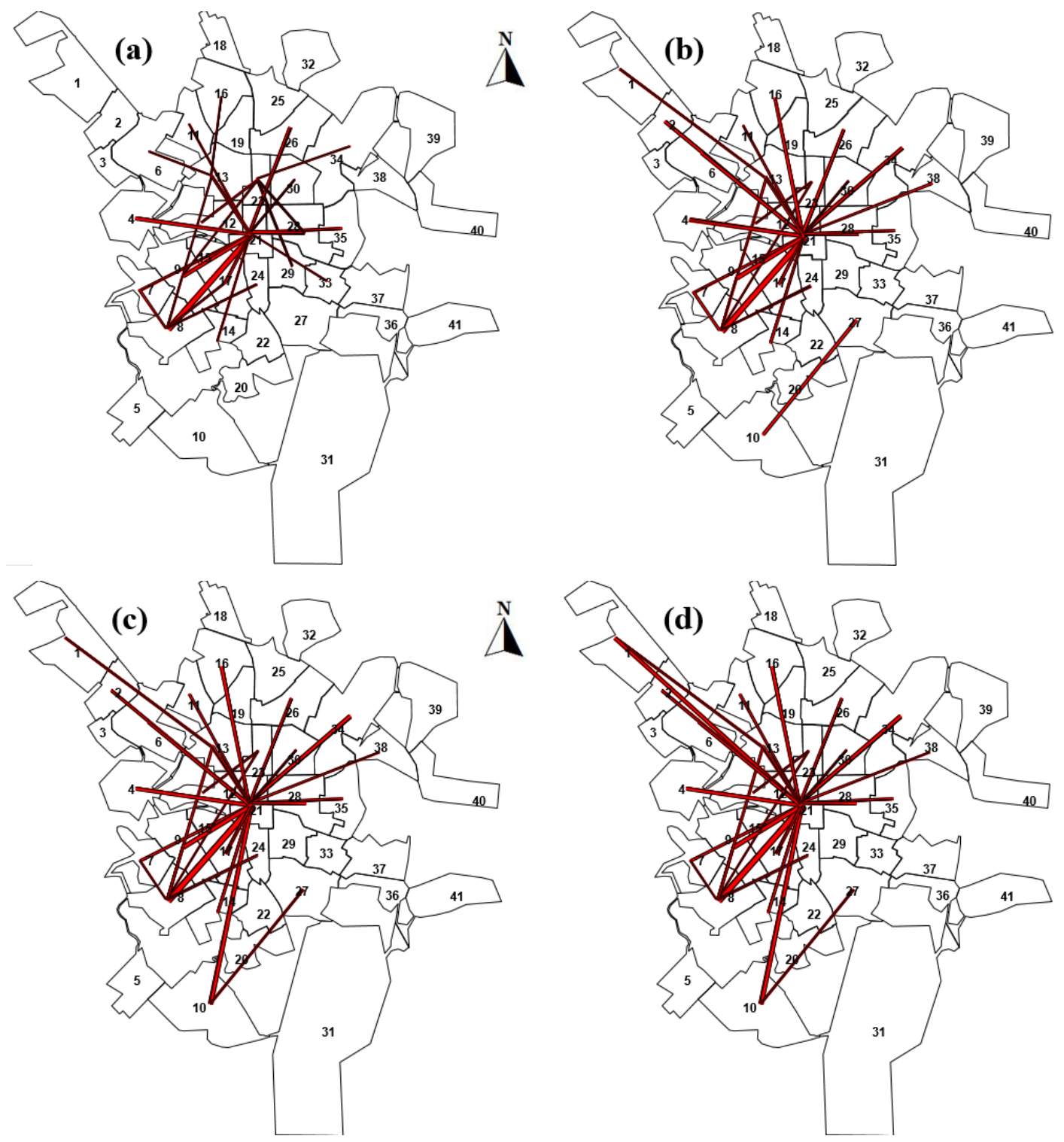

(d)
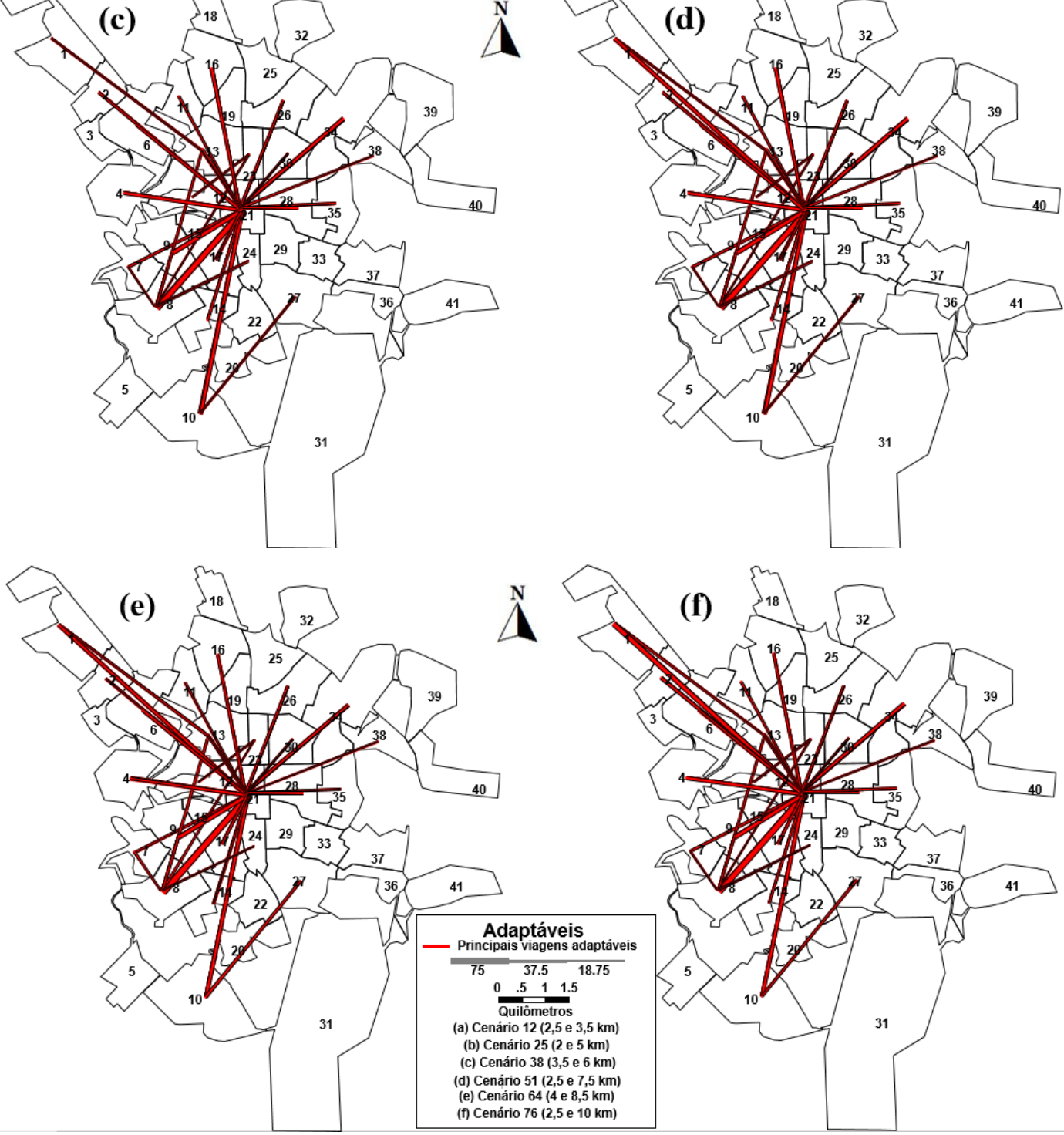

Figura 20. Principais viagens adaptáveis nos cenários 12, 25, 38, 51, 64 e 76 em São Carlos. 


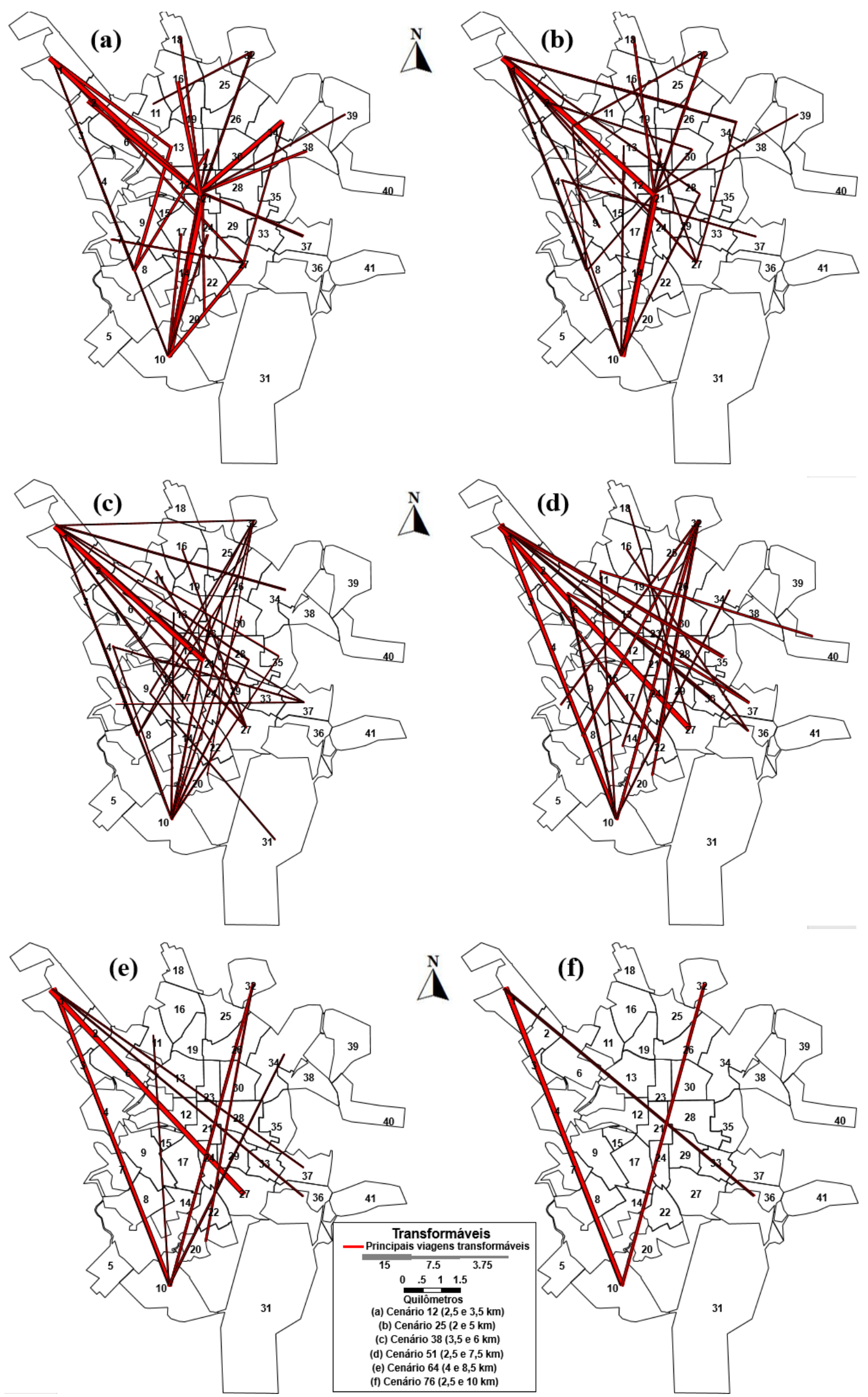

Figura 21. Principais viagens transformáveis nos cenários 12, 25, 38, 51, 64 e 76 em São Carlos. 
No caso da RMM, as viagens excepcionais, que tiveram 15,6\% no pior cenário e 1\% no cenário mais otimista, apresentaram um padrão espacial de viagens entre zonas vizinhas disperso ao longo de toda a região (Figura 22). As viagens persistentes, que variaram de $23,5 \%$ a $38,0 \%$, como esperado, também se mostraram intrazonais em sua maioria (Tabela 15). As viagens adaptáveis, por outro lado, representaram $4 \%$ do total no cenário mais pessimista e $61 \%$ no mais otimista. Conforme os cenários tornavam-se mais otimistas, as viagens concentraram-se na parte baixa da cidade (ao sul), ou originando-se na parte alta (ao norte) e com destino às zonas do centro da cidade, também ao sul (Figura 23). Por fim, as viagens transformáveis foram $57,0 \%$ no pior cenário e $0 \%$ no mais otimista. Este segmento teve suas viagens partindo da parte alta da cidade, para a parte baixa, e vice-versa. Enquanto os destinos na parte baixa eram as zonas nobres e o centro da cidade, a principal zona atratora de viagens na parte alta era a Universidade Federal de Alagoas (UFAL), na zona 75, ao norte (Figura 24).

Tabela 15. Cenários e zonas de Origem e Destino com as principais viagens persistentes na Região Metropolitana de Maceió

\begin{tabular}{|c|c|c|c|c|c|c|c|c|c|c|c|c|c|c|}
\hline \multirow{3}{*}{$\begin{array}{c}\text { Cenário } \\
N^{o} \text { de viagens }\end{array}$} & \multicolumn{2}{|c|}{5} & \multicolumn{2}{|c|}{37} & \multicolumn{2}{|c|}{74} & \multicolumn{2}{|c|}{111} & \multicolumn{2}{|c|}{148} & \multicolumn{2}{|c|}{185} & \multicolumn{2}{|c|}{222} \\
\hline & \multicolumn{2}{|c|}{ Zonas } & \multicolumn{2}{|c|}{ Zonas } & \multicolumn{2}{|c|}{ Zonas } & \multicolumn{2}{|c|}{ Zonas } & \multicolumn{2}{|c|}{ Zonas } & \multicolumn{2}{|c|}{ Zonas } & \multicolumn{2}{|c|}{ Zonas } \\
\hline & $\mathbf{O}$ & D & $\mathbf{O}$ & D & $\mathbf{O}$ & D & $\mathbf{O}$ & D & $\mathbf{O}$ & D & $\mathbf{O}$ & D & $\mathbf{O}$ & D \\
\hline 67 & 88 & 88 & 88 & 88 & 88 & 88 & 88 & 88 & 88 & 88 & 88 & 88 & 88 & 88 \\
\hline 65 & 62 & 62 & 62 & 62 & 62 & 62 & 62 & 62 & 62 & 62 & 62 & 62 & 62 & 62 \\
\hline 61 & 59 & 59 & 59 & 59 & 59 & 59 & 59 & 59 & 59 & 59 & 59 & 59 & 59 & 59 \\
\hline 55 & 70 & 70 & 70 & 70 & 70 & 70 & 70 & 70 & 70 & 70 & 70 & 70 & 70 & 70 \\
\hline 52 & 84 & 84 & 84 & 84 & 84 & 84 & 84 & 84 & 84 & 84 & 84 & 84 & 84 & 84 \\
\hline 50 & 7 & 7 & 7 & 7 & 7 & 7 & 7 & 7 & 7 & 7 & 7 & 7 & 7 & 7 \\
\hline 50 & 67 & 67 & 67 & 67 & 67 & 67 & 67 & 67 & 67 & 67 & 67 & 67 & 67 & 67 \\
\hline 48 & 53 & 53 & 53 & 53 & 53 & 53 & 53 & 53 & 53 & 53 & 53 & 53 & 53 & 53 \\
\hline 44 & 66 & 66 & 66 & 66 & 66 & 66 & 66 & 66 & 66 & 66 & 66 & 66 & 66 & 66 \\
\hline 42 & 89 & 89 & 89 & 89 & 89 & 89 & 89 & 89 & 89 & 89 & 89 & 89 & 89 & 89 \\
\hline
\end{tabular}



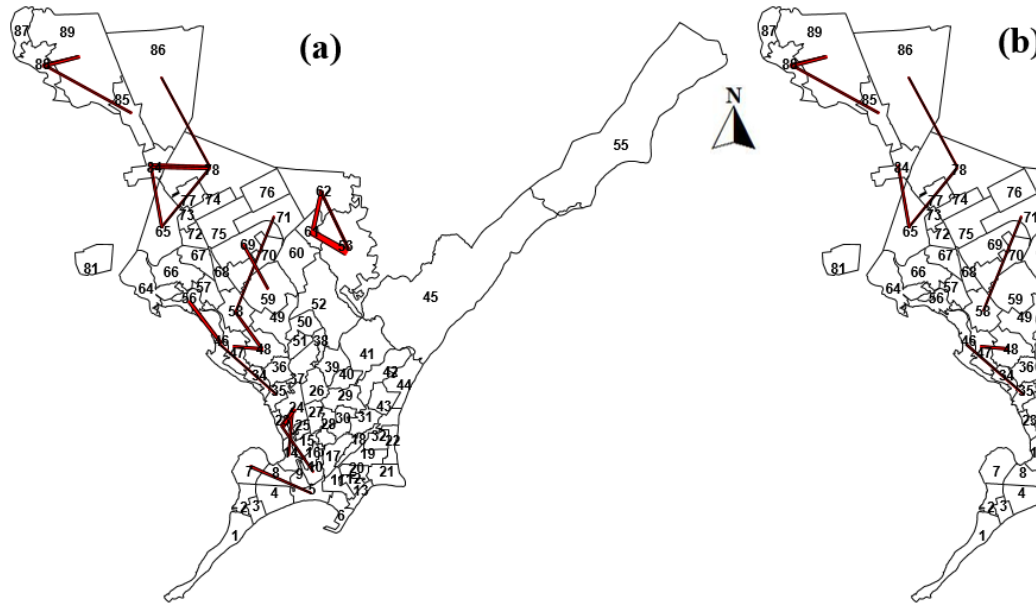

(b)
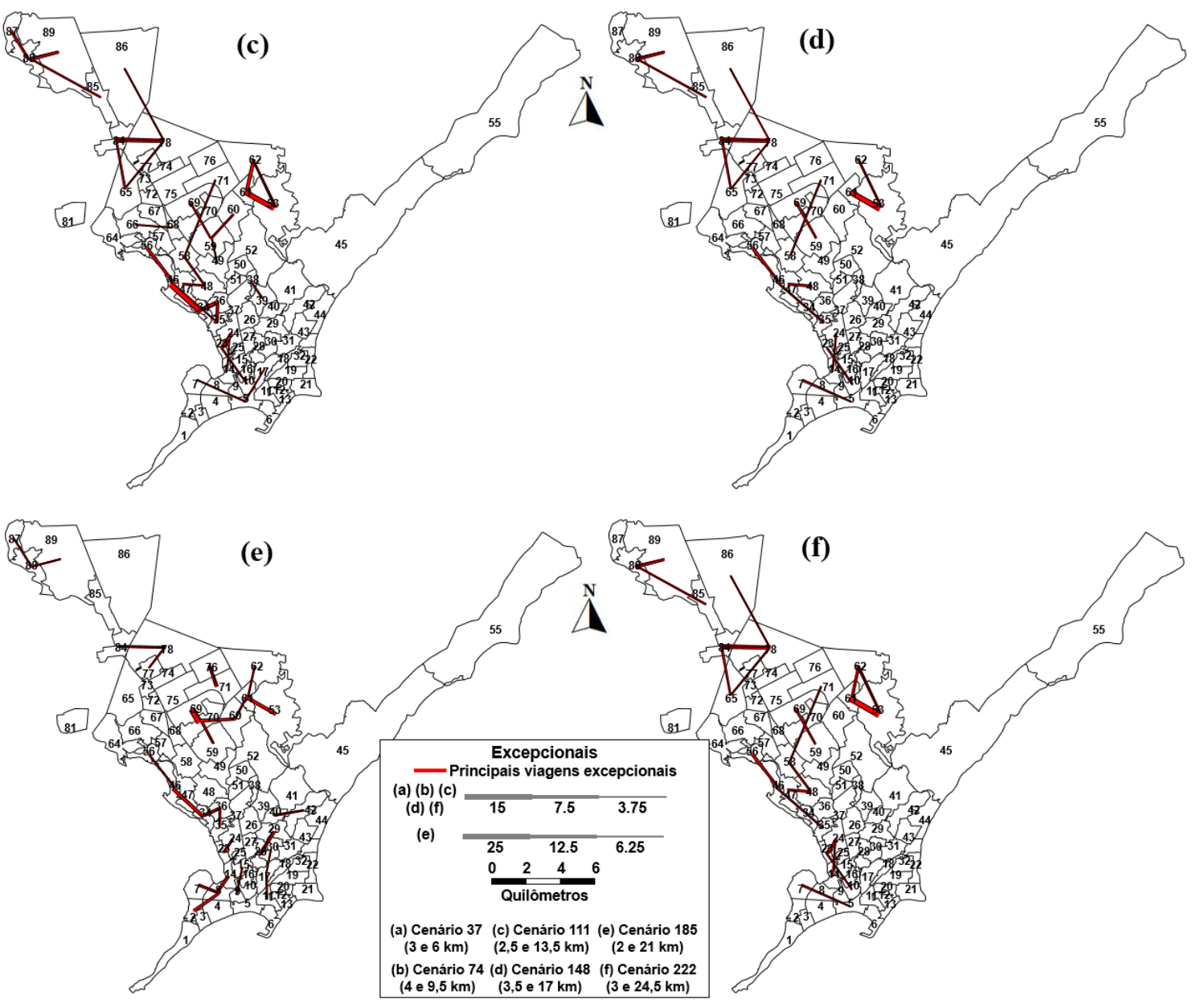

Figura 22. Principais viagens excepcionais nos cenários 37, 74, 111, 148, 185 e 222 na Região Metropolitana de Maceió. 

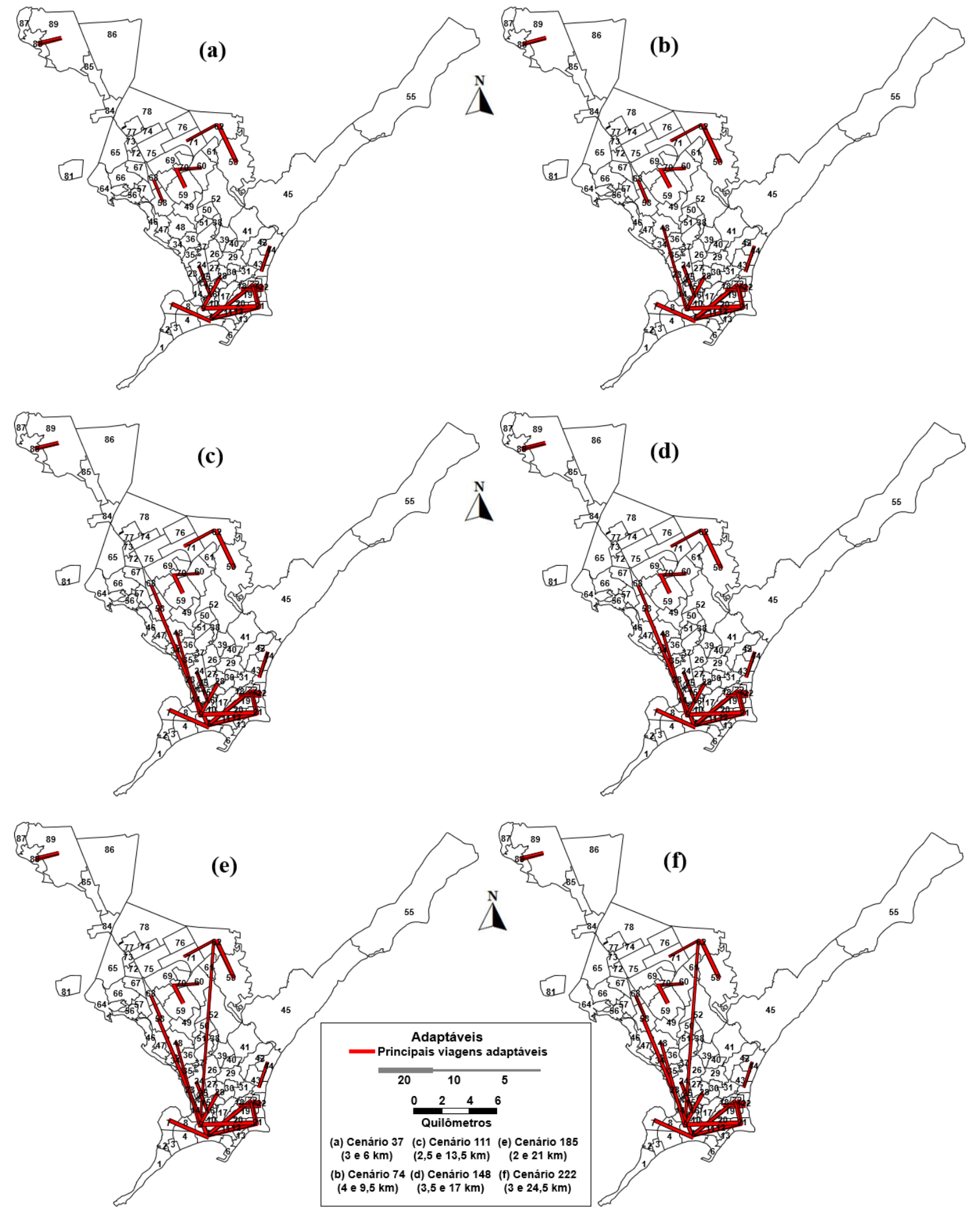

Figura 23. Principais viagens adaptáveis nos cenários 37, 74, 111, 148, 185 e 222 na Região Metropolitana de Maceió. 

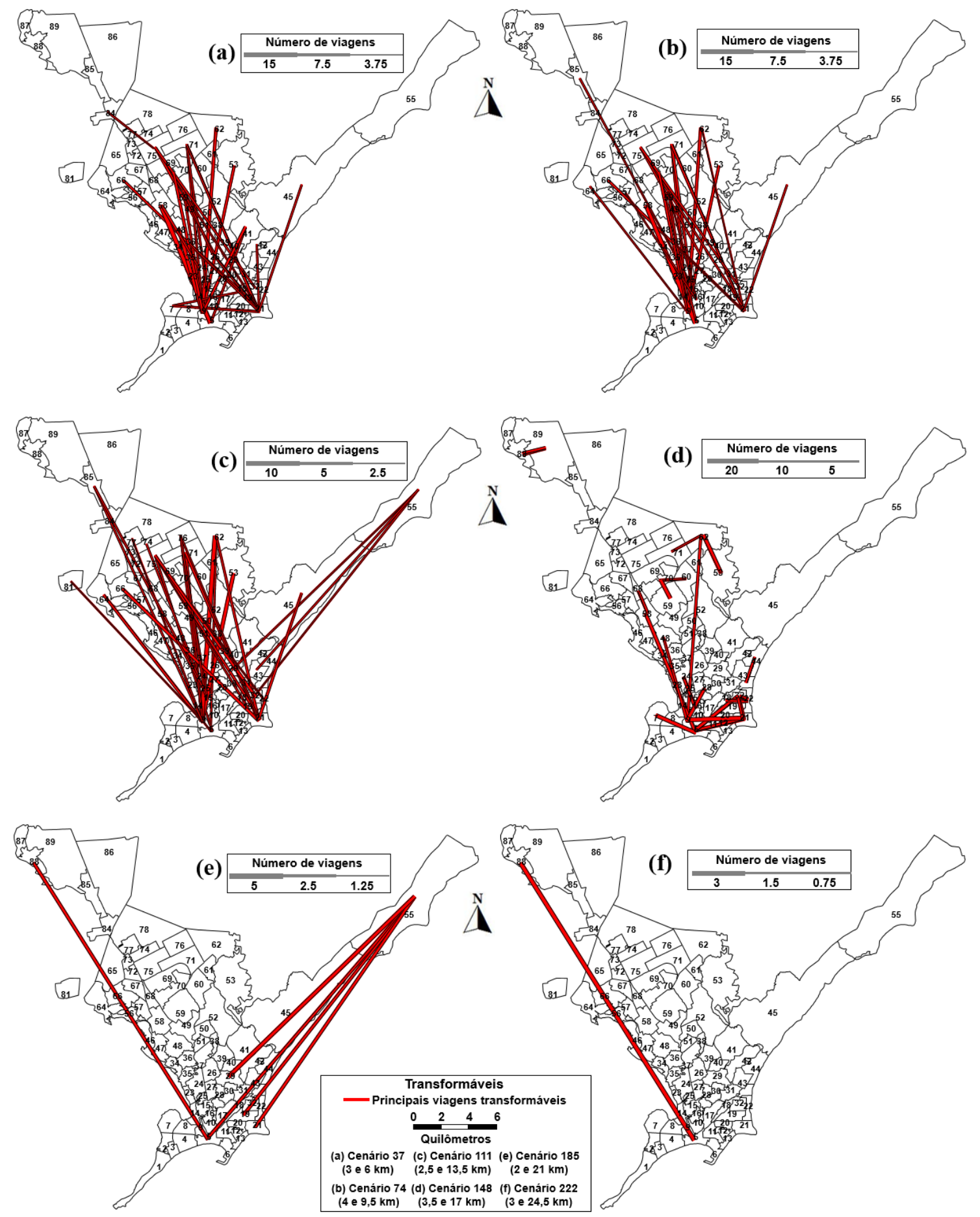

Figura 24. Principais viagens transformáveis nos cenários 37, 74, 111, 148, 185 e 222 na Região Metropolitana de Maceió.

Analisando a resiliência por zona, notou-se que no cenário 1 de São Carlos, 21 das 41 zonas de tráfego tinham níveis de resiliência baixo ou muito baixo, 17 zonas obtiveram resiliência média, e apenas 3 tiveram nível alto ou muito alto (entre elas, a zona 41, com apenas 1 viagem). No cenário mais otimista, o de número 89, todas as zonas tiveram níveis de resiliência alto ou muito alto. Observa-se nas Figuras 25 a 28 que as viagens transformáveis 
ocorrem com maior frequência em zonas afastadas, e conforme os cenários avançam para maiores valores de DMP, tornam-se persistentes e adaptáveis.

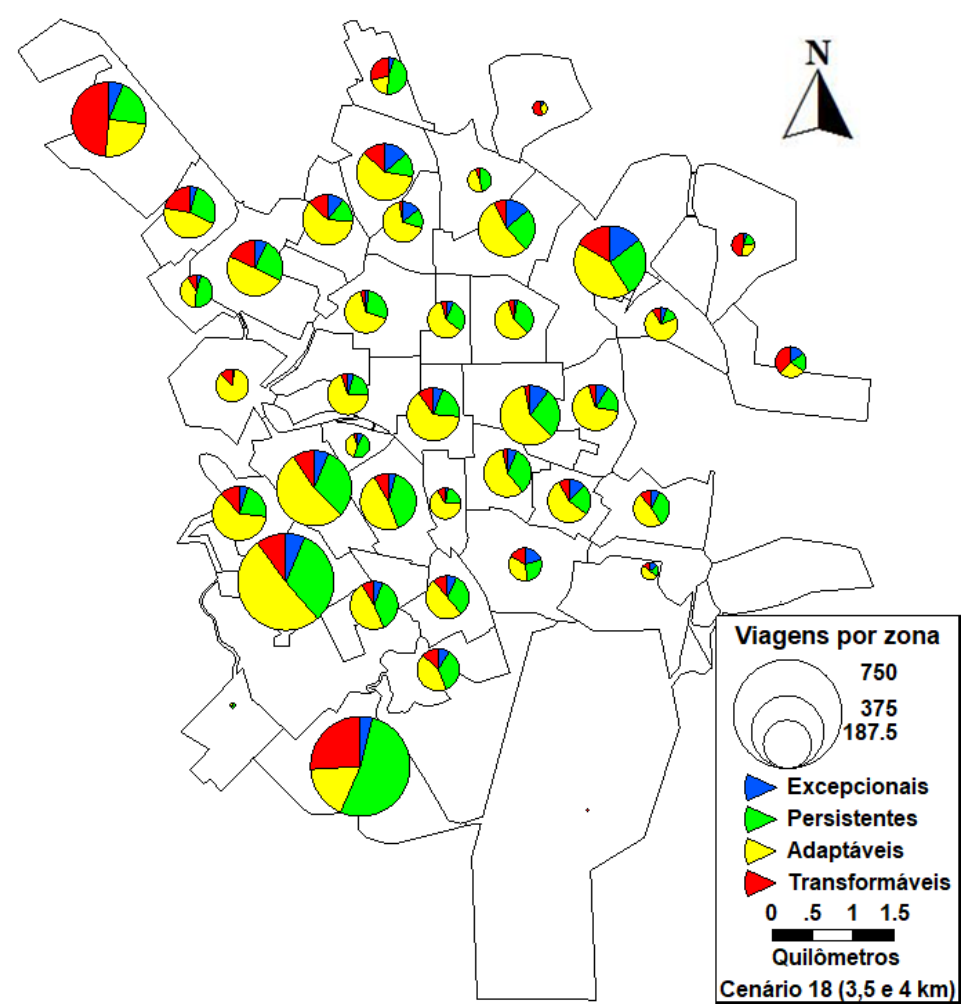

Figura 25. Proporção de viagens excepcionais, persistentes, adaptáveis e transformáveis por zona de tráfego no cenário 18 (DMP a pé $=3,5 \mathrm{~km}$ e DMP de bicicleta $=4 \mathrm{~km}$ ) na cidade de São Carlos. Nota: DMP significa Distância Máxima Possível. 


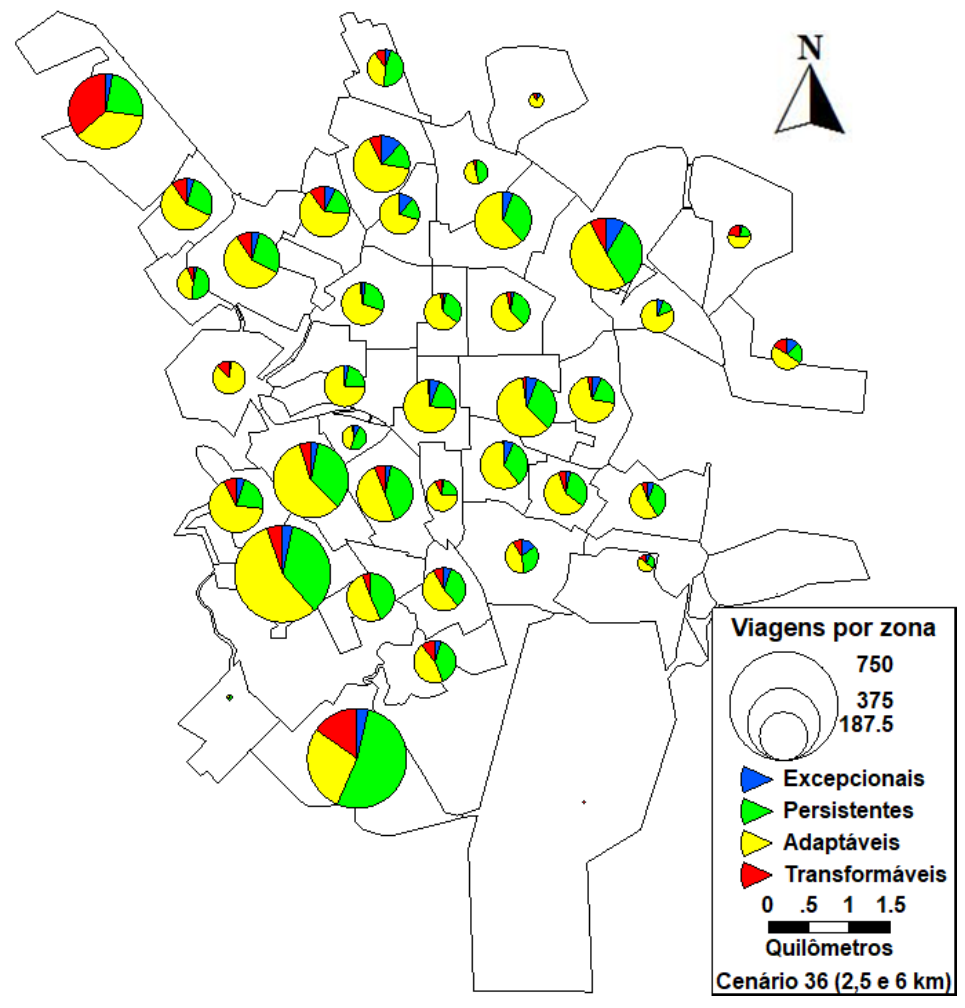

Figura 26. Proporção de viagens excepcionais, persistentes, adaptáveis e transformáveis por zona de tráfego no cenário 36 (DMP a pé $=2,5 \mathrm{~km}$ e DMP de bicicleta $=6 \mathrm{~km}$ ) na cidade de São Carlos.

Nota: DMP significa Distância Máxima Possível.

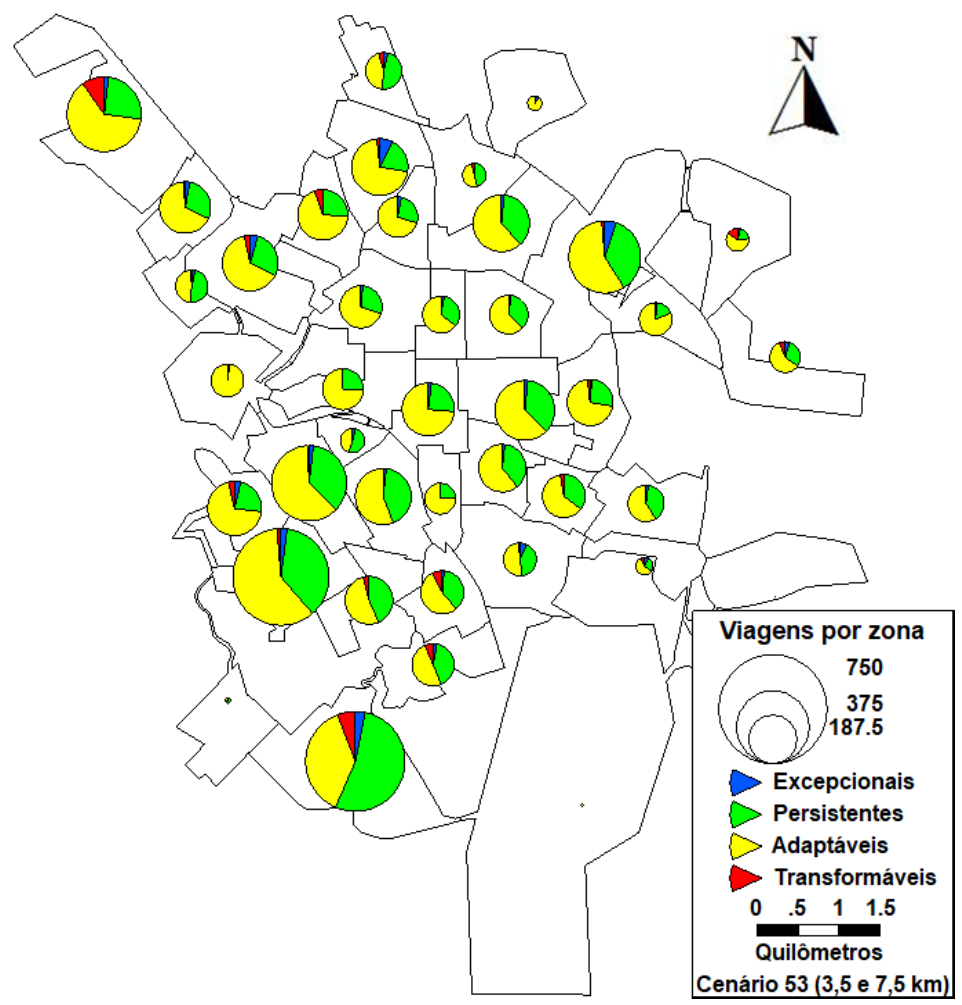

Figura 27. Proporção de viagens excepcionais, persistentes, adaptáveis e transformáveis por zona de tráfego no cenário 53 (DMP a pé $=3,5 \mathrm{~km}$ e DMP de bicicleta $=7,5 \mathrm{~km}$ ) na cidade de São Carlos. Nota: DMP significa Distância Máxima Possível. 


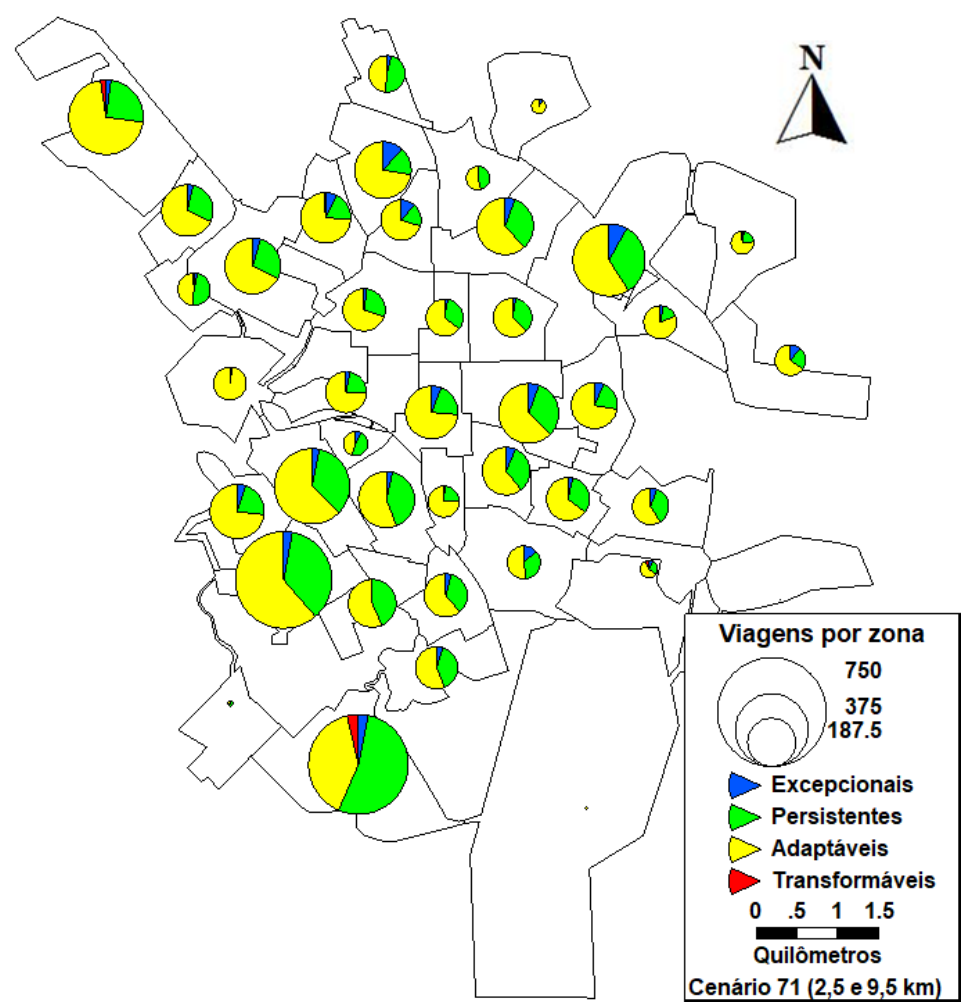

Figura 28. Proporção de viagens excepcionais, persistentes, adaptáveis e transformáveis por zona de tráfego no cenário 71 (DMP a pé $=2,5 \mathrm{~km}$ e DMP de bicicleta $=9,5 \mathrm{~km}$ ) na cidade de São Carlos. Nota: DMP significa Distância Máxima Possível.

A análise por zona na RMM apresentou, no pior cenário, 13 zonas de resiliência muito baixa, 26 de baixa, 31 de média, 2 de alta e 11 de muito alta. No cenário mais otimista, apenas 4 zonas onde não houve coleta de dados apresentaram $0 \%$ de resiliência, todas as outras tiveram níveis de resiliência muito altos. As Figuras 29 a 32 mostram que as viagens transformáveis têm maior ocorrência na parta alta da cidade, e aos poucos alteram-se em viagens persistentes e adaptáveis, à medida que os cenários envolvem maiores DMP. 


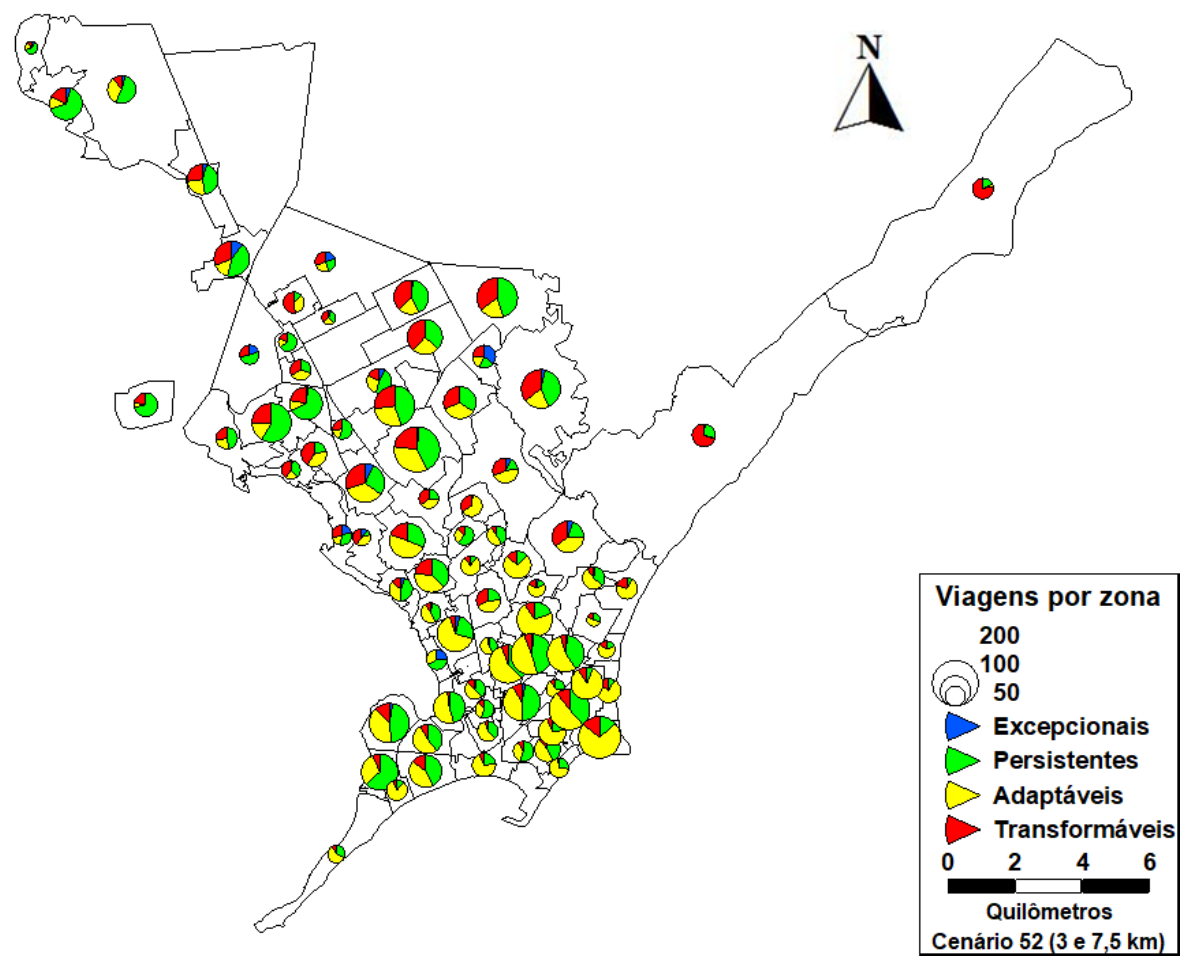

Figura 29. Proporção de viagens excepcionais, persistentes, adaptáveis e transformáveis por zona de tráfego no cenário 52 (DMP a pé $=3 \mathrm{~km}$ e DMP de bicicleta $=7,5 \mathrm{~km}$ ) na Região Metropolitana de Maceió. Nota: DMP significa Distância Máxima Possível.

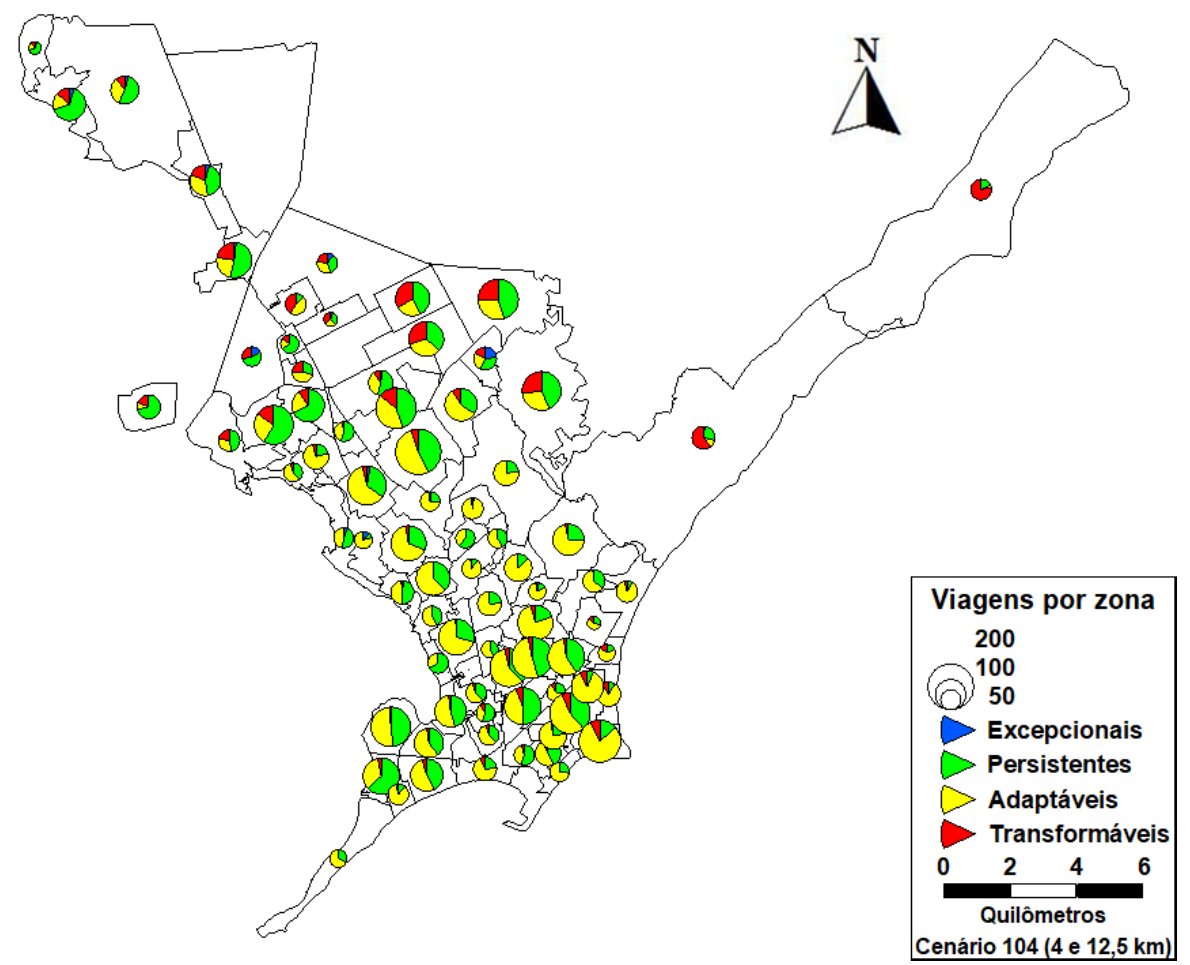

Figura 30. Proporção de viagens excepcionais, persistentes, adaptáveis e transformáveis por zona de tráfego no cenário 104 (DMP a pé $=4 \mathrm{~km}$ e DMP de bicicleta $=12,5 \mathrm{~km}$ ) na Região Metropolitana de Maceió. Nota: DMP significa Distância Máxima Possível. 


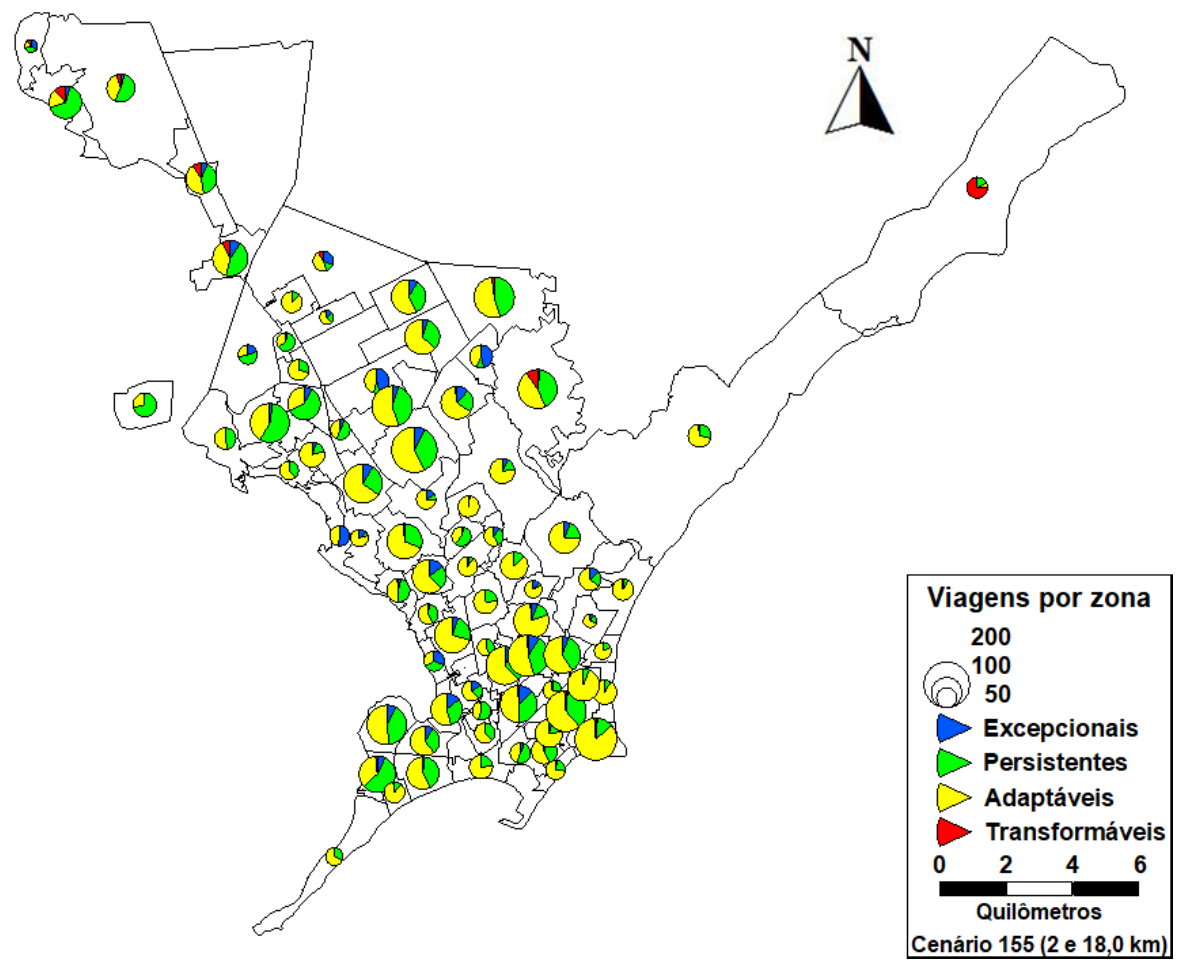

Figura 31. Proporção de viagens excepcionais, persistentes, adaptáveis e transformáveis por zona de tráfego no cenário $155($ DMP a pé $=2 \mathrm{~km}$ e DMP de bicicleta $=18 \mathrm{~km})$ na Região Metropolitana de Maceió. Nota: DMP significa Distância Máxima Possível.

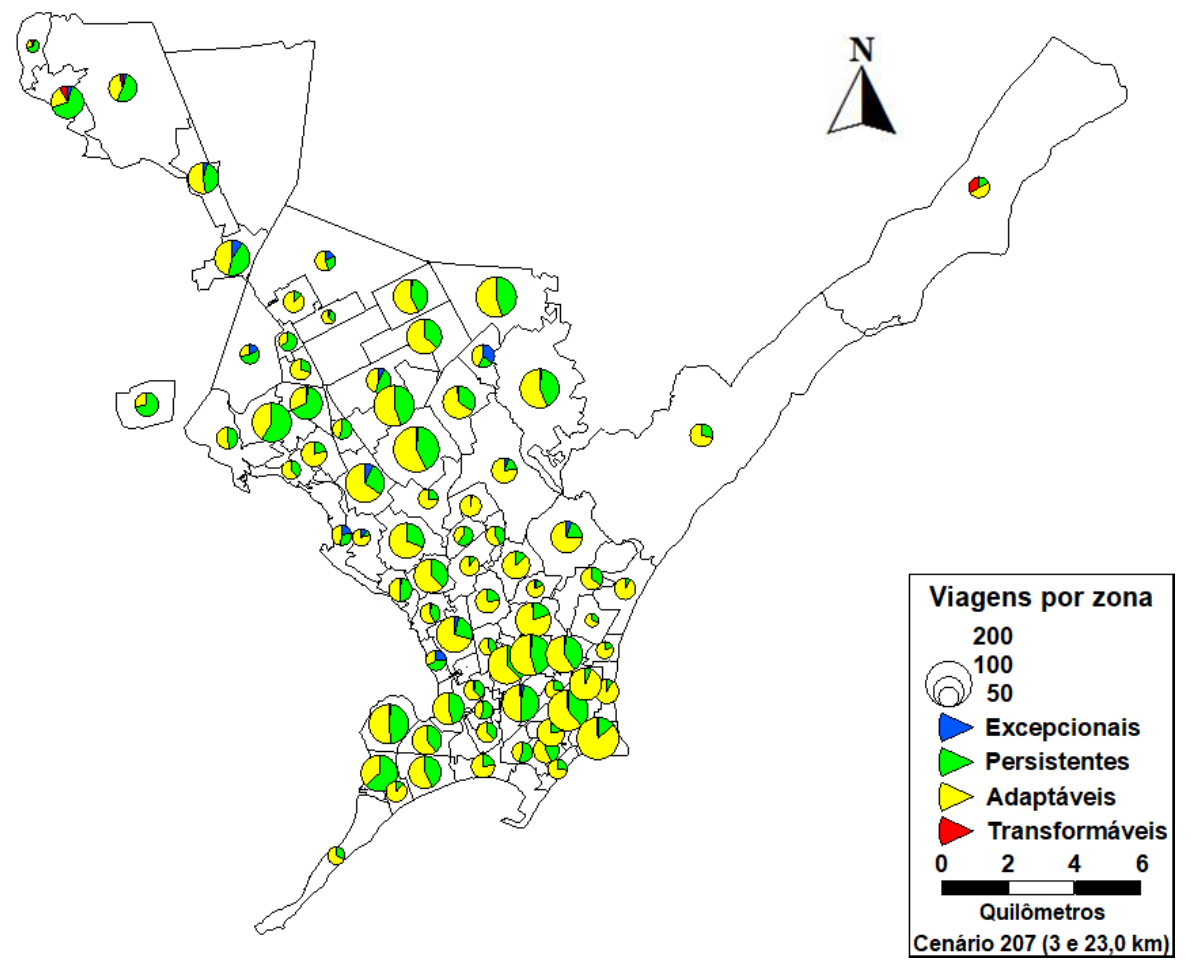

Figura 32. Proporção de viagens excepcionais, persistentes, adaptáveis e transformáveis por zona de tráfego no cenário 207 (DMP a pé $=3 \mathrm{~km}$ e DMP de bicicleta $=23 \mathrm{~km}$ ) na Região Metropolitana de Maceió. Nota: DMP significa Distância Máxima Possível. 


\section{CONCLUSÕES E RECOMENDAÇÕES}

Este capítulo conclui o trabalho. Incialmente são discutidos aspectos relativos à estratégia de avaliação da resiliência apresentada. Em seguida são analisados os principais resultados gerados através dos estudos de caso, respondendo assim às perguntas feitas na metodologia. Para finalizar, são feitas sugestões para trabalhos futuros, a fim de aprimorar esta pesquisa.

\subsection{A ESTRATÉGIA PARA AVALIAÇÃO DA RESILIÊNCIA NA MOBILIDADE URBANA}

O trabalho apresentado teve como objetivo a elaboração de uma estratégia para avaliar a resiliência na mobilidade urbana, com foco em uma eventual restrição a veículos motorizados. Dessa forma, as viagens pendulares urbanas poderiam ser feitas apenas pelo modo a pé e pelo modo bicicleta.

As distâncias das viagens foram medidas a partir dos centroides das zonas de tráfego, com uso de um Sistema de Informação Geográfica (SIG). As viagens em si foram obtidas em uma Pesquisa de Origem e Destino da região em estudo. Com base em Dantas et al. (2010), apenas as viagens consideradas necessárias e essenciais foram analisadas no trabalho. Estas distâncias entre os centroides (trajetos) foram comparadas com as Distâncias Máximas Possíveis (DMP) estabelecidas para o modo a pé e para o modo bicicleta, a fim de distinguir quais trajetos eram possíveis de serem feitos por cada modo de transporte.

As viagens foram então divididas com base em Folke et al. (2010), como segue: persistentes, viagens a pé e bicicleta que não sofreriam modificação; adaptáveis, viagens por modo motorizado que poderiam ser realizadas por modos ativos; e transformáveis, viagens por modo motorizados que seriam afetadas uma vez que ocorresse a restrição. As viagens persistentes e adaptáveis são consideradas resilientes, pois continuariam a ocorrer após a restrição hipotética imposta, enquanto as viagens transformáveis são consideradas vulneráveis. Uma nova segmentação precisou ser criada para este trabalho: a excepcionalidade, que engloba viagens por modo a pé ou bicicleta além dos limites das DMP. As viagens excepcionais foram somadas às viagens resilientes. A proporção de viagens resilientes em relação ao total de viagens na amostra seria o nível de resiliência da região em estudo. 


\subsection{PADRÕES DE RESILIÊNCIA OBSERVADOS NOS ESTUDOS DE CASO}

Os estudos de caso foram feitos na cidade de São Carlos e em um conjunto de três municípios da Região Metropolitana de Maceió (RMM): Maceió, Rio Largo e Satuba. O estudo foi focado nas restrições de veículos motorizados. Assim, hipoteticamente, apenas os modos a pé e bicicleta estariam disponíveis para a realização das viagens Foram utilizados dados da Pesquisa de Origem e Destino realizada nos anos de 2007/08 na cidade de São Carlos e em 2014 na RMM, Em São Carlos, para as medidas de distância entre os centroides das zonas de tráfego foram consideradas distâncias euclidianas majoradas em 30\%, seguindo a recomendação de Novaes (1989). Na RMM, as distâncias foram medidas através do sistema viário, percorrendo as principais vias da região.

No caso de São Carlos foram usadas as 41 zonas de tráfego presentes na pesquisa de Origem e Destino, totalizando 1681 trajetos possíveis para as 6821 viagens consideradas. $\mathrm{Na}$ RMM, das 90 zonas de tráfego que englobam os 3 municípios, 7 delas foram excluídas por fazerem parte de zonas rurais e agrícolas ou por coincidirem com um corpo d'água. Outras 5 zonas onde não foi feita coleta de dados em domicílios foram mantidas no estudo, por serem destinos de viagens. Desta maneira, 83 zonas de tráfego foram usadas no total, criando 6889 possibilidades de trajeto para as 6038 viagens analisadas.

Para separar as viagens consideradas necessárias ou essenciais, em São Carlos, utilizouse apenas aquelas com motivos de trabalho, estudo, negócios, assuntos pessoais e saúde, em todos os horários do dia. Na RMM foram usadas aquelas com origem domiciliar, e com um dos seguintes motivos de destino: trabalho, estudo, compras, saúde, assuntos pessoais e procura de emprego. Em São Carlos, 97,6\% das viagens envolviam distância menor ou igual a $8 \mathrm{~km}$. Na RMM, este valor era de $81,3 \%$. Estes resultados gerais já mostravam o potencial de modos ativos em viagens diárias em ambos os estudos de caso.

Os resultados destacados a seguir se referem à primeira questão formulada na apresentação da Metodologia: "Que distâncias poderiam ser percorridas por modos ativos, caso não houvesse veículos motorizados disponiveis?".

Os cenários variaram da distância mínima $(0 \mathrm{~km})$ até a resiliência máxima (100\%). Uma vez que a DMP a pé não pode ser maior que a DMP de bicicleta, cinco valores de DMP a pé, variando de 2 a $4 \mathrm{~km}$, a cada 500 metros, foram usadas para cada valor de 1 DMP de bicicleta. Isto não ocorre nos 14 primeiros cenários, onde a DMP de bicicleta é menor que $4 \mathrm{~km}$. Um 
total de 89 cenários foram criados em São Carlos, com a resiliência atingindo seu máximo aos $11 \mathrm{~km}$ da DMP de bicicleta. Na RMM, dos 259 cenários criados, a resiliência foi máxima aos $28 \mathrm{~km}$.

Os aspectos ressaltados a seguir se referem às questões "Quais viagens seriam afetadas?", "Quais permaneceriam?” e "É possível classificar estas viagens com base nas condições de resiliência?".

No estudo em São Carlos, o pior cenário teve 40,4\% de resiliência, com 18,2\% de viagens intrazonais e $22,2 \%$ de viagens excepcionais. Na RMM, o cenário mais pessimista apresentou uma resiliência de 43,0\%, com 27,4\% de viagens intrazonais e 15,6\% de viagens excepcionais. Constatou-se que a variação da resiliência, assim como os segmentos de transformabilidade e adaptabilidade, dependem apenas da mudança da DMP para o modo bicicleta. Já os segmentos de persistência e excepcionalidade se modificavam com mudanças tanto nas DMP a pé como de bicicleta.

No tocante à questão "Como se comportam cada um destes grupos de viagens?”, os resultados também revelaram um padrão de viagens para cada condição da resiliência. Em São Carlos, viagens persistentes apresentaram um padrão local, ou seja, em sua maioria eram intrazonais. Viagens adaptáveis mostraram um padrão radial, com origens em zonas afastadas e com destinos ao centro da cidade. As viagens transformáveis exibiam um padrão mais diametral, de um extremo ao outro da cidade, conforme o aumento das DMP. A análise por zona mostrou que as viagens transformáveis têm maior frequência em zonas afastadas do centro da cidade. $\mathrm{O}$ cenário mais pessimista teve um total de 21 zonas de resiliência baixa ou muito baixa, e apenas 3 com nível alto ou muito alto.

Na RMM, viagens persistentes também apresentaram um padrão pontual (intrazonal), com poucas viagens ocorrendo entre zonas vizinhas. As viagens adaptáveis, conforme os cenários tornavam-se mais otimistas, concentravam-se na parte baixa da cidade, ou com origem na parte alta (norte) e destino na parte baixa (sul), em sua maioria, o centro da cidade. As viagens transformáveis mostraram ter sua maioria partindo da parte alta para a parte baixa da cidade, e vice-versa. Com origem na parte alta, grande parte das viagens tinha como destino o centro da cidade e áreas nobres. Partindo da parte baixa, o destino principal era a zona 75, onde se localiza a Universidade Federal de Alagoas. A análise por zona mostrou que a parte alta (norte) concentra uma maior quantidade de viagens transformáveis. O pior cenário 
$(0 \mathrm{~km})$ teve um total de 39 zonas de resiliência baixa ou muito baixa, 31 com nível médio e 12 com nível alto ou muito alto.

Imaginou-se inicialmente que viagens oriundas dos municípios de Rio Largo e Satuba, para a cidade de Maceió, poderiam ter papel significativo no baixo nível de resiliência encontrado. Todavia, as viagens destes dois munícipios contabilizam apenas 7,8\% das 6038 viagens consideradas, e 73,8\% delas ocorre dentro dos próprios municípios. Assim, entendese que a maioria das viagens por modo motorizado, e consequentemente vulneráveis, tem origem e destino dentro da cidade de Maceió.

Este trabalho mostra a necessidade da adoção de políticas de incentivo aos modos ativos de transporte, no intuito de diminuir a dependência da sociedade aos veículos motorizados. É importante salientar que, ao analisar as viagens por veículo motorizado, o trabalho não fez distinção entre transporte público e transporte particular. Além disso, o tamanho da amostra utilizada na Região Metropolitana de Maceió (6038 viagens) é relativamente menor para as proporções da região em estudo, em comparação com o caso de São Carlos. Ainda assim, percebe-se que o uso de veículos motorizados, especialmente o transporte particular, é culturalmente intrínseco na sociedade brasileira, que optou por um desenvolvimento econômico através do automóvel ainda em meados do século XX. Esta atitude permanecendo assim, até os dias atuais. Todavia, o exemplo de outros países que encorajaram o uso de modos de transporte mais sustentáveis, assim como o aumento gradativo do combustível, podem ser os estímulos necessários para a mudança para uma sociedade menos dependente do veículo motorizado, consequentemente, mais resiliente na mobilidade urbana.

\subsection{SUGESTÕES PARA TRABALHOS FUTUROS}

O foco deste trabalho foi a elaboração de uma metodologia para a avaliação da resiliência na mobilidade urbana. Apesar da estratégia proposta ter gerados resultados interessantes, existe um grande potencial de aperfeiçoamento desta para novos trabalhos. É o caso, por exemplo, do uso de coordenadas de origem e destino, em lugar da concentração de viagens nos centroides das zonas de tráfego. Acredita-se que esta mudança traria resultados mais exatos para a análise.

Apesar de serem apenas dois estudos de caso, os resultados indicaram certo padrão na variação da resiliência na mobilidade urbana e de suas condições. Para trabalhos futuros, 
recomenda-se um aprofundamento nessa questão. Sugere-se a realização do estudo em outras regiões, de preferência, com tamanhos e populações variados. Isto deve levar à identificação de padrões mais abrangentes e confiáveis do ponto de vista de sua representatividade.

É compreensível que o valor de $28 \mathrm{~km}$ encontrado no cenário mais otimista da RMM seja demasiado alto para ser realizado pelos modos ativos apresentados. Contudo, a quantidade de viagens adaptáveis, tanto na cidade de São Carlos como na RMM, ainda foi considerada alta mesmo em cenários intermediários, nos quais viagens de bicicleta poderiam de fato ser realizadas. Isso levanta a questão da razão pela qual tais viagens não são realizadas por modos ativos. Assim, também é recomendado para estudos futuros, a análise de outros fatores, além da distância, que influenciam na escolha do modo de transporte. A sugestão é a criação de uma lista de fatores de influência e o uso de pesquisa direta com o usuário para se descobrir quais destes causam maiores impactos na escolha do modo e como isto se relaciona à resiliência na mobilidade. 


\section{REFERÊNCIAS BIBLIOGRÁFICAS}

AFTABUZZAMAN, M. e MAZLOUMI, E. (2011) Achieving sustainable urban transport mobility in post peak oil era. Transport Policy, v. 18, pp. 695-702.

AKIMURA, S. (2015) Transportation statistics that can contribute to policies and social infrastructure development aimed at ensuring the healthy growth of cities and providing support for smooth economic activity. IATSS Research, v. 39, pp. 9-18.

ANDRADE, B. R.; LIMA, L. S. e LOUREIRO, C. F. G. (2016) Compreensão da problemática do espraiamento urbano em Fortaleza no contexto do planejamento da acessibilidade. $7^{\mathbf{0}}$ Congresso Luso-Brasileiro para o Planejamento Urbano, Regional, Integrado e Sustentável. Maceió, AL, Brasil.

ARUP/SIEMENS (2015) Resilient Urban Mobility: A case study of integrated transport in Ho Chi Minh city. Research Project. Arup Group Limited e Siemens AG.

AYDIN, N. Y.; DUZGUN, S. \& HEINIMANN, H. (2017) Resilience evaluation for transportation networks accessibility under seismic risk. $15^{\text {th }}$ International Conference on Computers in Urban Planning and Urban Management, UniSA, Adelaide, Austrália.

BALLOU, R. H.; RAHARDJA, H. e SAKAI, N. (2002) Selected country circuity factors for road travel distance estimation. Transportation Research Part A, v. 36, pp. 843-848.

BERTOLINI, L.; LE CLERCQ F. e KAPOEN L. (2005) Sustainable accessibility: a conceptual framework to integrate transport and land use plan-making. Two test-applications in the Netherlands and a reflection on the way forward. Transport Policy, v. 12, pp. 207-220.

BHOITE, S.; BIRTILL, K.; GILLESPIE, S.; MORERA, B. E.; SILVA, J. e STRATTONSHORT, S. (2015) City resilience index: Understanding and measuring city resilience. The Rockefeller Foundation, Arup International Development.

BOHANNON, R.W. (1997) Comfortable and maximum walking speed of adults aged 20-79 years: reference values and determinants. Age and Ageing, v. 26: 15-19.

BOUSSAUW, K. e WITLOX, F. (2009) Introducing a commute-energy performance index for Flanders. Transportation Research Part A, v. 43, pp. 580-591.

BRUECKNER, J. K. (2000) Urban sprawl: diagnosis and remedies. International Regional Science Review, v. 23, n. 2, pp. 160-171.

BRUNEAU, M.; CHANG, S. E.; EGUCHI, R. T.; LEE, G. C.; O'ROURKE, T. D.; REINHORN, A. M.; SHINOZUKA, M.; TIERNEY, K.; WALLACE, W. A. e WINTERFELDT, D. (2003) A framework to quantitatively assess and enhance the seismic resilience of communities. Earthquake Spectra, v. 19, n. 4, pp. 733-752. 
BRUNNER, A. (2013) The effects of urban sprawl on daily life: Smart growth implementation of Atlantic Stations. Transportation Research Board 92 $^{\text {nd }}$ Annual Meeting. Washington, DC.

BUEHLER, R.; PUCHER, J.; MEROM, D.; BAUMAN, A. (2011) Active travel in Germany and the U.S. Contributions of daily walking and cycling to physical activity. American Journal of Preventive Medicine, v. 41, n. 3, pp. 241-250.

CHAN, R. e J. L. SCHOFER (2016) Measuring transportation system resilience: Response of rail transit to weather disruptions. Natural Hazards Review, v. 17, n. 1. Disponível em: $<$ doi.org/10.1061/(ASCE)NH.1527-6996.0000200>.

DANTAS, A.; PAGE, S. e KRUMDIECK, S. (2010) Urban form and long-term fuel supply decline: A method to investigate the peak oil risks to essential activities. Transportation Research Part A, v. 44, pp. 306-322.

DILL, J. (2004) Measuring network connectivity for bicycling and walking. Transportation Research Board 80 ${ }^{\text {th }}$ Annual Meeting. Washington, DC.

DONOVAN, B. e WORK, D. B. (2017) Empirically quantifying city-scale transportation system resilience to extreme events. Transportation Research Part C, v. 79, pp. 333-346.

EWING, R. (1997) Is Los Angeles style sprawl desirable? Journal of the American Planning Association, v. 63, n. 1, pp. 107-126.

EXNER, A.; POLITTI, E.; SCHRIEFL, E.; ERKER, S.; STANGL, R.; BAUD, S.; WARMUTH, H.; MATZENBERGER, J.; KRANZL, L.; PAULESICH, R.; WINDHABER, M.; SUPPER, S. e STÖGLEHNER, G. (2016) Measuring regional resilience towards fossil fuel supply constraints. Adaptability and vulnerability in socio-ecological transformations the case of Austria. Energy Policy, v. 91, pp. 128-137.

FERNANDES, V. A.; ROTHFUSS, R.; HOCHSCHILD, V.; SILVA, W. R. e SANTOS, M. P. S. (2015) Resiliência da mobilidade urbana: Uma proposta conceitual. XXIX Congresso Nacional de Pesquisa em Transporte da ANPET. Ouro Preto, MG, Brasil.

FERNANDES, V. A.; ROTHFUSS, R.; HOCHSCHILD, V.; SILVA, W. R. e SANTOS, M. P. S. (2017) Resiliência da mobilidade urbana: Uma proposta conceitual e de sistematização. Revista Transportes, v. 25, n. 4, pp. 147-160.

FOLKE, C.; CARPENTER, S. R; WALKER, B.; SCHEFFER, M; CHAPIN, T. e ROCKSTRÖM (2010) Resilience thinking: integrating resilience, adaptability and transformability. Ecology and Society, v. 15, n. 4.

FOTOUHI, H.; MILLER-HOOKS, E. e MORYADEE, S. (2017) Quantifying the resilience of an urban traffic-electric power coupled system. Reliability Engineering and System Safety, v. 163, pp. 79-94. Disponível em: <http://dx.doi.org/10.1016/j.ress.2017.01.026>. 
FRAME, G.; ARDILA-GOMEZ, A. e Y. CHEN (2016) The kingdom of the bicycle: What Wuhan can learn from Amsterdam. 14 ${ }^{\text {th }}$ World Conference on Transport Research, Shanghai, China.

GALDERISI, A. (2014) Urban resilience: A framework for empowering cities in face of heterogeneous risk factors. A|Z ITU Journal of the Faculty of Architecture, v. 11, n. 11, pp. 36-58.

GERVASONI, L.; BOSCH, M.; FENET, S. e STURM, P. (2017) Calculating spatial urban sprawl indices using open data. $\mathbf{1 5}^{\text {th }}$ International Conference on Computers in Urban Planning and Urban Management, UniSA, Adelaide, Austrália.

GOLÇALVES, D. N. S.; GONÇALVES, C. M.; ASSIS, T. F.; SILVA, M. A. (2014) Analysis of the difference between the Euclidean distance and the actual road distance in Brazil. Transportation Research Procedia, v. 3, pp. 876-885.

GORDON, P. e RICHARDSON, W. (1997) Are compact cities a desirable planning goal? Journal of the American Planning Association, v. 63, n. 1, pp. 95-106.

GUERREIRO, T. C. M.; PROVIDElO, J. K.; PITOMBO, C. S.; RAMOS, R. A. R.; RODRIGUES DA SILVA, A. N. (2017) Data-mining, GIS and multicriteria analysis in a comprehensive method for bicycle network planning and design. International Journal of Sustainable Transportation, v. 0, n. 0, pp. 1-13.

HAMIDI, S. e EWING R. (2015) Is sprawl affordable for Americans? Exploring the association between sprawl and housing + transportation affordability. Transportation Research Board $94^{\text {th }}$ Annual Meeting. Washington, DC.

HIRSCH R. L.; BEZDEK R. e WENDLING R. (2005) Peaking of world oil production: Impacts, mitigation and risk management. National Energy Technology Laboratory. US Department of Energy.

HORNING, J.; EL-GENEIDY, A. e KRIZEK, K. J. (2007) Perceptions of walking distance to neighbourhood retail and other public services. Transportation Research at McGill. School of Urban Planning, Faculty of Engineering at McGill University in Montreal, Canada.

HUBBERT, M. K. (1949) Energy from fossil fuels. Science, New Series, v. 109, n. 2823, pp. 103-109.

HYDÉN, C.; NILSSON, A. e RISSER R. (1999) How to enhance walking and cycling instead of shorter car trips and to make these modes safer. Department of Traffic Planning and Engineering, University of Lund, Sweden \& FACTUM Chaloupka, Praschl \& Risser OHG, Vienna, Austria.

IMRANA, M. e CHEYNEA, C. (2016) Measuring transport resilience in New Zealand. 14 World Conference on Transport Research, Shanghai, China. 
KING, D. e SHALABY, A. (2016) Performance metrics and analysis of transit network resilience in Toronto. Transportation Research Board 95 $^{\text {th }}$ Annual Meeting. Washington, DC.

LARSEN, J.; EL-GENEIDY, A. e YASMIN, F. (2010). Beyond the quarter mile: Reexamining travel distances by active transportation. Canadian Journal of Urban Research: Canadian Planning and Policy (supplement), n. 19, v. 1, pp. 70-88.

LEU, G.; ABBASS, H. e CURTIS, N. (2010) Resilience of ground transportation networks: a case study on Melbourne. Australasian Transport Research Forum 2010 Proceedings, Camberra, Austrália.

LIU, C. \& TITHERIDGE, H. (2016) The influence of built environment and perceived walkability on walking behaviour in Taiwan. $14^{\text {th }}$ World Conference on Transport Research, Shanghai, China.

LOVELACE, R. e PHILIPS, I. (2014) The "oil vulnerability" of commuter patterns: A case study from Yorkshire and the Humber, UK. Geoforum, v. 51, pp. 169-182.

MAJUMDAR, B. B. e MITRA, S. (2016) Perception of bicycle users towards key routerelated attributes influencing bicycling using the concept of willingness to pay. $14^{\text {th }}$ World Conference on Transport Research, Shanghai, China.

MATTIOLI, G.; PHILIPS, I.; ANABLE, J. e CHATTERTON, T. (2017) Developing an index of vulnerability to motor fuel price increases in England. $49^{\text {th }}$ Annual UTSG Conference, Dublin, Irlanda.

MARQUÉS, R.; HERNÁNDEZ-HERRADOR, V.; CALVO-SALAZAR, M. e GARCÍACEBRIAN, J.A. (2015) How infrastructure can promote cycling in cities: Lessons from Seville. Research in Transportation Economics, v. 53, pp. 31-44.

MARINO, R.; FOLIENTE, G. e PETTIT, C. (2017) Metropolitan Melbourne residential transport: a VKT regression model to estimate energy consumption and GHG emissions. $\mathbf{1 5}^{\text {th }}$ International Conference on Computers in Urban Planning and Urban Management. UniSA, Adelaide, Australia.

MCCORMACK, G. R.; CERIN, E.; LESLIE, E.; DU TOIT, L. e OWEN, N. (2008) Objective versus perceived walking distances to destinations. Environment and Behavior, v. 40, n. 3.

MODARRES, A. (2013) Commuting and energy: toward an equitable transportation policy. Journal of Transport Geography, v. 33, pp. 240-249.

MOUDON, A. V.; LEE, C.; CHEADLE, A. D.; CHEZA, G.; JOHNSON, D.; SCHMID, T. L.; WEATHERS, R. D. e LIN, L. (2006) Operational definitions of walkable neighbourhood: theoretical and empirical insights. Journal of Physical Activity and Health, v. 3, n. 1, pp. 99-117. 
NELSON, A. C.; MILLER, M.; GANNING, J. O.; STOKER, P.; LIU, J. H. e EWING, R. (2015) Transit and economic resilience. Transportation Research Board $94^{\text {th }}$ Annual Meeting. Washington, DC.

NEUMAN, M. (2005) The compact city fallacy. Journal of Planning Education and Research, v. 25, pp. 11-26.

NEWMAN, P. W. G. e KENWORTHY, J. R. (2011) 'Peak Car Use': Understanding the demise of automobile dependence. World Transport Policy and Practice, v. 17, n. 2, pp. $31-42$.

NEWMAN, P. W. G. e KENWORTHY, J. R. (1989) Gasoline consumption and cities: a comparison of U.S. cities with a global survey. Journal of the American Planning Association, v. 55, n. 1, pp. 24-37.

NOVAES, A. G. (1989) Sistemas logísticos: Transporte, armazenagem e distribuição física de produtos. Editora Edgard Blücher, São Paulo - SP, Brasil.

ODANI, M. e TERAYAMA, K. (2017) Evaluation of convenience in daily travel for residents in housing development areas in the suburbs using utility-based accessibility measures. $\mathbf{1 5}^{\text {th }}$ International Conference on Computers in Urban Planning and Urban Management, UniSA, Adelaide, Austrália.

OLIVEIRA, A.; TAN, F. e RODRIGUES DA SILVA, A. N. (2016) Adequação do modo de transporte: um indicador de mobilidade sustentável em campus universitário. $\mathbf{X X X}$ Congresso Nacional de Pesquisa em Transporte da ANPET. Rio de Janeiro, RJ, Brasil.

PALOHEIMO, H.; LETTENMEIER, M. e WARIS, H. (2016) Transport reduction by crowdsourced deliveries - a library case in Finland. Journal of Cleaner Production, v. 132, pp. 240-251.

PELTAN, T.; FRANKE, D.; VOREL, J. e MAZIER, K. (2017) Model for evaluation of transport energy needs of alternative development scenarios on regional scale. Smart Cities Symposium. Praga, República Checa.

PHILIPS, I. (2014) The potential role of walking and cycling to increase resilience of transport systems to future external shocks. Tese (Doutorado) - The University of Leeds Institute for Transport Studies. Leeds, RU.

REGGIANI, A.; NIJKAMP, P. e LANZI, D. (2015) Transport resilience and vulnerability: The role of connectivity. Transportation Research Part A: Policy and Practice, v. 81, pp. 4-15.

RENDALL, S.; PAGE, S.; REITSMA, F.; VAN HOUTEN, E. e KRUMDIECK, S. (2011) Quantifying transport energy resilience: Active mode accessibility. Transportation Research Record: Journal of the Transportation Research Board, n. 2242, pp. 72-80. 
RODRIGUES DA SILVA, A. N.; FERREIRA, F.; MANZATO, G. e FABRICIO, M.(2017) Identifying barriers to sustainable mobility through a combination of focus groups and online surveys. $\mathbf{1 5}^{\text {th }}$ International Conference on Computers in Urban Planning and Urban Management, UniSA, Adelaide, Austrália.

RODRIGUES DA SILVA, A. N.; COSTA, G. C. F. e BRONDINO, N. C. M. (2007) Urban sprawl and energy use for transportation in the largest Brazilian cities. Energy for sustainable development, v. 11, n. 3, pp. 44-50.

SAUNDERS, M. J. (2010) Urban planning at the micro scale considering transport energy dependence. Tese (Doutorado) - Escola de Engenharia de São Carlos - Universidade de São Paulo. São Carlos, SP, Brasil.

SAUNDERS, M. J. e RODRIGUES DA SILVA, A. N. (2009) Reducing urban transport energy dependence: A new urban development framework and GIS-based tool. International Journal of Sustainable Transportation, v. 3, n. 2, pp. 71-87. Disponível em: $<$ doi: $10.1080 / 15568310701648037>$.

SCHWANEN, T. (2016) Rethinking resilience as capacity to endure. City, v. 20, n. 1, pp. 152-160.

SERULlE, N. U.; HEASLIP, K.; BRADY, B.; LOUISELL, W. C. e COLLURA, J. (2011) Resiliency of transportation network of Santo Domingo, Dominican Republic. Transportation Research Record: Journal of the Transportation Research Board. n. 2234, pp. 22-30. Disponível em: < doi: 10.3141/2234-03>.

SHIM, G. E.; RHEE, S. M.; AHN, K. H. e CHUNG, S. B. (2006) The relationship between the characteristics of transportation energy consumption and urban form. The Annals of Regional Science, v. 40, n. 2, pp. 351-367.

SUGIHARA, R.; IKARUGA, S.; KOBAYASHI, T.; SONG, J.; ZHAO, S.; ARMSTRONG, T. e KOBEL, N. (2017) Proposal of a support system for formulating compact city planning based on the "20-minute neighborhoods" concept. $15^{\text {th }}$ International Conference on Computers in Urban Planning and Urban Management, UniSA, Adelaide, Austrália.

WALKER, J. e COOPER, M. (2011) Genealogies of resilience: From systems ecology to the political economy of crisis adaptation. Security Dialogue, v. 42, n. 2, pp. 143 - 160.

WEN, J. O. H.; OTHMAN, N. B.; EN, T. H.; JIA, T. B.; SHENG, Y. J.; LEE, J. B. P. e LEGARA, E. F. (2018) Formulation of a resilience index for metropolitan rapid transit networks. Transportation Research Board $97^{\text {th }}$ Annual Meeting. Washington, DC.

YANG, Y. e DIEZ-ROUX, A. V. (2012) Walking distance by trip purpose and population subgroups. American Journal of Preventive Medicine, n. 43, v. 1, pp. 11-19. Disponível em: <doi: 0.1016/j.amepre.2012.03.015>. 
ZHANG, W. e KOCKELMAN, K. M. (2014) Urban sprawl, job decentralization, and congestion: the welfare effects of congestion tolls and urban growth boundaries. Transportation Research Board $93^{\text {rd }}$ Annual Meeting. Washington, DC. 
APÊNDICE A

Tabela A.1. Matriz de viagens da pesquisa de Origem e Destino da cidade de São Carlos.

Matriz de Origem e Destino

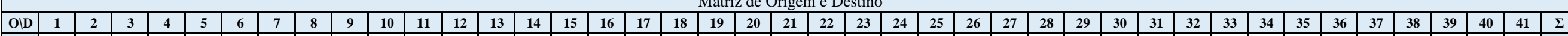

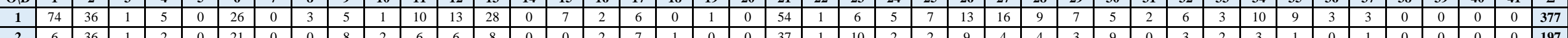

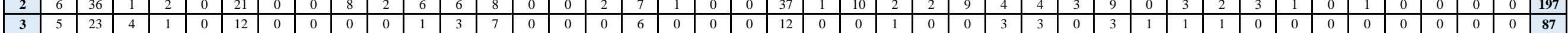
\begin{tabular}{|l|l|l|l|l|l|l|l|l|l|l|l|l|l|l|l|l|l|l|l|l|l|l|l|l|l|l|l|l|l|l|lllllllllllllll}
\hline $\mathbf{4}$ & 0 & 0 & 0 & 6 & 0 & 0 & 0 & 0 & 0 & 0 & 0 & 1 & 9 & 0 & 3 & 0 & 1 & 0 & 0 & 0 & 41 & 0 & 10 & 3 & 0 & 0 & 0 & 2 & 1 & 2 & 0 & 1 & 0 & 1 & 0 & 0 & 9 & 0 & 0 & 0 & 0 & $\mathbf{9 0}$ \\
\hline
\end{tabular}

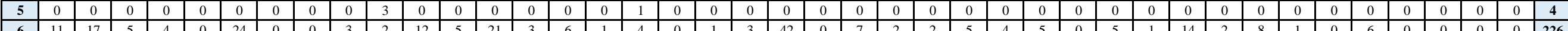

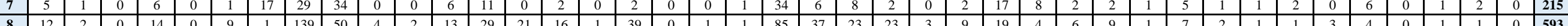

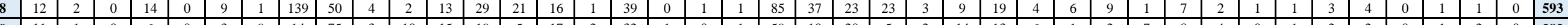

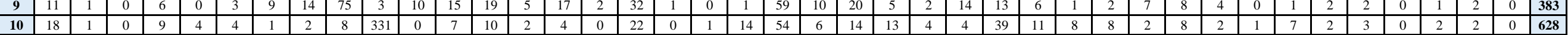

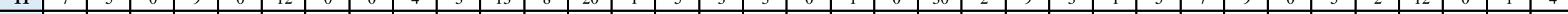
\begin{tabular}{|l|l|l|l|l|l|l|l|l|l|l|l|l|l|l|l|l|l|l|l|l|l|l|l|l|l|l|l|l|l|l|l|l|llllllllllll}
\hline $\mathbf{1 2}$ & 2 & 0 & 0 & 3 & 0 & 0 & 0 & 1 & 2 & 0 & 1 & 13 & 18 & 0 & 2 & 0 & 2 & 2 & 0 & 0 & 28 & 0 & 24 & 7 & 2 & 5 & 2 & 1 & 2 & 0 & 0 & 5 & 0 & 5 & 4 & 0 & 1 & 0 & 0 & 0 & 0 & $\mathbf{1 3 2}$ \\
\hline
\end{tabular}

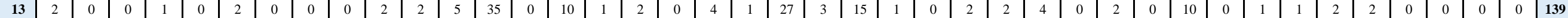
\begin{tabular}{llllllllllllllllllllllllllllllllllllllllll|l|l|l}
144 & 2 & 0 & 0 & 3 & 0 & 2 & 0 & 22 & 10 & 4 & 2 & 3 & 4 & 10 & 3 & 0 & 11 & 0 & 0 & 1 & 27 & 24 & 3 & 10 & 0 & 2 & 9 & 1 & 5 & 2 & 1 & 4 & 3 & 3 & 1 & 0 & 0 & 0 & 1 & 0 & 0 & 173 \\
\hline
\end{tabular} \begin{tabular}{llllllllllllllllllllllllllllllllllllllllllllllllllllll}
$1 \mathbf{1 5}$ & 1 & 0 & 0 & 3 & 0 & 1 & 0 & 0 & 0 & 0 & 1 & 4 & 3 & 0 & 10 & 0 & 13 & 0 & 0 & 2 & 5 & 1 & 1 & 1 & 1 & 0 & 3 & 0 & 0 & 0 & 0 & 2 & 1 & 0 & 0 & 0 & 0 & 0 & 0 & 0 & 0 & $\mathbf{5 3}$ \\
\hline
\end{tabular}

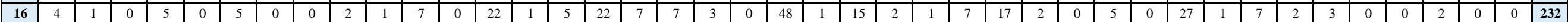

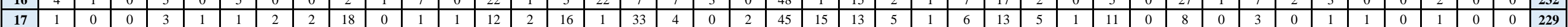

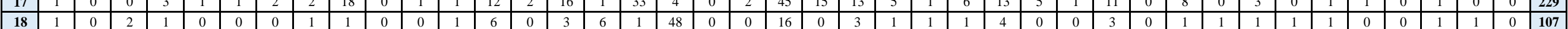

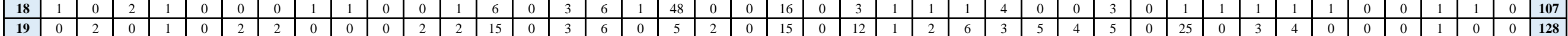

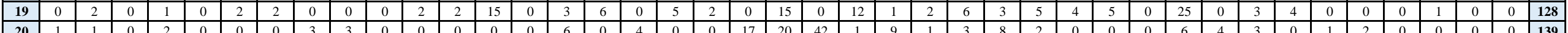

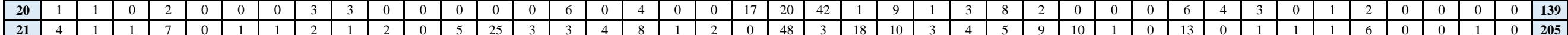
\begin{tabular}{llllllllllllllllllllllllllllllllllllllllllllllllllllll}
22 & 7 & 0 & 0 & 1 & 0 & 0 & 0 & 2 & 4 & 5 & 1 & 0 & 9 & 6 & 1 & 0 & 8 & 2 & 0 & 13 & 22 & 26 & 6 & 2 & 0 & 0 & 14 & 3 & 2 & 1 & 0 & 4 & 0 & 4 & 0 & 2 & 0 & 0 & 0 & 0 & 0 & $\mathbf{1 4 5}$ \\
\hline
\end{tabular}

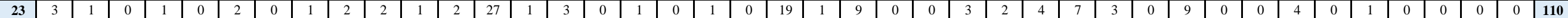
\begin{tabular}{|l|l|l|l|l|l|l|l|llllllllllllllllllllllllllllllllllllll}
$\mathbf{2 4}$ & 1 & 1 & 0 & 0 & 0 & 0 & 0 & 2 & 5 & 1 & 1 & 0 & 6 & 0 & 3 & 0 & 4 & 0 & 0 & 0 & 14 & 7 & 11 & 1 & 5 & 0 & 3 & 0 & 6 & 1 & 0 & 5 & 1 & 1 & 2 & 0 & 0 & 0 & 0 & 0 & 0 & $\mathbf{8 1}$ \\
\hline
\end{tabular}

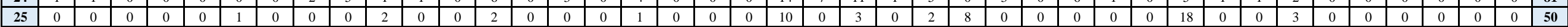

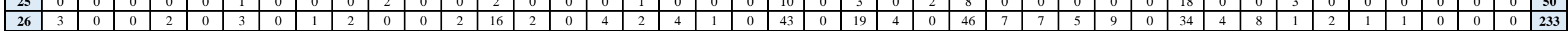

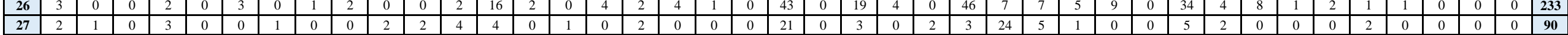

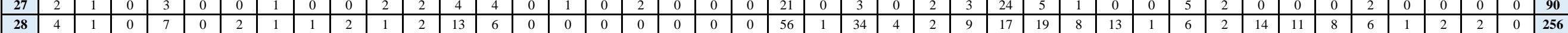

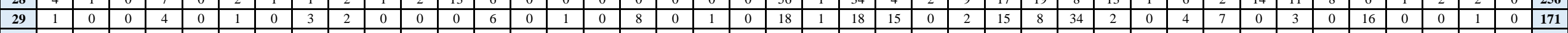
\begin{tabular}{|l|l|l|l|l|l|l|l|l|l|l|l|l|l|l|l|l|l|l|l|l|l|l|l|l|l|l|l|l|l|l|llllllllllllll}
\hline 30 & 4 & 2 & 0 & 0 & 0 & 0 & 0 & 0 & 1 & 2 & 0 & 1 & 12 & 0 & 0 & 0 & 2 & 0 & 0 & 0 & 29 & 1 & 18 & 3 & 3 & 4 & 0 & 5 & 0 & 12 & 0 & 11 & 0 & 7 & 0 & 0 & 1 & 0 & 0 & 1 & 0 & $\mathbf{1 1 9}$ \\
\hline 31
\end{tabular}

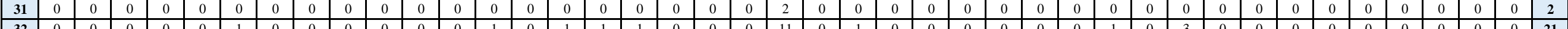

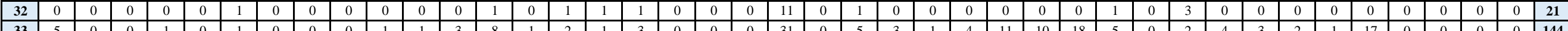

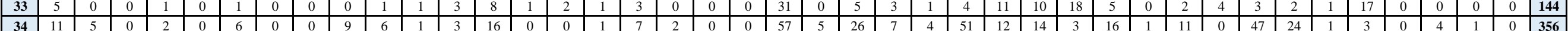

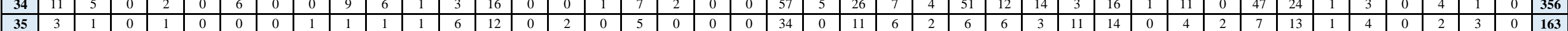

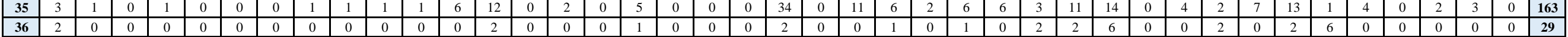

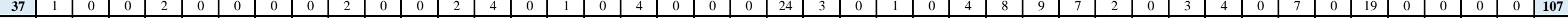

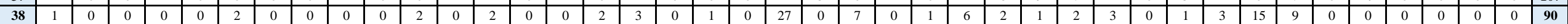
\begin{tabular}{|l|l|l|l|l|l|l|l|l|llllllllllllllllllllllllllllllllllllllll}
39 & 1 & 0 & 0 & 0 & 0 & 1 & 0 & 3 & 2 & 1 & 0 & 1 & 1 & 0 & 0 & 0 & 1 & 0 & 0 & 0 & 13 & 1 & 2 & 0 & 0 & 2 & 0 & 0 & 0 & 4 & 0 & 2 & 0 & 1 & 2 & 0 & 0 & 0 & 8 & 1 & 0 & 47 \\
\hline
\end{tabular} \begin{tabular}{|l|l|l|l|l|l|l|l|l|l|l|l|l|l|l|l|l|l|l|l|l|l|l|l|l|l|l|l|l|l|l|l|l|l|l|l|l|l|l|l|l|l|l|}
\hline $\mathbf{4 0}$ & 0 & 0 & 0 & 2 & 0 & 1 & 0 & 0 & 0 & 2 & 0 & 1 & 3 & 0 & 0 & 1 & 4 & 0 & 0 & 0 & 9 & 0 & 1 & 0 & 0 & 7 & 3 & 5 & 0 & 8 & 0 & 0 & 1 & 6 & 4 & 0 & 2 & 1 & 9 & 10 & 0 & $\mathbf{8 0}$ \\
\hline $\mathbf{4}$ & 0 & 0 & 0 & 0 & 0 & 0 & 0 & 0 & 0 & 0 & 0 & 0 & 0 & 0 & 0 & 0 & 0 & 0 & 0 & 0 & 0 & 0 & 0 & 0 & 0 & 0 & 0 & 0 & 0 & 0 & 0 & 0 & 0 & 0 & 0 & 0 & 0 & 0 & 0 & 0 & 1 & 1 \\
\hline
\end{tabular}

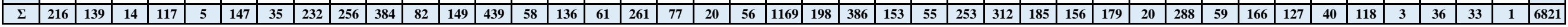


Tabela A.2. Matriz das distâncias euclidianas entre os centroides das zonas de tráfego da cidade de São Carlos. Distâncias euclidianas entre centroides de zonas $(\mathrm{km})$

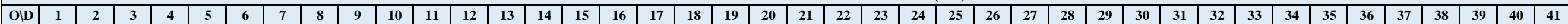

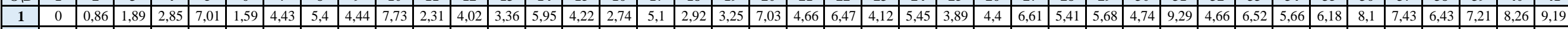

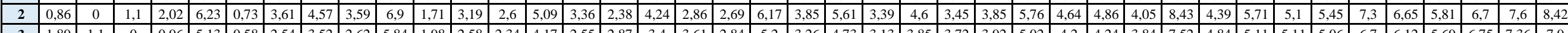

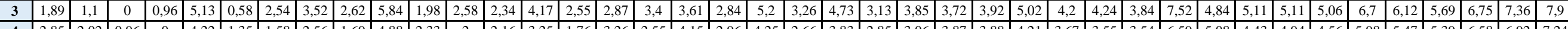

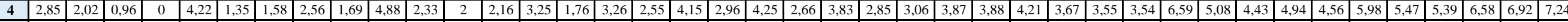

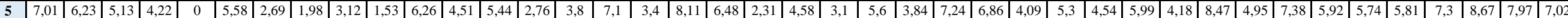

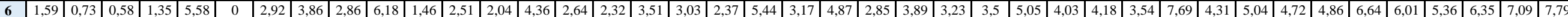

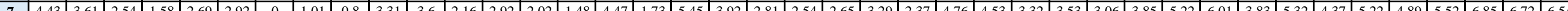

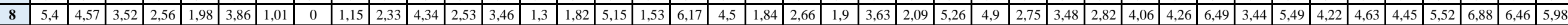

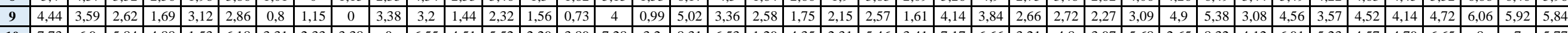
\begin{tabular}{|l|l|l|l|l|l|l|l|l|l|l|l|l|l|l|l|l|l|l|l|}
$\mathbf{1 0}$ & 7,73 & 6,9 & 5,84 & 4,88 & 1,53 & 6,18 & 3,31 & 2,33 & 3,38 & 0 & 6,55 & 4,51 & 5,52 & 2,29 & 3,89 & 7,28 & 3,2 & 8,31 & 6 \\
\hline 11 & 3 & 1,71 & 1,98 & 233 & 6,26 & 1,6 & 3,6 & 4,34 & 3,2 & 6,55 & 0 & 2,6 & 1,2 & 4,4 & 2,66 & 0,93 & 3,46 & 1,86
\end{tabular}

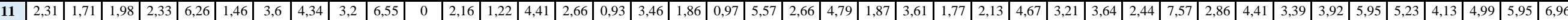

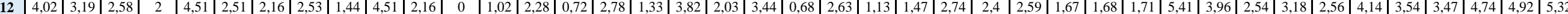

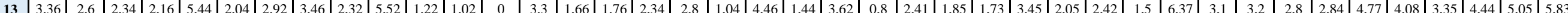

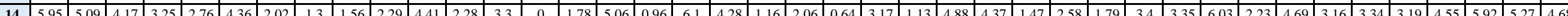

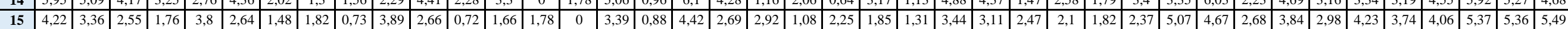

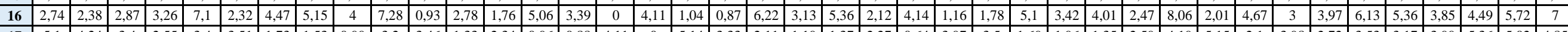

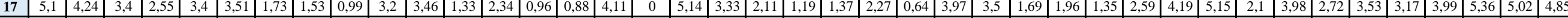

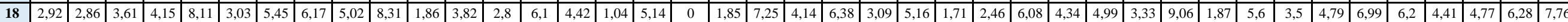

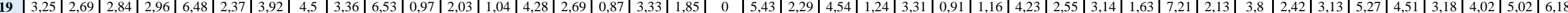

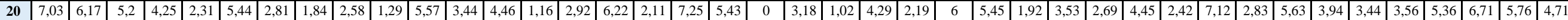

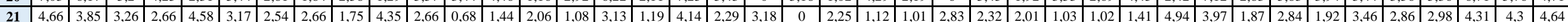

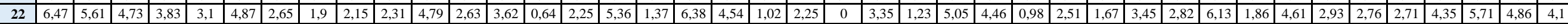

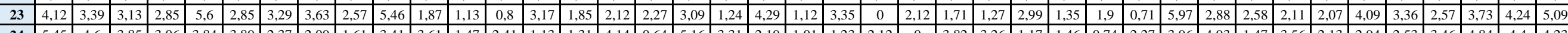

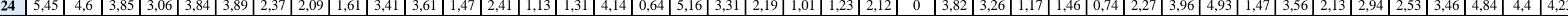

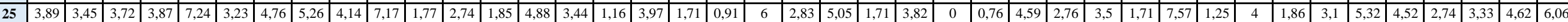

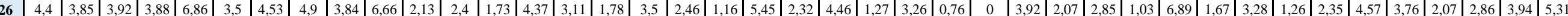

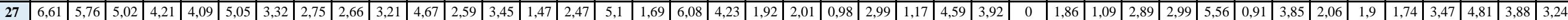

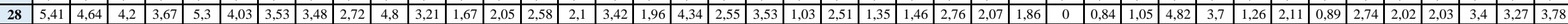

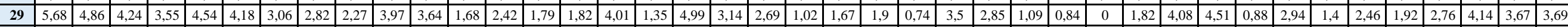

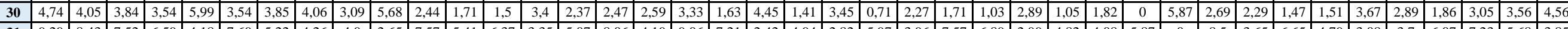

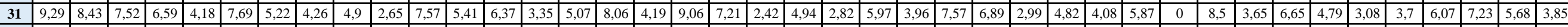

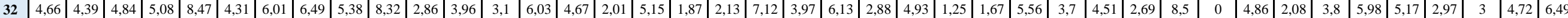

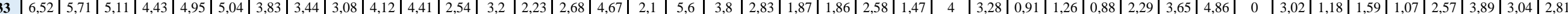

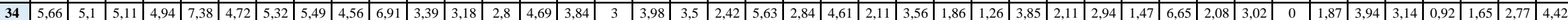

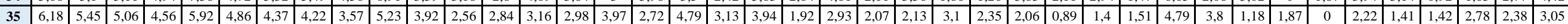

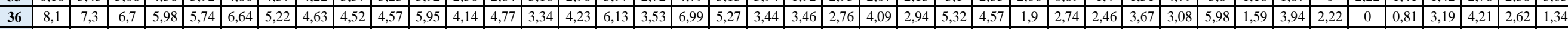

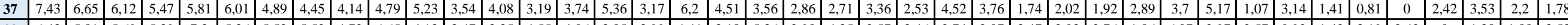

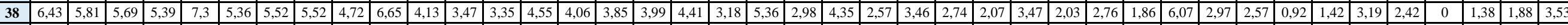

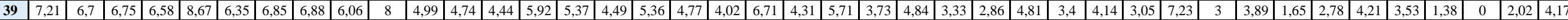

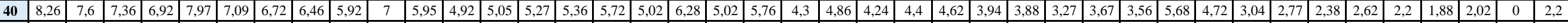

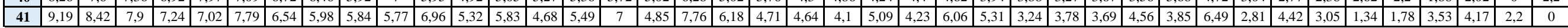


Tabela A.3. Matriz das distâncias euclidianas entre os centroides das zonas de tráfego da cidade de São Carlos, multiplicadas por "fator de rota" de 1,3.

Distâncias euclidianas entre centroides de zonas majoradas em $30 \%(\mathbf{k m})$

\begin{tabular}{|c|c|c|c|c|c|c|c|c|c|c|c|c|c|c|c|c|c|c|c|c|c|c|c|c|c|c|c|c|c|c|c|c|c|c|c|c|c|c|c|c|c|}
\hline & & & & & & & & & & & & & & 14 & 15 & 16 & 17 & 18 & 19 & 20 & 21 & 22 & 23 & 24 & 25 & 26 & 27 & & & & & & & & & & 37 & & 39 & 40 & \\
\hline 1 & 0 & 1,12 & & 3,7 & 9,11 & & 76 & & & & & & & 74 & & & & & & 9,14 & 56 & 8,41 & 5,35 & \begin{tabular}{l|}
09 \\
\end{tabular} & \begin{tabular}{l|l|}
05 \\
\end{tabular} & \begin{tabular}{|l|l|}
5,72 \\
\end{tabular} & \begin{tabular}{|l|}
8,59 \\
\end{tabular} & \begin{tabular}{|l|}
7,03 \\
\end{tabular} & \begin{tabular}{|l|l|}
7,38 \\
\end{tabular} & 6,16 & \begin{tabular}{|l|}
12,1 \\
\end{tabular} & \begin{tabular}{|c|}
6,05 \\
\end{tabular} & \begin{tabular}{|l|}
8,47 \\
\end{tabular} & 7,35 & 8,04 & 10,5 & \begin{tabular}{|l|}
9,66 \\
\end{tabular} & \begin{tabular}{|l|}
8,36 \\
\end{tabular} & \begin{tabular}{|l|l|}
9,37 \\
\end{tabular} & 10,7 & 12 \\
\hline 2 & 12 & 0 & 43 & & & & & & & & & & & & & & & & & & & 29 & 41 & 98 & 48 & & 49 & 03 & 32 & 26 & \begin{tabular}{ll|}
11 \\
\end{tabular} & 71 & 42 & 63 & 08 & 49 & 64 & 56 & 71 & 88 & 11 \\
\hline g & & & 0 & & & & & & & & & & & & & & & & & & 24 & & & & & 5,1 & & & \begin{tabular}{|l|}
5,51 \\
\end{tabular} & 99 & \begin{tabular}{|l|l}
9,77 \\
\end{tabular} & 3 & & & & & 96 & \begin{tabular}{|l|}
7,4 \\
\end{tabular} & & 56 & 0,3 \\
\hline & & & & & & & & & & & & & & & & & & & & & & & & \begin{tabular}{|l|}
3,98 \\
\end{tabular} & & & & & & & & & & & & & 11 & \begin{tabular}{|l|}
7,01 \\
\end{tabular} & & & \\
\hline 5 & & & & & & & & & & & & & & & & & & & & & & 04 & 28 & & 41 & & & & \begin{tabular}{|l|}
5,9 \\
\end{tabular} & & 5,43 & & 43 & 59 & 7,7 & 47 & 7,55 & 49 & 11,3 & & \\
\hline 6 & & & & & & & 3,8 & & 72 & 04 & & & 66 & 66 & & & & & & & 13 & 34 & 7 & 5,06 & 19 & .55 & \begin{tabular}{|l|}
6,57 \\
\end{tabular} & \begin{tabular}{|l|}
5,23 \\
\end{tabular} & \begin{tabular}{|l|l|}
5,44 \\
\end{tabular} & 4,6 & 10 & 5,6 & 56 & 13 &, 32 & 3,63 & 7,81 & 97 & 8,26 & & 0,1 \\
\hline$\frac{1}{2}$ & & & & & & & & & & & & & 19 & 2,62 & & & & & & & 3 & 45 & \begin{tabular}{|l|l|}
4,28 \\
\end{tabular} & & & & \begin{tabular}{|l|l|}
4,32 \\
\end{tabular} & \begin{tabular}{|l|}
4,59 \\
\end{tabular} & 3,97 & 5,01 & \begin{tabular}{|l|l|}
6,79 \\
\end{tabular} & \begin{tabular}{|l|l|}
7,81 \\
\end{tabular} & 98 & 92 & 68 & & \begin{tabular}{|l|}
6,36 \\
\end{tabular} & \begin{tabular}{|l|l|}
7,18 \\
\end{tabular} & 8,9 & , & 51 \\
\hline & & & & & & & & & & & & & & & & & & & & & & 2,48 & & & & & & & & & & & & & & & & \begin{tabular}{|l|}
7,17 \\
\end{tabular} & & & \\
\hline & & & & & & & & & & & & & & & & & & & & & & 2,8 & 34 & & & & & & & & & & & & 64 & & 3,39 & \begin{tabular}{|l|}
6,14 \\
\end{tabular} & & & \\
\hline 10 & , 1 & & & 3 & & & 3 & 22 & 39 & & & 36 & 18 & 98 & & 9,46 & & & & & 55 & & \begin{tabular}{|l|}
7,1 \\
\end{tabular} & \begin{tabular}{|l|l|}
4,43 \\
\end{tabular} & \begin{tabular}{|l|}
9,32 \\
\end{tabular} & \begin{tabular}{|l|}
8,66 \\
\end{tabular} & \begin{tabular}{|l|}
4,17 \\
\end{tabular} & \begin{tabular}{|l|}
6,24 \\
\end{tabular} & \begin{tabular}{|l|l}
5,16 \\
\end{tabular} & \begin{tabular}{|l|l|}
7,38 \\
\end{tabular} & \begin{tabular}{|l|}
3,45 \\
\end{tabular} & 10,8 & \begin{tabular}{|l|l|}
5,36 \\
\end{tabular} & 98 & $\begin{array}{l}, 8 \\
\end{array}$ &,, 94 & \begin{tabular}{|l|}
6,23 \\
\end{tabular} & $\begin{array}{l}8,65 \\
\end{array}$ & 0,4 & 1 & 7,5 \\
\hline 11 & 3 & & & & & & 4,67 & & & & & 31 & 59 & 5,74 & 3, & & & 2,42 & & & 46 & 6,22 & 2,43 & \begin{tabular}{|l|l|} 
\\
\end{tabular} & 2,31 & $2,77 \mid$ & 6,08 & 4, & 4, & 3,18 & 9,84 & 72 & 73 & & & & 6,8 & 5,37 & ,49 & ,73 & \begin{tabular}{|l|}
9,05 \\
\end{tabular} \\
\hline 12 & & & & & & & & & & & & & & 91 & & & & 4, & & & 89 & 3,41 & \begin{tabular}{|l|}
1,48 \\
\end{tabular} & 1,9 & \begin{tabular}{|l|}
3,56 \\
\end{tabular} & \begin{tabular}{|l|}
3,11 \\
\end{tabular} & \begin{tabular}{|l|}
3,37 \\
\end{tabular} & 2,17 & 2,18 & 2,22 & \begin{tabular}{|l|l|}
7,04 \\
\end{tabular} & 5,15 & 31 & & 3,33 & 5,38 & \begin{tabular}{|l|l|}
4,61 \\
\end{tabular} & \begin{tabular}{|l|}
4,52 \\
\end{tabular} & , & & 6,92 \\
\hline 13 & & & & & & & & & & & & & & & & & & & & & & \begin{tabular}{|l|}
4,7 \\
\end{tabular} & 04 & & & & \begin{tabular}{|l|l|}
4,49 \\
\end{tabular} & & & & & & & & & & \begin{tabular}{|l|}
5,3 \\
\end{tabular} & \begin{tabular}{l|l|}
4,35 \\
\end{tabular} & & & \\
\hline 4 & & & & & & & & & & & & & & & 31 & & & & & & & |0,83 & 12 & 48 & 34 & & \begin{tabular}{|l|}
1,9 \\
\end{tabular} & & & & & & & 09 & & & 15 & 91 & & & 08 \\
\hline 15 & & & & & & & & & & & & & & 2,31 & & t1 & & & & & & 92 & & & & \begin{tabular}{l|l}
04 \\
\end{tabular} & \begin{tabular}{|l|}
3,22 \\
\end{tabular} & & & & & & & & & & 4,86 & \begin{tabular}{|l|}
5,27 \\
\end{tabular} & & &, 14 \\
\hline 16 & & & & & & & & & & & & 52 & &, 58 & 1.41 & & & & & & $0 /$ & 5,97 & \begin{tabular}{|l|}
2,75 \\
\end{tabular} &, 38 & \begin{tabular}{|l|}
1,51 \\
\end{tabular} & \begin{tabular}{|l|}
2,32 \\
\end{tabular} & \begin{tabular}{|l|}
6,63 \\
\end{tabular} & 45 & & 3,21 & \begin{tabular}{l|l|}
, 5 & \\
\end{tabular} & 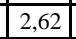 & & & & 7,9 & \begin{tabular}{|l|l|}
6,97 \\
\end{tabular} & & 83 & &,, 11 \\
\hline 17 & & & & & & & & & & & & & & & & & & \begin{tabular}{|l|}
6,69 \\
\end{tabular} & & & & 1,78 & 95 & 0,83 & 16 & \begin{tabular}{|l|}
4,55 \\
\end{tabular} & \begin{tabular}{|l|}
2,19 \\
\end{tabular} & & 1,75 & 3,37 & \begin{tabular}{|l|l|}
5,45 \\
\end{tabular} & & & & & & 4,111 & 5,19 & 6,96 & & 3 \\
\hline 18 & & & & & & & & & & & & & & & & & & & & & & 3 & 22 & & & & 7,9 & & & & & & & & & & 8,06 & & & & , \\
\hline 19 & & & & & & & & & & & & & & & & & & & & & & & 1 & & & & 5 & & & & & & & & & & & & & & 03 \\
\hline 20 & & & & & & & 3,66 & & & & & & & & & & & & & & 13 & \begin{tabular}{|c|}
1,33 \\
\end{tabular} & \begin{tabular}{|l|}
5,58 \\
\end{tabular} & \begin{tabular}{|l|l|}
2,84 \\
\end{tabular} & & 7,08 & & & & 5, & & & & & † & + & \begin{tabular}{|l|}
4,63 \\
\end{tabular} & \begin{tabular}{|l|}
6,97 \\
\end{tabular} & \begin{tabular}{|l|l|}
8,72 \\
\end{tabular} & & 13 \\
\hline 21 & & 5 & & & & & & & & & & & & & & & & & & & & \begin{tabular}{|l|}
2,92 \\
\end{tabular} & 45 & 52 & & 01 & & & & & & & & & & &,, 72 & 3,87 & & & \\
\hline 22 & & & & & & & & & & & & & & & & & & & 5 & & & \begin{tabular}{|l|}
0 \\
\end{tabular} & \begin{tabular}{|l|l}
4,36 \\
\end{tabular} & & & 8 & \begin{tabular}{|l|}
1,28 \\
\end{tabular} & 3, & & & 67 & & & & & & \begin{tabular}{|l|} 
\\
\end{tabular} & 5,65 & & &, 33 \\
\hline 23 & & & & & & & & & & & & & & & & & & & & & & 4,36 & & & & & & & & & & & & & & & & & & & \\
\hline 24 & & & & & & & & & & & & & 14 & 48 & & & & & & & & 6 & 76 & & \begin{tabular}{|l|}
4,97 \\
\end{tabular} & 4,24 & \begin{tabular}{|l|}
1,52 \\
\end{tabular} & & 0,96 & 2,95 & & & 91 & & & & 3,29 & & 9 & 5, &, 5 \\
\hline 25 & & & 84 & & & & & & & & & & & & & & & & & & & 56 & 22 & & & \begin{tabular}{|l|}
0,98 \\
\end{tabular} & \begin{tabular}{|l|}
5,96 \\
\end{tabular} & & & & & & & & 04 & 0,9 & 5,87 & T & & & 8 \\
\hline 26 & & 5 & 5 & & & & & & & & & & & & & & & & & & & & & & & & 5 & 69 & & & & & & & & & \begin{tabular}{|l|l|}
4,89 \\
\end{tabular} & & & & 9 \\
\hline 27 & & & & & & & & & & & & & & 1 & & & & & & & & & & & & & & & & & & & & & & & \begin{tabular}{|l|}
2,26 \\
\end{tabular} & & & & 21 \\
\hline & & & & & & & & & & & & & & 35 & & & & & & & & 26 & 75 & & 59 & \begin{tabular}{|l|}
2,69 \\
\end{tabular} & 2,4 & & 1,0 & & & & & & & 3,5 & \begin{tabular}{|l|}
2,63 \\
\end{tabular} & 2,6 & & & \\
\hline 29 & & & & & & 5,44 & & & & & & & & 32 & & & & & & & & 2,18 & .47 & 96 & \begin{tabular}{|l|}
4,55 \\
\end{tabular} & \begin{tabular}{|l|l}
3,71 \\
\end{tabular} & 1,42 & 1,0 & & 2,37 & & & & 82 & & & 25 & 3,59 & & & \\
\hline 30 & & & & & & 4 & & & & & & & & & & & & & & & & 49 & 92 & & & & & & & & \begin{tabular}{|l|}
7,63 \\
\end{tabular} & & & 91 & & 4,77 & 3,76 & 2,4 & & &, 92 \\
\hline 31 & & 11 & \begin{tabular}{|l|}
9,77 \\
\end{tabular} & 8, & 5,43 & 1 & 6,79 & & & & & & & 4,35 & & 10 & & & & & & \begin{tabular}{|l|}
3,67 \\
\end{tabular} & \begin{tabular}{|l|l|}
7,76 \\
\end{tabular} & & 9, & \begin{tabular}{|l|}
8,96 \\
\end{tabular} & \begin{tabular}{|l|l}
3,8 \\
\end{tabular} & & & & & \begin{tabular}{|l|l|}
11,1 \\
\end{tabular} & 75 & 8,65 & & & \begin{tabular}{|l|l|}
4,81 \\
\end{tabular} & \begin{tabular}{|l|l|}
7,89 \\
\end{tabular} & & & 5,01 \\
\hline & & & & & & & & & & & & & & & & & & & & & & & & & & & & & & & & & & & & & & & & & \\
\hline 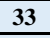 & & & & & & & & & & & & & & & & & & & & & & & 35 & & & & & & & & & & & & & & & & & & \\
\hline 34 & & & & & & & & & 5, & & & & & & 5 & 3,9 & & & & 7 & 69 & 5,99 & \begin{tabular}{|l|}
2,75 \\
\end{tabular} & 62 & \begin{tabular}{|l|}
2,42 \\
\end{tabular} & \begin{tabular}{|l|}
1,64 \\
\end{tabular} & \begin{tabular}{|l|}
5,01 \\
\end{tabular} & 2,75 & \begin{tabular}{|l|}
3,82 \\
\end{tabular} & 1,91 & \begin{tabular}{|l|l|}
8,65 \\
\end{tabular} & 2,7 & 93 & & $2,43 \mid$ & 13 & \begin{tabular}{|l|}
4,08 \\
\end{tabular} & \begin{tabular}{|l|l|} 
\\
\end{tabular} & 2,14 & 0 & 5,74 \\
\hline 35 & 04 & & & 5 & r, & 6,32 & \begin{tabular}{|l|l|}
5,68 \\
\end{tabular} & & 64 & & 5,1 & 3,33 & \begin{tabular}{|l|}
3,69 \\
\end{tabular} & 4,11 & 3,88 & 5,16 & \begin{tabular}{|l|}
3,53 \\
\end{tabular} & 6, & 08 & 5,12 & 2,5 & 3,81 & \begin{tabular}{|l|}
2,69 \\
\end{tabular} & \begin{tabular}{|l|}
2,77 \\
\end{tabular} & \begin{tabular}{|l|}
4,04 \\
\end{tabular} & \begin{tabular}{|l|}
3,06 \\
\end{tabular} & 2,68 & 1,16 & 1,82 & 1,96 & \begin{tabular}{|l|}
6,22 \\
\end{tabular} & \begin{tabular}{|l|l|}
4,94 \\
\end{tabular} & 1,53 & 43 & & \begin{tabular}{|l|}
2,88 \\
\end{tabular} & 1,84 & \begin{tabular}{|l|}
1,84 \\
\end{tabular} & 3,61 & 3,09 & 3,96 \\
\hline 36 & & & & & & & & & & & , & & & & & & & & & & & \begin{tabular}{|l|}
3,59 \\
\end{tabular} & \begin{tabular}{|l|}
5,32 \\
\end{tabular} & & & & & & & & & & & & & & $\mid$\begin{tabular}{|l|}
1,06 \\
\end{tabular} & & & & \\
\hline & & & & & & & & & & & & & & & & & & & & & & & & & & & & & & & & & & & & & & & & & \\
\hline 38 & & & & & & & 7, & & & & & & & & & $\mathrm{~J}$ & & & & & & & & & & & & & & & 39 & & & & & & 14 & & 1,79 & & \\
\hline 39 & 37 . & & 8,77 & \begin{tabular}{|l|}
8,55 \\
\end{tabular} & \begin{tabular}{|l|l}
11,3 \\
\end{tabular} & & 8,9 & 8,95 & \begin{tabular}{|l|}
7,87 \\
\end{tabular} & \begin{tabular}{|l|}
10,4 \\
\end{tabular} & 6,49 & 6,17 & \begin{tabular}{|l|}
5,78 \\
\end{tabular} & 7,7 & 6,98 & 5,83 & 6 & & 5, & 72 & 5,6 & \begin{tabular}{ll|}
7,42 \\
\end{tabular} & \begin{tabular}{|l|}
4,85 \\
\end{tabular} & \begin{tabular}{|l|}
6,29 \\
\end{tabular} & \begin{tabular}{|l|}
433 \\
\end{tabular} & \begin{tabular}{|l|}
3,72 \\
\end{tabular} & \begin{tabular}{|l|}
6,25 \\
\end{tabular} & \begin{tabular}{|l|}
4,42 \\
\end{tabular} & \begin{tabular}{|l|l|}
5,38 \\
\end{tabular} & \begin{tabular}{|l|}
3,97 \\
\end{tabular} & \begin{tabular}{|l|}
9,4 \\
\end{tabular} & 3,9 & 5,06 & 2,14 & 61 & \begin{tabular}{|l|l|}
5,48 \\
\end{tabular} & \begin{tabular}{|l|}
4,59 \\
\end{tabular} & 1,79 & \begin{tabular}{|l|}
0 \\
\end{tabular} & 2,63 & 5,42 \\
\hline 40 & $10, \frac{1}{10}$ & 9,88 & & 9 & & & 8,73 & 8, & 7, & 9 , & 7, & 6, & 6,5 & 6,85 & & 7,4 & 6 & & & & & 6,32 & \begin{tabular}{|l|}
5,52 \\
\end{tabular} & 5,72 & & \begin{tabular}{|l|l|}
5,12 \\
\end{tabular} & 5,05 & $4,25 \mid$ & 4,78 & \begin{tabular}{|l|l|}
4,62 \\
\end{tabular} & . & 13 & 95 & & 09 & & 2,87 & 2,44 & 2,6 & & 2,86 \\
\hline 41 & 12 & \begin{tabular}{|l|}
11 \\
\end{tabular} & \begin{tabular}{|l|}
10,3 \\
\end{tabular} & 9,41 & \begin{tabular}{|l|l|}
9,13 \\
\end{tabular} & \begin{tabular}{|l|}
10,1 \\
\end{tabular} & \begin{tabular}{|l|l|}
8,51 \\
\end{tabular} & 7,77 & & & & & & & & & & & & & & \begin{tabular}{|l|l|}
5,33 \\
\end{tabular} & \begin{tabular}{|l|}
6,62 \\
\end{tabular} & & & & & & & & & & & & & $\mid 1,14$ & 2,31 & 4,59 & \begin{tabular}{|l|l}
5,4 \\
\end{tabular} & 2,0 & \\
\hline
\end{tabular}


Tabela A.4. Variação da resiliência e seus segmentos nos 89 cenários do estudo de caso de São Carlos.

\begin{tabular}{|c|c|c|c|c|c|c|c|}
\hline \multirow{3}{*}{ Cenário } & \multirow{2}{*}{\multicolumn{2}{|c|}{ DMP (km) }} & \multicolumn{4}{|c|}{ Viagens (\%) } & \multirow{3}{*}{$\begin{array}{c}\text { Resiliência } \\
(\mathbf{E}+\mathbf{P}+\mathbf{A})\end{array}$} \\
\hline & & & \multirow{2}{*}{$\begin{array}{c}\text { Excepcionais } \\
\text { (E) }\end{array}$} & \multirow{2}{*}{$\begin{array}{l}\text { Persistentes } \\
\text { (P) }\end{array}$} & \multirow{2}{*}{$\begin{array}{c}\text { Adaptáveis } \\
\text { (A) }\end{array}$} & \multirow{2}{*}{$\begin{array}{l}\text { Transformáveis } \\
\text { (T) }\end{array}$} & \\
\hline & A pé & Bicicleta & & & & & \\
\hline 1 & 0 & 0 & 22,2 & 14,5 & 3,7 & 59,6 & 40,4 \\
\hline 2 & 0,5 & 0,5 & 22,2 & 14,5 & 3,7 & 59,6 & 40,4 \\
\hline 3 & 1 & 1 & 20,4 & 16,3 & 4,8 & 58,4 & 41,5 \\
\hline 4 & 1,5 & 1,5 & 13,6 & 23,2 & 10,2 & 53,1 & 47 \\
\hline 5 & 2 & 2 & 9,3 & 27,4 & 15,4 & 47,9 & 52,1 \\
\hline 6 & 2 & 2,5 & 8,8 & 27,9 & 20,6 & 42,7 & 57,3 \\
\hline 7 & 2,5 & 2,5 & 6,5 & 30,2 & 20,6 & 42,7 & 57,3 \\
\hline 8 & 2 & 3 & 8,5 & 28,2 & 27 & 36,3 & 63,7 \\
\hline 9 & 2,5 & 3 & 6,2 & 30,6 & 27 & 36,3 & 63,8 \\
\hline 10 & 3 & 3 & 4,8 & 32 & 27 & 36,3 & 63,8 \\
\hline 11 & 2 & 3,5 & 8,3 & 28,5 & 34,6 & 28,7 & 71,4 \\
\hline 12 & 2,5 & 3,5 & 5,9 & 30,8 & 34,6 & 28,7 & 71,3 \\
\hline 13 & 3 & 3,5 & 4,5 & 32,2 & 34,6 & 28,7 & 71,3 \\
\hline 14 & 3,5 & 3,5 & 3,7 & 33 & 34,6 & 28,7 & 71,3 \\
\hline 15 & 2 & 4 & 8 & 28,8 & 39,2 & 24,1 & 76 \\
\hline 16 & 2,5 & 4 & 5,6 & 31,1 & 39,2 & 24,1 & 75,9 \\
\hline 17 & 3 & 4 & 4,2 & 32,5 & 39,2 & 24,1 & 75,9 \\
\hline 18 & 3,5 & 4 & 3,4 & 33,3 & 39,2 & 24,1 & 75,9 \\
\hline 19 & 4 & 4 & 2,8 & 33,9 & 39,2 & 24,1 & $\begin{array}{l}75,9 \\
\end{array}$ \\
\hline 20 & 2 & 4,5 & 7,6 & 29,1 & 45,1 & 18,2 & 81,8 \\
\hline 21 & 2,5 & 4,5 & 5,3 & 31,5 & 45,1 & 18,2 & 81,9 \\
\hline 22 & 3 & 4,5 & 3,9 & 32,9 & 45,1 & 18,2 & 81,9 \\
\hline 23 & 3,5 & 4,5 & 3,1 & 33,7 & 45,1 & 18,2 & 81,9 \\
\hline 24 & 4 & 4,5 & 2,5 & 34,3 & 45,1 & 18,2 & 81,9 \\
\hline 25 & 2 & 5 & 7,5 & 29,2 & 48,6 & 14,7 & 85,3 \\
\hline 26 & 2,5 & 5 & 5,2 & 31,6 & 48,6 & 14,7 & 85,3 \\
\hline 27 & 3 & 5 & 3,7 & 33 & 48,6 & 14,7 & 85,3 \\
\hline 28 & 3,5 & 5 & 3 & 33,8 & 48,6 & 14,7 & 85,3 \\
\hline 29 & 4 & 5 & 2,4 & 34,4 & 48,6 & 14,7 & 85,3 \\
\hline 30 & 2 & 5,5 & 7,5 & 29,3 & 51,9 & 11,4 & 88,6 \\
\hline 31 & 2,5 & 5,5 & 5,1 & 31,6 & 51,9 & 11,4 & 88,6 \\
\hline 32 & 3 & 5,5 & 3,7 & 33 & 51,9 & 11,4 & 88,6 \\
\hline 33 & 3,5 & 5,5 & 2,9 & 33,8 & 51,9 & 11,4 & 88,6 \\
\hline 34 & 4 & 5,5 & 2,3 & 34,4 & 51,9 & 11,4 & 88,6 \\
\hline 35 & 2 & 6 & 7,3 & 29,4 & 54,9 & 8,4 & 91,6 \\
\hline 36 & 2,5 & 6 & 5 & 31,7 & 54,9 & 8,4 & 91,6 \\
\hline 37 & 3 & 6 & 3,6 & 33,2 & 54,9 & 8,4 & 91,6 \\
\hline 38 & 3,5 & 6 & 2,8 & 33,9 & 54,9 & 8,4 & 91,6 \\
\hline 39 & 4 & 6 & 2,2 & 34,5 & 54,9 & 8,4 & 91,6 \\
\hline 40 & 2 & 6,5 & 7,3 & 29,5 & 57,4 & 5,8 & 94,2 \\
\hline 41 & 2,5 & 6,5 & 4,9 & 31,8 & 57,4 & 5,8 & 94,2 \\
\hline 42 & 3 & 6,5 & 3,5 & 33,2 & 57,4 & 5,8 & 94,2 \\
\hline 43 & 3,5 & 6,5 & 2,7 & 34 & 57,4 & 5,8 & 94,2 \\
\hline 44 & 4 & 6,5 & 2,1 & 34,6 & 57,4 & 5,8 & 94,2 \\
\hline 45 & 2 & 7 & 7,2 & 29,6 & 58,7 & 4,6 & 95,4 \\
\hline
\end{tabular}




\begin{tabular}{|c|c|c|c|c|c|c|c|}
\hline 46 & 2,5 & 7 & 4,8 & 31,9 & 58,7 & 4,6 & 95,4 \\
\hline 47 & 3 & 7 & 3,4 & 33,3 & 58,7 & 4,6 & 95,4 \\
\hline 48 & 3,5 & 7 & 2,6 & 34,1 & 58,7 & 4,6 & 95,4 \\
\hline 49 & 4 & 7 & 2 & 34,7 & 58,7 & 4,6 & 95,4 \\
\hline 50 & 2 & 7,5 & 7,1 & 29,6 & 60,6 & 2,7 & 97,3 \\
\hline 51 & 2,5 & 7,5 & 4,8 & 32 & 60,6 & 2,7 & 97,3 \\
\hline 52 & 3 & 7,5 & 3,3 & 33,4 & 60,6 & 2,7 & 97,3 \\
\hline 53 & 3,5 & 7,5 & 2,6 & 34,2 & 60,6 & 2,7 & 97,3 \\
\hline 54 & 4 & 7,5 & 1,9 & 34,8 & 60,6 & 2,7 & 97,3 \\
\hline 55 & 2 & 8 & 7,1 & 29,6 & 61,2 & 2,1 & 97,9 \\
\hline 56 & 2,5 & 8 & 4,8 & 32 & 61,2 & 2,1 & 97,9 \\
\hline 57 & 3 & 8 & 3,3 & 33,4 & 61,2 & 2,1 & 97,9 \\
\hline 58 & 3,5 & 8 & 2,6 & 34,2 & 61,2 & 2,1 & 97,9 \\
\hline 59 & 4 & 8 & 1,9 & 34,8 & 61,2 & 2,1 & 97,9 \\
\hline 60 & 2 & 8,5 & 7 & 29,7 & 61,8 & 1,5 & 98,6 \\
\hline 61 & 2,5 & 8,5 & 4,7 & 32 & 61,8 & 1,5 & 98,6 \\
\hline 62 & 3 & 8,5 & 3,3 & 33,4 & 61,8 & 1,5 & 98,5 \\
\hline 63 & 3,5 & 8,5 & 2,5 & 34,2 & 61,8 & 1,5 & 98,6 \\
\hline 64 & 4 & 8,5 & 1,9 & 34,8 & 61,8 & 1,5 & 98,6 \\
\hline 65 & 2 & 9 & 7 & 29,7 & 62,4 & 0,9 & 99,1 \\
\hline 66 & 2,5 & 9 & 4,7 & 32,1 & 62,4 & 0,9 & 99,1 \\
\hline 67 & 3 & 9 & 3,3 & 33,5 & 62,4 & 0,9 & 99,1 \\
\hline 68 & 3,5 & 9 & 2,5 & 34,3 & 62,4 & 0,9 & 99,1 \\
\hline 69 & 4 & 9 & 1,9 & 34,9 & 62,4 & 0,9 & 99,1 \\
\hline 70 & 2 & 9,5 & 7 & 29,7 & 62,7 & 0,6 & 99,4 \\
\hline 71 & 2,5 & 9,5 & 4,7 & 32,1 & 62,7 & 0,6 & 99,4 \\
\hline 72 & 3 & 9,5 & 3,2 & 33,5 & 62,7 & 0,6 & 99,4 \\
\hline 73 & 3,5 & 9,5 & 2,5 & 34,3 & 62,7 & 0,6 & 99,4 \\
\hline 74 & 4 & 9,5 & 1,9 & 34,9 & 62,7 & 0,6 & 99,4 \\
\hline 75 & 2 & 10 & 7 & 29,7 & 62,8 & 0,5 & 99,5 \\
\hline 76 & 2,5 & 10 & 4,7 & 32,1 & 62,8 & 0,5 & 99,5 \\
\hline 77 & 3 & 10 & 3,2 & 33,5 & 62,8 & 0,5 & 99,5 \\
\hline 78 & 3,5 & 10 & 2,5 & 34,3 & 62,8 & 0,5 & 99,5 \\
\hline 79 & 4 & 10 & 1,9 & 34,9 & 62,8 & 0,5 & 99,5 \\
\hline 80 & 2 & 10,5 & 6,9 & 29,8 & 63,1 & 0,2 & 99,8 \\
\hline 81 & 2,5 & 10,5 & 4,6 & 32,1 & 63,1 & 0,2 & 99,8 \\
\hline 82 & 3 & 10,5 & 3,2 & 33,5 & 63,1 & 0,2 & 99,8 \\
\hline 83 & 3,5 & 10,5 & 2,4 & 34,3 & 63,1 & 0,2 & 99,8 \\
\hline 84 & 4 & 10,5 & 1,8 & 34,9 & 63,1 & 0,2 & 99,8 \\
\hline 85 & 2 & 11 & 6,9 & 29,8 & 63,3 & 0 & 100 \\
\hline 86 & 2,5 & 11 & 4,6 & 32,1 & 63,3 & 0 & 100 \\
\hline 87 & 3 & 11 & 3,2 & 33,5 & 63,3 & 0 & 100 \\
\hline 88 & 3,5 & 11 & 2,4 & 34,3 & 63,3 & 0 & 100 \\
\hline 89 & 4 & 11 & 1,8 & 34,9 & 63,3 & 0 & 100 \\
\hline
\end{tabular}


APÊNDICE

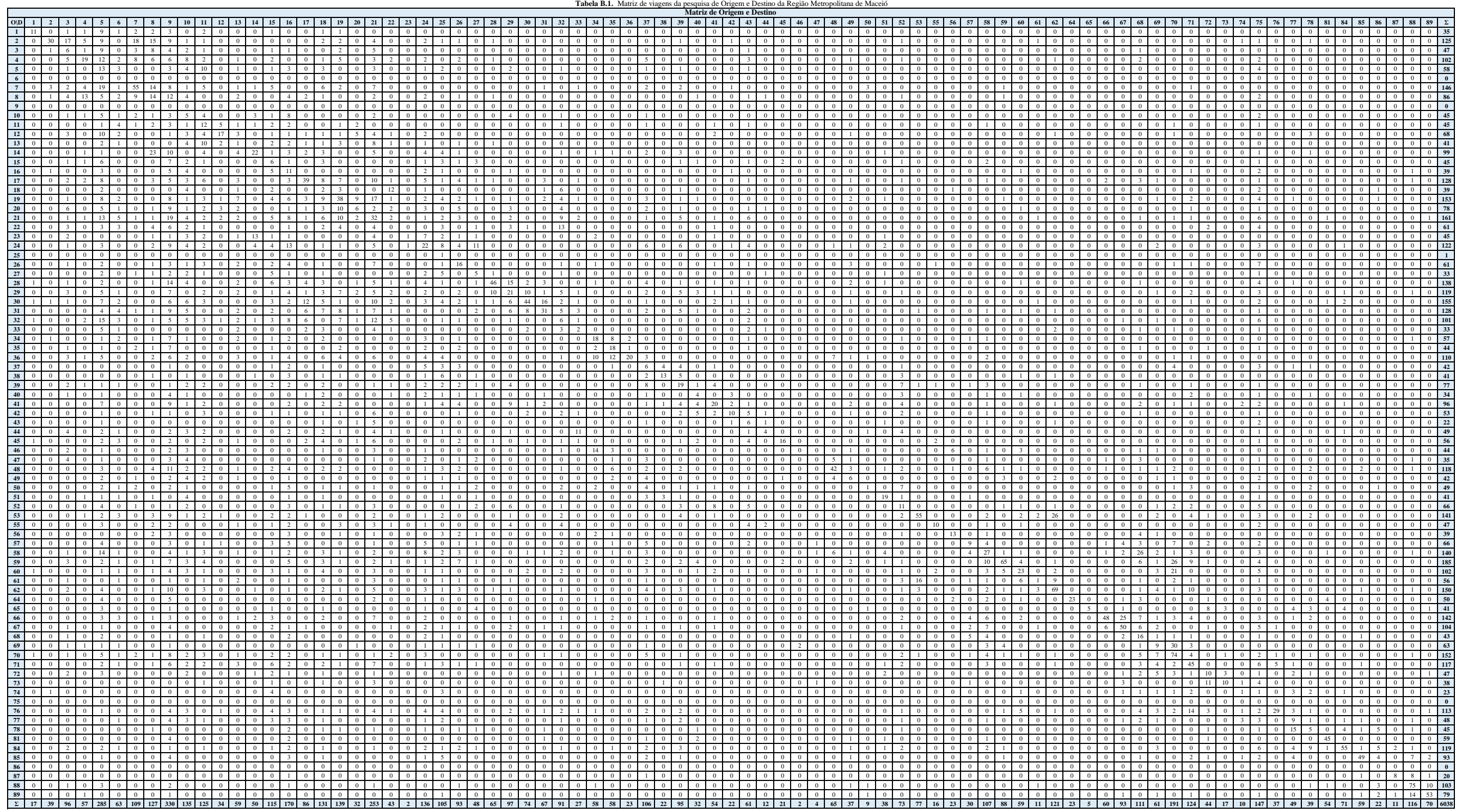




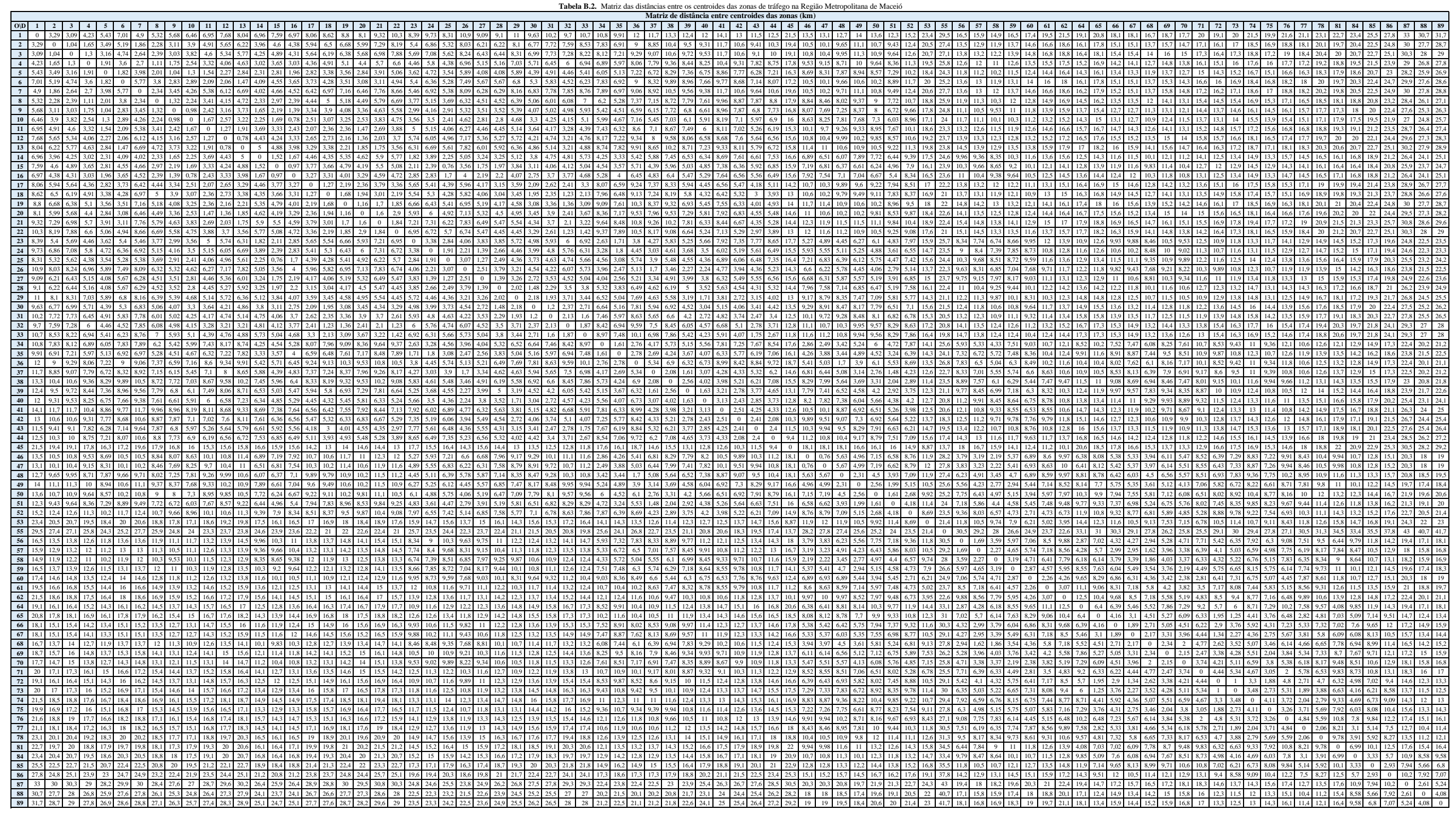


Tabela B.3. Variação da resiliência e seus segmentos nos 259 cenários do estudo de caso da Região Metropolitana de Maceió.

\begin{tabular}{|c|c|c|c|c|c|c|c|}
\hline \multirow[b]{2}{*}{ Cenário } & \multicolumn{2}{|c|}{ DMP (km) } & \multicolumn{4}{|c|}{ Viagens (\%) } & \multirow{2}{*}{$\begin{array}{c}\text { Resiliência } \\
(\mathbf{E}+\mathbf{P}+\mathbf{A})\end{array}$} \\
\hline & A pé & Bicicleta & $\begin{array}{c}\text { Excepcionais } \\
\text { (E) }\end{array}$ & $\begin{array}{l}\text { Persistentes } \\
\text { (P) }\end{array}$ & $\begin{array}{l}\text { Adaptáveis } \\
\text { (A) }\end{array}$ & $\begin{array}{c}\text { Transformáveis } \\
\text { (T) }\end{array}$ & \\
\hline 1 & 0 & 0 & 15,6 & 23,5 & 4 & 57 & 43 \\
\hline 2 & 0,5 & 0,5 & 15,6 & 23,5 & 4 & 57 & 43 \\
\hline 3 & 1 & 1 & 15 & 24,1 & 4,1 & 56,8 & 43,2 \\
\hline 4 & 1,5 & 1,5 & 12,9 & 26,1 & 5,6 & 55,4 & 44,6 \\
\hline 5 & 2 & 2 & 9,7 & 29,3 & 8 & 53 & 47 \\
\hline 6 & 2 & 2,5 & 9,1 & 29,9 & 12,6 & 48,4 & 51,6 \\
\hline 7 & 2,5 & 2,5 & 5,9 & 33,1 & 12,6 & 48,4 & 51,6 \\
\hline 8 & 2 & 3 & 8,9 & 30,2 & 15,4 & 45,6 & 54,4 \\
\hline 9 & 2,5 & 3 & 5,7 & 33,4 & 15,4 & 45,6 & 54,4 \\
\hline 10 & 3 & 3 & 4,3 & 34,8 & 15,4 & 45,6 & 54,4 \\
\hline 11 & 2 & 3,5 & 8,5 & 30,5 & 19,4 & 41,5 & 58,5 \\
\hline 12 & 2,5 & 3,5 & 5,3 & 33,7 & 19,4 & 41,5 & 58,5 \\
\hline 13 & 3 & 3,5 & 4 & 35,1 & 19,4 & 41,5 & 58,5 \\
\hline 14 & 3,5 & 3,5 & 3,3 & 35,7 & 19,4 & 41,5 & 58,5 \\
\hline 15 & 2 & 4 & 8,2 & 30,8 & 23,5 & 37,5 & 62,5 \\
\hline 16 & 2,5 & 4 & 5 & 34,1 & 23,5 & 37,5 & 62,5 \\
\hline 17 & 3 & 4 & 3,6 & 35,4 & 23,5 & 37,5 & 62,5 \\
\hline 18 & 3,5 & 4 & 3 & 36,1 & 23,5 & 37,5 & 62,5 \\
\hline 19 & 4 & 4 & 2,2 & 36,9 & 23,5 & 37,5 & 62,5 \\
\hline 20 & 2 & 4,5 & 8,1 & 31 & 27 & 34 & 66,1 \\
\hline 21 & 2,5 & 4,5 & 4,8 & 34,2 & 27 & 34 & 66,1 \\
\hline 22 & 3 & 4,5 & 3,5 & 35,6 & 27 & 34 & 66,1 \\
\hline 23 & 3,5 & 4,5 & 2,8 & 36,2 & 27 & 34 & 66 \\
\hline 24 & 4 & 4,5 & 2 & 37 & 27 & 34 & 66,1 \\
\hline 25 & 2 & 5 & 7,9 & 31,1 & 29,9 & 31 & 69 \\
\hline 26 & 2,5 & 5 & 4,7 & 34,4 & 29,9 & 31 & 69 \\
\hline 27 & 3 & 5 & 3,3 & 35,7 & 29,9 & 31 & 69 \\
\hline 28 & 3,5 & 5 & 2,7 & 36,4 & 29,9 & 31 & 69 \\
\hline 29 & 4 & 5 & 1,9 & 37,2 & 29,9 & 31 & 69 \\
\hline 30 & 2 & 5,5 & 7,7 & 31,4 & 32,8 & 28,1 & 71,9 \\
\hline 31 & 2,5 & 5,5 & 4,5 & 34,6 & 32,8 & 28,1 & 71,9 \\
\hline 32 & 3 & 5,5 & 3,1 & 35,9 & 32,8 & 28,1 & 71,9 \\
\hline 33 & 3,5 & 5,5 & 2,5 & 36,6 & 32,8 & 28,1 & 71,9 \\
\hline 34 & 4 & 5,5 & 1,7 & 37,4 & 32,8 & 28,1 & 71,9 \\
\hline 35 & 2 & 6 & 7,6 & 31,5 & 35,1 & 25,9 & 74,1 \\
\hline 36 & 2,5 & 6 & 4,4 & 34,7 & 35,1 & 25,9 & 74,1 \\
\hline 37 & 3 & 6 & 3 & 36 & 35,1 & 25,9 & 74,1 \\
\hline 38 & 3,5 & 6 & 2,4 & 36,7 & 35,1 & 25,9 & 74,1 \\
\hline 39 & 4 & 6 & 1,6 & 37,5 & 35,1 & 25,9 & 74,1 \\
\hline 40 & 2 & 6,5 & 7,5 & 31,5 & 36,9 & 24,1 & 75,9 \\
\hline 41 & 2,5 & 6,5 & 4,3 & 34,7 & 36,9 & 24,1 & 75,9 \\
\hline 42 & 3 & 6,5 & 3 & 36,1 & 36,9 & 24,1 & 75,9 \\
\hline 43 & 3,5 & 6,5 & 2,3 & 36,7 & 36,9 & 24,1 & 75,9 \\
\hline 44 & 4 & 6,5 & 1,5 & 37,5 & 36,9 & 24,1 & 75,9 \\
\hline 45 & 2 & 7 & 7,4 & 31,6 & 39,1 & 21,9 & 78,1 \\
\hline
\end{tabular}




\begin{tabular}{|c|c|c|c|c|c|c|c|}
\hline 46 & 2,5 & 7 & 4,2 & 34,8 & 39,1 & 21,9 & 78,1 \\
\hline 47 & 3 & 7 & 2,9 & 36,2 & 39,1 & 21,9 & 78,1 \\
\hline 48 & 3,5 & 7 & 2,2 & 36,8 & 39,1 & 21,9 & 78,1 \\
\hline 49 & 4 & 7 & 1,4 & 37,6 & 39,1 & 21,9 & 78,1 \\
\hline 50 & 2 & 7,5 & 7,3 & 31,8 & 40,8 & 20,1 & 79,9 \\
\hline 51 & 2,5 & 7,5 & 4,1 & 35 & 40,8 & 20,1 & 79,9 \\
\hline 52 & 3 & 7,5 & 2,7 & 36,3 & 40,8 & 20,1 & 79,9 \\
\hline 53 & 3,5 & 7,5 & 2,1 & 37 & 40,8 & 20,1 & 79,9 \\
\hline 54 & 4 & 7,5 & 1,3 & 37,8 & 40,8 & 20,1 & 79,9 \\
\hline 55 & 2 & 8 & 7,2 & 31,8 & 42,4 & 18,5 & 81,5 \\
\hline 56 & 2,5 & 8 & 4 & 35 & 42,4 & 18,5 & 81,5 \\
\hline 57 & 3 & 8 & 2,7 & 36,4 & 42,4 & 18,5 & 81,5 \\
\hline 58 & 3,5 & 8 & 2 & 37 & 42,4 & 18,5 & 81,5 \\
\hline 59 & 4 & 8 & 1,2 & 37,8 & 42,4 & 18,5 & 81,5 \\
\hline 60 & 2 & 8,5 & 7,2 & 31,8 & 43,4 & 17,6 & 82,4 \\
\hline 61 & 2,5 & 8,5 & 4 & 35 & 43,4 & 17,6 & 82,4 \\
\hline 62 & 3 & 8,5 & 2,6 & 36,4 & 43,4 & 17,6 & 82,4 \\
\hline 63 & 3,5 & 8,5 & 2 & 37,1 & 43,4 & 17,6 & 82,4 \\
\hline 64 & 4 & 8,5 & 1,2 & 37,8 & 43,4 & 17,6 & 82,4 \\
\hline 65 & 2 & 9 & 7,1 & 31,9 & 44,6 & 16,4 & 83,6 \\
\hline 66 & 2,5 & 9 & 3,9 & 35,1 & 44,6 & 16,4 & 83,6 \\
\hline 67 & 3 & 9 & 2,6 & 36,5 & 44,6 & 16,4 & 83,6 \\
\hline 68 & 3,5 & 9 & 1,9 & 37,1 & 44,6 & 16,4 & 83,6 \\
\hline 69 & 4 & 9 & 1,1 & 37,9 & 44,6 & 16,4 & 83,6 \\
\hline 70 & 2 & 9,5 & 7,1 & 31,9 & 45,4 & 15,6 & 84,4 \\
\hline 71 & 2,5 & 9,5 & 3,9 & 35,1 & 45,4 & 15,6 & 84,4 \\
\hline 72 & 3 & 9,5 & 2,6 & 36,5 & 45,4 & 15,6 & 84,4 \\
\hline 73 & 3,5 & 9,5 & 1,9 & 37,1 & 45,4 & 15,6 & 84,4 \\
\hline 74 & 4 & 9,5 & 1,1 & 37,9 & 45,4 & 15,6 & 84,4 \\
\hline 75 & 2 & 10 & 7,1 & 32 & 46,1 & 14,9 & 85,1 \\
\hline 76 & 2,5 & 10 & 3,9 & 35,2 & 46,1 & 14,9 & 85,1 \\
\hline 77 & 3 & 10 & 2,5 & 36,5 & 46,1 & 14,9 & 85,1 \\
\hline 78 & 3,5 & 10 & 1,9 & 37,2 & 46,1 & 14,9 & 85,1 \\
\hline 79 & 4 & 10 & 1,1 & 38 & 46,1 & 14,9 & 85,1 \\
\hline 80 & 2 & 10,5 & 7,1 & 32 & 47,4 & 13,6 & 86,4 \\
\hline 81 & 2,5 & 10,5 & 3,9 & 35,2 & 47,4 & 13,6 & 86,4 \\
\hline 82 & 3 & 10,5 & 2,5 & 36,5 & 47,4 & 13,6 & 86,4 \\
\hline 83 & 3,5 & 10,5 & 1,9 & 37,2 & 47,4 & 13,6 & 86,4 \\
\hline 84 & 4 & 10,5 & 1,1 & 38 & 47,4 & 13,6 & 86,4 \\
\hline 85 & 2 & 11 & 7,1 & 32 & 48,8 & 12,2 & 87,8 \\
\hline 86 & 2,5 & 11 & 3,9 & 35,2 & 48,8 & 12,2 & 87,8 \\
\hline 87 & 3 & 11 & 2,5 & 36,5 & 48,8 & 12,2 & 87,8 \\
\hline 88 & 3,5 & 11 & 1,9 & 37,2 & 48,8 & 12,2 & 87,8 \\
\hline 89 & 4 & 11 & 1,1 & 38 & 48,8 & 12,2 & 87,8 \\
\hline 90 & 2 & 11,5 & 7,1 & 32 & 49,3 & 11,6 & 88,4 \\
\hline 91 & 2,5 & 11,5 & 3,9 & 35,2 & 49,3 & 11,6 & 88,4 \\
\hline 92 & 3 & 11,5 & 2,5 & 36,5 & 49,3 & 11,6 & 88,4 \\
\hline 93 & 3,5 & 11,5 & 1,9 & 37,2 & 49,3 & 11,6 & 88,4 \\
\hline 94 & 4 & 11,5 & 1,1 & 38 & 49,3 & 11,6 & 88,4 \\
\hline 95 & 2 & 12 & 7,1 & 32 & 50,1 & 10,9 & 89,2 \\
\hline
\end{tabular}




\begin{tabular}{|c|c|c|c|c|c|c|c|}
\hline 96 & 2,5 & 12 & 3,9 & 35,2 & 50,1 & 10,9 & 89,2 \\
\hline 97 & 3 & 12 & 2,5 & 36,5 & 50,1 & 10,9 & 89,2 \\
\hline 98 & 3,5 & 12 & 1,9 & 37,2 & 50,1 & 10,9 & 89,2 \\
\hline 99 & 4 & 12 & 1,1 & 38 & 50,1 & 10,9 & 89,2 \\
\hline 100 & 2 & 12,5 & 7,1 & 32 & 50,8 & 10,1 & 89,9 \\
\hline 101 & 2,5 & 12,5 & 3,9 & 35,2 & 50,8 & 10,1 & 89,9 \\
\hline 102 & 3 & 12,5 & 2,5 & 36,5 & 50,8 & 10,1 & 89,9 \\
\hline 103 & 3,5 & 12,5 & 1,9 & 37,2 & 50,8 & 10,1 & 89,9 \\
\hline 104 & 4 & 12,5 & 1,1 & 38 & 50,8 & 10,1 & 89,9 \\
\hline 105 & 2 & 13 & 7,1 & 32 & 51,9 & 9,1 & 90,9 \\
\hline 106 & 2,5 & 13 & 3,9 & 35,2 & 51,9 & 9,1 & 90,9 \\
\hline 107 & 3 & 13 & 2,5 & 36,5 & 51,9 & 9,1 & 90,9 \\
\hline 108 & 3,5 & 13 & 1,9 & 37,2 & 51,9 & 9,1 & 90,9 \\
\hline 109 & 4 & 13 & 1,1 & 38 & 51,9 & 9,1 & 90,9 \\
\hline 110 & 2 & 13,5 & 7,1 & 32 & 52,8 & 8,2 & 91,8 \\
\hline 111 & 2,5 & 13,5 & 3,9 & 35,2 & 52,8 & 8,2 & 91,8 \\
\hline 112 & 3 & 13,5 & 2,5 & 36,5 & 52,8 & 8,2 & 91,8 \\
\hline 113 & 3,5 & 13,5 & 1,9 & 37,2 & 52,8 & 8,2 & 91,8 \\
\hline 114 & 4 & 13,5 & 1,1 & 38 & 52,8 & 8,2 & 91,8 \\
\hline 115 & 2 & 14 & 7,1 & 32 & 53,4 & 7,5 & 92,5 \\
\hline 116 & 2,5 & 14 & 3,9 & 35,2 & 53,4 & 7,5 & 92,5 \\
\hline 117 & 3 & 14 & 2,5 & 36,5 & 53,4 & 7,5 & 92,5 \\
\hline 118 & 3,5 & 14 & 1,9 & 37,2 & 53,4 & 7,5 & 92,5 \\
\hline 119 & 4 & 14 & 1,1 & 38 & 53,4 & 7,5 & 92,5 \\
\hline 120 & 2 & 14,5 & 7,1 & 32 & 54,5 & 6,4 & 93,6 \\
\hline 121 & 2,5 & 14,5 & 3,9 & 35,2 & 54,5 & 6,4 & 93,6 \\
\hline 122 & 3 & 14,5 & 2,5 & 36,5 & 54,5 & 6,4 & 93,6 \\
\hline 123 & 3,5 & 14,5 & 1,9 & 37,2 & 54,5 & 6,4 & 93,6 \\
\hline 124 & 4 & 14,5 & 1,1 & 38 & 54,5 & 6,4 & 93,6 \\
\hline 125 & 2 & 15 & 7,1 & 32 & 55,2 & 5,8 & 94,2 \\
\hline 126 & 2,5 & 15 & 3,9 & 35,2 & 55,2 & 5,8 & 94,2 \\
\hline 127 & 3 & 15 & 2,5 & 36,5 & 55,2 & 5,8 & 94,2 \\
\hline 128 & 3,5 & 15 & 1,9 & 37,2 & 55,2 & 5,8 & 94,2 \\
\hline 129 & 4 & 15 & 1,1 & 38 & 55,2 & 5,8 & 94,2 \\
\hline 130 & 2 & 15,5 & 7 & 32 & 55,9 & 5,1 & 94,9 \\
\hline 131 & 2,5 & 15,5 & 3,8 & 35,2 & 55,9 & 5,1 & 94,9 \\
\hline 132 & 3 & 15,5 & 2,5 & 36,6 & 55,9 & 5,1 & 94,9 \\
\hline 133 & 3,5 & 15,5 & 1,8 & 37,2 & 55,9 & 5,1 & 94,9 \\
\hline 134 & 4 & 15,5 & 1 & 38 & 55,9 & 5,1 & 94,9 \\
\hline 135 & 2 & 16 & 7 & 32 & 56,6 & 4,3 & 95,7 \\
\hline 136 & 2,5 & 16 & 3,8 & 35,2 & 56,6 & 4,3 & 95,7 \\
\hline 137 & 3 & 16 & 2,5 & 36,6 & 56,6 & 4,3 & 95,7 \\
\hline 138 & 3,5 & 16 & 1,8 & 37,2 & 56,6 & 4,3 & 95,7 \\
\hline 139 & 4 & 16 & 1 & 38 & 56,6 & 4,3 & 95,7 \\
\hline 140 & 2 & 16,5 & 7 & 32 & 57,4 & 3,6 & 96,4 \\
\hline 141 & 2,5 & 16,5 & 3,8 & 35,2 & 57,4 & 3,6 & 96,4 \\
\hline 142 & 3 & 16,5 & 2,5 & 36,6 & 57,4 & 3,6 & 96,4 \\
\hline 143 & 3,5 & 16,5 & 1,8 & 37,2 & 57,4 & 3,6 & 96,4 \\
\hline 144 & 4 & 16,5 & 1 & 38 & 57,4 & 3,6 & 96,4 \\
\hline 145 & 2 & 17 & 7 & 32 & 58 & 3 & 97,1 \\
\hline
\end{tabular}




\begin{tabular}{|c|c|c|c|c|c|c|c|}
\hline 146 & 2,5 & 17 & 3,8 & 35,2 & 58 & 3 & 97,1 \\
\hline 147 & 3 & 17 & 2,5 & 36,6 & 58 & 3 & 97,1 \\
\hline 148 & 3,5 & 17 & 1,8 & 37,2 & 58 & 3 & 97,1 \\
\hline 149 & 4 & 17 & 1 & 38 & 58 & 3 & 97,1 \\
\hline 150 & 2 & 17,5 & 7 & 32 & 58,5 & 2,5 & 97,5 \\
\hline 151 & 2,5 & 17,5 & 3,8 & 35,2 & 58,5 & 2,5 & 97,5 \\
\hline 152 & 3 & 17,5 & 2,5 & 36,6 & 58,5 & 2,5 & 97,5 \\
\hline 153 & 3,5 & 17,5 & 1,8 & 37,2 & 58,5 & 2,5 & 97,5 \\
\hline 154 & 4 & 17,5 & 1 & 38 & 58,5 & 2,5 & 97,5 \\
\hline 155 & 2 & 18 & 7 & 32 & 59 & 2 & 98,1 \\
\hline 156 & 2,5 & 18 & 3,8 & 35,2 & 59 & 2 & 98,1 \\
\hline 157 & 3 & 18 & 2,5 & 36,6 & 59 & 2 & 98,1 \\
\hline 158 & 3,5 & 18 & 1,8 & 37,2 & 59 & 2 & 98 \\
\hline 159 & 4 & 18 & 1 & 38 & 59 & 2 & 98,1 \\
\hline 160 & 2 & 18,5 & 7 & 32 & 59,1 & 1,9 & 98,1 \\
\hline 161 & 2,5 & 18,5 & 3,8 & 35,2 & 59,1 & 1,9 & 98,1 \\
\hline 162 & 3 & 18,5 & 2,5 & 36,6 & 59,1 & 1,9 & 98,1 \\
\hline 163 & 3,5 & 18,5 & 1,8 & 37,2 & 59,1 & 1,9 & 98,1 \\
\hline 164 & 4 & 18,5 & 1 & 38 & 59,1 & 1,9 & 98,1 \\
\hline 165 & 2 & 19 & 7 & 32 & 59,5 & 1,5 & 98,5 \\
\hline 166 & 2,5 & 19 & 3,8 & 35,2 & 59,5 & 1,5 & 98,5 \\
\hline 167 & 3 & 19 & 2,5 & 36,6 & 59,5 & 1,5 & 98,5 \\
\hline 168 & 3,5 & 19 & 1,8 & 37,2 & 59,5 & 1,5 & 98,5 \\
\hline 169 & 4 & 19 & 1 & 38 & 59,5 & 1,5 & 98,5 \\
\hline 170 & 2 & 19,5 & 7 & 32 & 59,6 & 1,4 & 98,7 \\
\hline 171 & 2,5 & 19,5 & 3,8 & 35,2 & 59,6 & 1,4 & 98,7 \\
\hline 172 & 3 & 19,5 & 2,5 & 36,6 & 59,6 & 1,4 & 98,7 \\
\hline 173 & 3,5 & 19,5 & 1,8 & 37,2 & 59,6 & 1,4 & 98,6 \\
\hline 174 & 4 & 19,5 & 1 & 38 & 59,6 & 1,4 & 98,7 \\
\hline 175 & 2 & 20 & 7 & 32 & 59,7 & 1,2 & 98,8 \\
\hline 176 & 2,5 & 20 & 3,8 & 35,2 & 59,7 & 1,2 & 98,8 \\
\hline 177 & 3 & 20 & 2,5 & 36,6 & 59,7 & 1,2 & 98,8 \\
\hline 178 & 3,5 & 20 & 1,8 & 37,2 & 59,7 & 1,2 & 98,8 \\
\hline 179 & 4 & 20 & 1 & 38 & 59,7 & 1,2 & 98,8 \\
\hline 180 & 2 & 20,5 & 7 & 32 & 59,9 & 1,1 & 98,9 \\
\hline 181 & 2,5 & 20,5 & 3,8 & 35,2 & 59,9 & 1,1 & 98,9 \\
\hline 182 & 3 & 20,5 & 2,5 & 36,6 & 59,9 & 1,1 & 98,9 \\
\hline 183 & 3,5 & 20,5 & 1,8 & 37,2 & 59,9 & 1,1 & 98,9 \\
\hline 184 & 4 & 20,5 & 1 & 38 & 59,9 & 1,1 & 98,9 \\
\hline 185 & 2 & 21 & 7 & 32 & 60,1 & 0,9 & 99,1 \\
\hline 186 & 2,5 & 21 & 3,8 & 35,2 & 60,1 & 0,9 & 99,1 \\
\hline 187 & 3 & 21 & 2,5 & 36,6 & 60,1 & 0,9 & 99,1 \\
\hline 188 & 3,5 & 21 & 1,8 & 37,2 & 60,1 & 0,9 & 99,1 \\
\hline 189 & 4 & 21 & 1 & 38 & 60,1 & 0,9 & 99,1 \\
\hline 190 & 2 & 21,5 & 7 & 32 & 60,2 & 0,8 & 99,2 \\
\hline 191 & 2,5 & 21,5 & 3,8 & 35,2 & 60,2 & 0,8 & 99,2 \\
\hline 192 & 3 & 21,5 & 2,5 & 36,6 & 60,2 & 0,8 & 99,2 \\
\hline 193 & 3,5 & 21,5 & 1,8 & 37,2 & 60,2 & 0,8 & 99,2 \\
\hline 194 & 4 & 21,5 & 1 & 38 & 60,2 & 0,8 & 99,2 \\
\hline 195 & 2 & 22 & 7 & 32 & 60,2 & 0,7 & 99,3 \\
\hline
\end{tabular}




\begin{tabular}{|c|c|c|c|c|c|c|c|}
\hline 196 & 2,5 & 22 & 3,8 & 35,2 & 60,2 & 0,7 & 99,3 \\
\hline 197 & 3 & 22 & 2,5 & 36,6 & 60,2 & 0,7 & 99,3 \\
\hline 198 & 3,5 & 22 & 1,8 & 37,2 & 60,2 & 0,7 & 99,3 \\
\hline 199 & 4 & 22 & 1 & 38 & 60,2 & 0,7 & 99,3 \\
\hline 200 & 2 & 22,5 & 7 & 32 & 60,4 & 0,6 & 99,4 \\
\hline 201 & 2,5 & 22,5 & 3,8 & 35,2 & 60,4 & 0,6 & 99,4 \\
\hline 202 & 3 & 22,5 & 2,5 & 36,6 & 60,4 & 0,6 & 99,4 \\
\hline 203 & 3,5 & 22,5 & 1,8 & 37,2 & 60,4 & 0,6 & 99,4 \\
\hline 204 & 4 & 22,5 & 1 & 38 & 60,4 & 0,6 & 99,4 \\
\hline 205 & 2 & 23 & 7 & 32 & 60,4 & 0,6 & 99,4 \\
\hline 206 & 2,5 & 23 & 3,8 & 35,2 & 60,4 & 0,6 & 99,4 \\
\hline 207 & 3 & 23 & 2,5 & 36,6 & 60,4 & 0,6 & 99,4 \\
\hline 208 & 3,5 & 23 & 1,8 & 37,2 & 60,4 & 0,6 & 99,4 \\
\hline 209 & 4 & 23 & 1 & 38 & 60,4 & 0,6 & 99,4 \\
\hline 210 & 2 & 23,5 & 7 & 32 & 60,4 & 0,6 & 99,4 \\
\hline 211 & 2,5 & 23,5 & 3,8 & 35,2 & 60,4 & 0,6 & 99,4 \\
\hline 212 & 3 & 23,5 & 2,5 & 36,6 & 60,4 & 0,6 & 99,4 \\
\hline 213 & 3,5 & 23,5 & 1,8 & 37,2 & 60,4 & 0,6 & 99,4 \\
\hline 214 & 4 & 23,5 & 1 & 38 & 60,4 & 0,6 & 99,4 \\
\hline 215 & 2 & 24 & 7 & 32 & 60,5 & 0,5 & 99,5 \\
\hline 216 & 2,5 & 24 & 3,8 & 35,2 & 60,5 & 0,5 & 99,5 \\
\hline 217 & 3 & 24 & 2,5 & 36,6 & 60,5 & 0,5 & 99,5 \\
\hline 218 & 3,5 & 24 & 1,8 & 37,2 & 60,5 & 0,5 & 99,5 \\
\hline 219 & 4 & 24 & 1 & 38 & 60,5 & 0,5 & 99,5 \\
\hline 220 & 2 & 24,5 & 7 & 32 & 60,6 & 0,4 & 99,6 \\
\hline 221 & 2,5 & 24,5 & 3,8 & 35,2 & 60,6 & 0,4 & 99,6 \\
\hline 222 & 3 & 24,5 & 2,5 & 36,6 & 60,6 & 0,4 & 99,6 \\
\hline 223 & 3,5 & 24,5 & 1,8 & 37,2 & 60,6 & 0,4 & 99,6 \\
\hline 224 & 4 & 24,5 & 1 & 38 & 60,6 & 0,4 & 99,6 \\
\hline 225 & 2 & 25 & 7 & 32 & 60,7 & 0,3 & 99,7 \\
\hline 226 & 2,5 & 25 & 3,8 & 35,2 & 60,7 & 0,3 & 99,7 \\
\hline 227 & 3 & 25 & 2,5 & 36,6 & 60,7 & 0,3 & 99,7 \\
\hline 228 & 3,5 & 25 & 1,8 & 37,2 & 60,7 & 0,3 & 99,7 \\
\hline 229 & 4 & 25 & 1 & 38 & 60,7 & 0,3 & 99,7 \\
\hline 230 & 2 & 25,5 & 7 & 32 & 60,7 & 0,3 & 99,8 \\
\hline 231 & 2,5 & 25,5 & 3,8 & 35,2 & 60,7 & 0,3 & 99,8 \\
\hline 232 & 3 & 25,5 & 2,5 & 36,6 & 60,7 & 0,3 & 99,8 \\
\hline 233 & 3,5 & 25,5 & 1,8 & 37,2 & 60,7 & 0,3 & 99,8 \\
\hline 234 & 4 & 25,5 & 1 & 38 & 60,7 & 0,3 & 99,8 \\
\hline 235 & 2 & 26 & 7 & 32 & 60,8 & 0,2 & 99,8 \\
\hline 236 & 2,5 & 26 & 3,8 & 35,2 & 60,8 & 0,2 & 99,8 \\
\hline 237 & 3 & 26 & 2,5 & 36,6 & 60,8 & 0,2 & 99,8 \\
\hline 238 & 3,5 & 26 & 1,8 & 37,2 & 60,8 & 0,2 & 99,8 \\
\hline 239 & 4 & 26 & 1 & 38 & 60,8 & 0,2 & 99,8 \\
\hline 240 & 2 & 26,5 & 7 & 32 & 60,8 & 0,1 & 99,9 \\
\hline 241 & 2,5 & 26,5 & 3,8 & 35,2 & 60,8 & 0,1 & 99,9 \\
\hline 242 & 3 & 26,5 & 2,5 & 36,6 & 60,8 & 0,1 & 99,9 \\
\hline 243 & 3,5 & 26,5 & 1,8 & 37,2 & 60,8 & 0,1 & 99,9 \\
\hline 244 & 4 & 26,5 & 1 & 38 & 60,8 & 0,1 & 99,9 \\
\hline 245 & 2 & 27 & 7 & 32 & 60,9 & 0,1 & 99,9 \\
\hline
\end{tabular}




\begin{tabular}{|c|c|c|c|c|c|c|c|}
\hline 246 & 2,5 & 27 & 3,8 & 35,2 & 60,9 & 0,1 & 99,9 \\
\hline 247 & 3 & 27 & 2,5 & 36,6 & 60,9 & 0,1 & 99,9 \\
\hline 248 & 3,5 & 27 & 1,8 & 37,2 & 60,9 & 0,1 & 99,9 \\
\hline 249 & 4 & 27 & 1 & 38 & 60,9 & 0,1 & 99,9 \\
\hline 250 & 2 & 27,5 & 7 & 32 & 60,9 & 0,1 & 99,9 \\
\hline 251 & 2,5 & 27,5 & 3,8 & 35,2 & 60,9 & 0,1 & 99,9 \\
\hline 252 & 3 & 27,5 & 2,5 & 36,6 & 60,9 & 0,1 & 99,9 \\
\hline 253 & 3,5 & 27,5 & 1,8 & 37,2 & 60,9 & 0,1 & 99,9 \\
\hline 254 & 4 & 27,5 & 1 & 38 & 60,9 & 0,1 & 99,9 \\
\hline 255 & 2 & 28 & 7 & 32 & 60,9 & 0,1 & 100 \\
\hline 256 & 2,5 & 28 & 3,8 & 35,2 & 60,9 & 0,1 & 100 \\
\hline 257 & 3 & 28 & 2,5 & 36,6 & 60,9 & 0,1 & 100 \\
\hline 258 & 3,5 & 28 & 1,8 & 37,2 & 60,9 & 0,1 & 100 \\
\hline 259 & 4 & 28 & 1 & 38 & 60,9 & 0,1 & 100 \\
\hline
\end{tabular}

